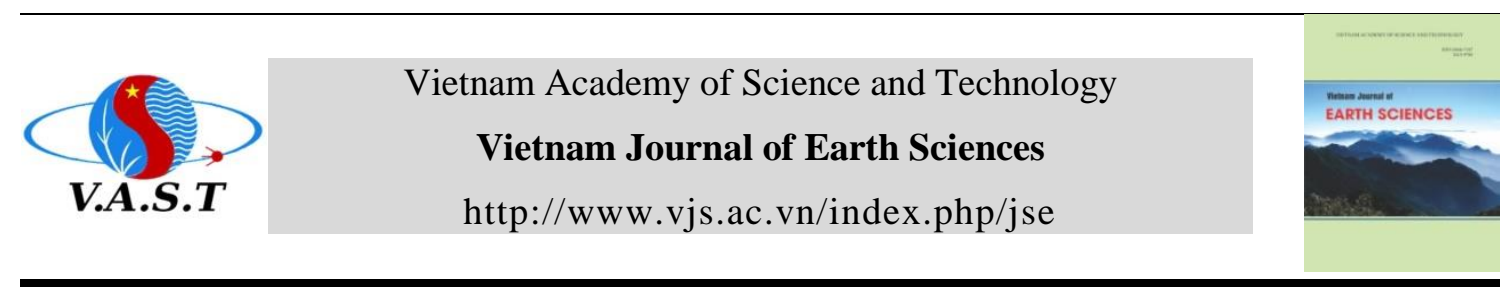

\title{
NDSHA - The New Paradigm for RSHA - An Updated Review ${ }^{1}$
}

\author{
J. Bela1,2,", G.F. Panza ${ }^{3,4,5,6}$ \\ ${ }^{1}$ International Seismic Safety Organization, ISSO, Arsita, Italy \\ ${ }^{2}$ Oregon Earthquake Awareness, Portland, Oregon, USA \\ ${ }^{3}$ Accademia Nazionale dei Lincei, Rome, Italy \\ ${ }^{4}$ Institute of Geophysics, China Earthquake Administration, Beijing, China \\ ${ }^{5}$ Accademia Nazionale delle Scienze detta dei XL, Rome, Italy \\ ${ }^{6}$ Beijing University of Civil Engineering and Architecture (BUCEA), China
}

Received 10 December 2020; Received in revised form 16 January 2021; Accepted 21 February 2021

\section{ABSTRACT}

A New Paradigm (data driven and not like the currently model driven) is needed for Reliable Seismic Hazard Assessment RSHA. Neo-Deterministic Seismic Hazard Assessment (NDSHA) integrates earthquake geology, earthquake science, and particularly earthquake physics to finally achieve a New (and needed) Paradigm for Reliable Seismic Hazard Assessment RSHA.

Although observations from many recent destructive earthquakes have all confirmed the validity of NDSHA's approach and application to earthquake hazard forecasting - nonetheless damaging earthquakes still cannot yet be predicted with a precision requirement consistent with issuing a red alert and evacuation order to protect civil populations. However, intermediate-term (time scale) and middle-range (space scale) predictions of main shocks above a pre-assigned threshold may be properly used for the implementation of low-key preventive safety actions, as recommended by UNESCO in 1997. Furthermore, a proper integration of both seismological and geodetic information has been shown to also reliably contribute to a reduction of the geographic extent of alarms - and it therefore defines a New Paradigm for TimeDependent Hazard Scenarios: Intermediate-Term (time scale) and Narrow-Range (space scale) Earthquake Prediction.

Keywords: NDSHA; RSHA; Earthquake prediction; Time-dependent earthquake hazard; Site effects warnings; Macroseismic Intensity; PGA

(C2021 Vietnam Academy of Science and Technology

\section{Introduction}

Since our world-wide experiences (expressed in terms of unacceptable human losses) of now more than half-a-century of equating earthquake risk models with earthquake hazard (or likelihood of having an

\footnotetext{
${ }^{1}$ Invited paper

*Corresponding author, Email: sasquake@gmail.com
}

earthquake) have proven unreliable, a New Paradigm is needed for Reliable Seismic Hazard Assessment RSHA. The NeoDeterministic Seismic Hazard Assessment NDSHA method, proposed some twenty years ago, is shown to both reliably and realistically simulate the wide suite of earthquake ground motions that may impact civil populations, as well as their heritage buildings. 
Building upon the familiarity and long experience of successful practice with Deterministic Seismic Hazard Assessment, NDSHA now convolves a comprehensive physical knowledge of: (i) the seismic source process; (ii) the propagation of earthquake waves; and (iii) their combined interactions with site conditions - and thus effectively accounts for the tensor nature of earthquake ground motions.

Standard NDSHA, using geological and geophysical data, computationally estimates an envelope of scenario ground-shaking characteristics from both: (1) the largest historically observed earthquake within a region; and (2) also from the Maximum Credible Earthquake MCE. Because each scenario is always "a real earthquake", it therefore does not require considerations of either probabilistic hazard model temporal representations of earthquake "likelihood", or scalar empirical Ground Motion Prediction Equation attenuation models (GMPEs).

Hence NDSHA provides both robust and safely conservative hazard estimates for engineering design and mitigation decision strategies; but, importantly, without invoking the chimeric (illusory) and physically rootless Hazard Curve: "annual frequency of earthquakes"|"earthquake return period"- often depicted as a "475 yr. earthquake" or the more rare "2475 yr. earthquake". Observations from recent destructive earthquakes in Italy: (i) $\mathrm{Mw}$ 5.9 Emilia 2012; (ii) Central Italy - Mw 6.3 L'Aquila 2009; and 2016-2017 Seismic Crisis - Mw 6.1 Amatrice; Mw 5.9 Visso; Mw 6.5 Norcia; Mw 5.7 L'Aquila; (iii) Mw 7.8 Nepal 2015; and (iv) Mw 3.9 Ischia 2017 - have all confirmed the validity of NDSHA's approach and application: (1) NDSHA has been applied to schools

- http://www.xeris.it/CaseStudies/index.html
- and (2) to tangible cultural heritage http://www.veneto.beniculturali.it/prevenzion e-sismica-area-veneta.

Therefore, we not only recommend, but also very strongly encourage its widespread application in all earthquake-prone regions to enhance both earthquake safety of civil populations to reduce human losses, and also to provide for resilience of community economies and infrastructure.

Rugarli et al., 2019b have pointed out that the consideration of a fixed increment of a given earthquake magnitude at a specific fault is very analogous to multiplying the mechanical moment at that fault by some factor, as is similarly done in structural engineering practice when determining the applied loads mandated by the most current structural engineering standards (e.g., Eurocodes). Then, in parallel with the currently accepted Eurocode 0 Paradigm (CEN EN-1990, 2002), these same authors introduced a tunable safety factor $\gamma_{\mathrm{EM}}$ - which quantitatively captures uncertainties in the seismic moments of assessed faults.

When a comparison was made between the hazard maps obtained with the scenario NDSHA technique (however using two different and completely independent approaches for the definition of the seismic sources considered for the computation of the synthetic seismograms) - for most of the territory considered: (i) the hazard map computed using seismogenic nodes (Gorshkov et al., 2003), together with the tunable safety factor $\gamma_{\mathrm{EM}}$; (ii) envelopes (or is comparable to) the alternate hazard map obtained using instead the 1000 + years-long earthquake catalogue record! Since the two hazard maps are developed from totally independent data sets, and further because the Italian earthquake catalogue is very long - these together supply both a validation of the 
seismogenic nodes method of Gorshkov et al (2003), and also a refined quantitative estimate of the tunable safety factor $\gamma_{\mathrm{EM}} \approx 2$.

Although deadly and damaging earthquakes cannot yet be predicted with a precision requirement consistent with issuing a red alert and evacuation order to protect civil populations; however, intermediate-term (i.e. several months' time scale) and middlerange (i.e. few hundred kilometers space scale) predictions of main shocks above a preassigned threshold - based on seismicity "alarms" generated by interpretive algorithms like CN and M8 (Keilis-Borok and Soloviev, 2003) - may be properly used for the implementation of low-key preventive safety actions, as recommended by UNESCO in 1997.

Furthermore, a proper integration of both seismological and geodetic information has now been shown to also reliably contribute to a reduction of the geographic extent of alarms. Indeed, recent experiments focused on the joint use of $\mathrm{CN}$ algorithm with GPS and GNSS data have led from formerly only intermediate-term and middle-range scale predictions to now intermediate-term and narrow-range scale (Panza et al., 2018; Crespi et al., 2019) - and it therefore defines a New Paradigm for Time-Dependent Hazard Scenarios: Intermediate-Term (time scale) and Narrow-Range (space scale) Earthquake Prediction!

A detailed description of the development and evolution of NDSHA methodologies during these last two decades has been previously published in Panza and Bela (2019) and Supplementary material therein. This paper now presents both a critical updating of that previous work, which comprehensively also includes as illustration "A Bibliographic Journey to a New Paradigm" - (7) (PDF) Supplementary material for "NDSHA: A new paradigm for reliable seismic hazard assessment"/Giuliano
Panza - Academia.edu - as well as a focused orientation on how we can better keep alert for the "safety of human lives" - by also more selectively basing our efforts on reliable seismic hazard assessment methods, as are available in NDSHA. The inclusion of selected examples which illustrate the engineering applications of NDSHA to strategic buildings and cultural heritage, we hope underscores our commitment that "it is not acceptable (and indeed unbearable) that so many people continue to die from earthquakes!"

\section{2. "Return period" or chimera?}

\section{Cuiusvis hominis est errare: nullius nisi insipientis, in errore perseverare}

Cicerone: Filippiche, XII. 5

Quantitative estimates of "engineering seismic risk analysis", per Cornell 1968 and McGuire 1992; 1995; 2004 - are by design associated with Hazard Curves and their oft misunderstood implicit concept of an "average return period" or "return time". But, in light of the huge human losses that misfortunately have accompanied the application of the method, in now its own 50 yrs... the fundamental question needs to be asked again, revisited and re-examined:

\section{"Return Period" or Chimera?}

These seismic risk models falsely presume that "once the fracture is created" - then the seismic cycle dutifully resets again from zero, per "the average activity rates assigned to them", until the next fracture occurs, and in roughly equal time intervals (Parkfield EQ Prediction 1985). The Cornell method, which was later known as the Cornell - McGuire PSHA (Wang 2012; McGuire 1976), was originally formulated "for the evaluation of the seismic risk at the site of an engineering project;" and formally required using the "more commonly assumed magnitude distribution and attenuation laws" - 
Gutenberg-Richter Law and now present-day "next-generation" (but unfortunately now problematically unstable) GMPEs!

The above postulated earthquake behavior could perhaps be possible if the physical and chemical conditions around the fault did not change! However, both: (i) immediately after the fracture; and (ii) on longer time frames as imposed by the active tectonics - the fault boundary conditions can vary considerably. And indeed, some recent evidences of this earthquake-induced transformation of the crust have been described in illuminating detail by Jamtveit et al. (2018) and Zhang et al. (2019). Furthermore: (a) the theoretical model by Carlson (1991) gives rise to slipping events of all sizes - the smaller events being consistent with the Gutenberg-Richter statistical law, whereas the characteristic events (here meaning larger and near the maximum) have separate statistical distributions; (b) the theoretical study by Cattania 2019, in extending the modeling to a continuum, explores why small earthquake sources can produce quasiperiodic sequences of identical events; whereas earthquakes on large faults are intrinsically more variable, showing that simple, isolated faults do not necessarily produce regular and periodic earthquakes, especially when the faults are relatively large.

\subsection{Tried but Not True...Return to Sender}

Since nothing provided in the Cornell "return period" risk model has ever been both successfully tried and experimentally verified (e.g., Chen et al., 2020); we must therefore agree that this unsupported concept of aseismic design belief and convenience - per Cornell 1968, that: "Owing to the uncertainty in the number, sizes, and locations of future earthquakes it is appropriate that engineers express seismic risk, as design winds or floods are, in terms of return periods [cited references 1952-1967]" - is too simple and simplistic to survive the limitations of its own probabilistic presumptive assumptions! Bummer!

Also, there is even further proof that a collective pause is now warranted in the appropriateness of this concept of "expressing seismic risk in terms of return periods" - given that flood risk is no longer expressed in terms of either the "100-year flood" or the "500year flood" - rather now, for flood insurance purposes, flood risk is expressed as "a flood that has a $1 \%$ or a $5 \%$ chance of occurrence in any one year, based on stream-flow hydrograph records. (See USGS "The 100Year Flood" https://www.usgs.gov/special-topic/waterscience-school/science/100-year-flood?qtscience_center_objects $=0 \#$ qt science_center_objects - and also Wang and Ormsbee 2005).

Because concepts are fundamental building blocks of thoughts and belief, they can cognitively create their own concept space meaning therefore that they can mean different things in the minds of different individuals (e.g., see Tall and Vinner 1981; FEMA P-749 2010; Geller et al., 2016). This has, unfortunately, become especially problematic when practitioners are no longer intimately involved in all of the qualifying aspects of the earthquake resistant design process; and, in particular, when they may also lack a correct and fundamental knowledge of both why and how that process came to be (see Preface in Junbo, 2017).

Finally, it should be emphasized that even though it failed to make clear distinctions between facts and seismic risk model presumptions and assumptions; importantly, the Cornell 1968 probabilistic (or quantitatively crafted) "return period" concept was originally intended to both enhance and also facilitate the other stated requirements for an engineering seismic risk analysis, namely that: (i) "the engineer must consider the performance of the [building, dam, highway 
bridge or other infrastructural] system under moderate as well as large motions;" (ii) "the engineer should have available all pertinent data and professional judgement of those trained in seismology and geology"; and that most importantly (iii) that information should then be provided "in a form most suitable for making this decision wisely." Clearly the "return period" is not the "form most suitable for making this decision wisely" - which seems to us to have been Cornell's intended conclusion here, albeit one rather based on circular reasoning (a logical fallacy wherein the premise and the conclusion are one-andthe-same) . . . and not so much on the science behind "all the pertinent data and professional judgement of those trained in seismology and geology!"

With these original and qualifying safeguards now seemingly (and bewilderingly so) expunged from the fully complemented Cornell 1968 seismic risk analysis method, ... we observe: (i) Return Period alone now tends to dominate the design decision process, which has always had at its root the belief that "the engineer professionally responsible for the aseismic design of a project must make a fundamental trade-off between costly higher resistances and higher risks of economic loss (Blume, 1965)"; (ii) Return Period is represented as capturing public policy requirements to then address "uncertainty in the number, sizes, and locations of future earthquakes"; and finally when (iii) Return Period is, as it now is, scaled to apply to the entire civil population (new buildings, existing buildings, cultural heritage buildings and infrastructure) - the true collective and geographically regional risks are neither effectively conveyed nor addressed so that (per Gilbert 1909... "safety shall be secured"!

That this is not, indeed, a surprise is because, as Ferraes (1967), Kanamori (1981), Cisternas et al. (2017) and Craig et al. (2016) all have shown - the lithospheric thought concept that an "average return period" (supposedly realistic physically only over very long time-scales not yet observed) is qualified as an "appropriate expression of seismic risk" - unfortunately disagrees with too many of the available data!

\subsection{Sometimes a Great Notion}

Nevertheless, the notion of "average return period", convolved systematically behind-thecurtain with the mystique of "probability", is still today (more than a half-century later) the basis of most probabilistic methods (See Hays 1980; Geller et al., 2016; Stark and Freedman, 2001; 2016; and here particularly Stark, 2017). In the oft required Probabilistic Seismic Hazard Analysis/Assessment (PSHA) method, it is postulated that in a certain place, of unspecified size, the "annual probability" of experiencing an earthquake ground motion having an intensity greater than Y (in short, "a probability of exceedance") does not change from year-to-year. This stationary hypothesis has certainly never yet been verified; and given the driving mechanism of progressive accumulation of energy that characterizes earthquakes, such verification remains unlikely, as do many other things consistent with early simple models of elastic rebound. More details are given in section 8 .

$P$ : annual probability of exceedance (a dimensionless number between $0-1$ ).

$P<10 \%$ or $P<0.002105$ (required by Ordinance).

1-P: annual probability of non-exceedance

Let the "annual probability of exceedance" be indicated by the symbol $P$. Then, in order for $P<10 \%$ in 50 years (as required for example by Ordinance 3274/2003 http://www.bosettiegatti.eu/info/circolari/stata li/2003_ord3274_sismica.htm - the annual probability $P$ must be less than 0.002105 . Conversely: (a) the annual probability of nonexceedance is (1-P); (b) the biennial $2 \mathrm{yr}$ 
probability of non-exceedance is $(1-P)^{1} \times$ $(1-P)^{1}$, the semicentennial or $50 \mathrm{yr}$. probability of non-exceedance is $(1-P)^{50}$. If such a probability of non-exceedance is, as above, set by law to be $(1-0.10)=0.90$ - then we obtain $(1-P)^{50}=0.9$ that gives back $P=0.002105$.

Now, if the earthquake were more like a comet and could have an annual probability equal to 0.002105 per $\mathrm{yr}$, this would then imply that it returns every $1 / 0.002105$ years $=475$ years. This is how the earthquake "average return period" is defined.

\subsection{The fault lies not in our stars, but in ourselves}

The rules for making these calculations are exactly the same as those used to calculate the "probabilities" of lottery numbers or those associated with repeated throws of the dice! The next step of a PSHA (but which is totally wrong and without any scientific foundation), is that: if the indicated earthquake has an "annual probability of exceedance", which is by definition an adimensional or dimensionless quantity (between $0-1$ ) equal to 0.002105 , then its "average return period", which now surprisingly has dimension of time, must be $(1 / 0.002105)$ years, or about 475 years.

The error (one which anyone is liable to make) is similar to the one committed by those who, having established that the probability of exit or of an outcome of 3 with a throw-of-a die is $1 / 6$, wanted to conclude that the 3 returns "on average" every 6 throws! This is the known fallacy of the player, who persists in his error because he attaches a memory to the probability, where it does not and cannot have it!

From Earthquake Science, which at the time of Aristotle postulated but four theories on earthquakes -

http://www.geophysics.geol.uoa.gr/frame_en/ histo/aristotle_en.html - we can only conclude that, due to the inadequate amount of data available: (i) there is no scientific evidence to define which memory model to assign to earthquakes; and (b) PSHA is based simplistically (and with obvious internal contradiction) on the presumption that earthquakes occur randomly over time following a process without memory (e.g., Bilham, 2009). For more details see section 8.

Aristotle found the but three preceding theories of earthquakes that existed at his time to be illogical, irrational, unfounded, and replete with what we today would describe as parascientific reasoning underlying their hypotheses. We find today that the concept space surrounding the "average return period" underpinning of PSHA is likewise similarly fraught with both parascientific reasoning and error - such that, even in the last 50 yrs, PSHA hasn't even climaxed at a $10 \%$ chance of exceeding expectations The conundrum is, however, because PSHA remains the required basis of the many seismic building regulations in force in various parts of the World, including Italy and the United States - safety is neither secured, nor assured!

The late Carl Sagan strongly believed in the power of science, here observing in a 1987 conference keynote address:

In science it often happens that scientists say, 'You know that's a really good argument; my position is mistaken,' and then they would actually change their minds and you never hear that old view from them again. They really do it. It doesn't happen as often as it should, because scientists are human and change is sometimes painful. But it happens every day. I cannot recall the last time something like that happened in politics or religion.

He would later add, noting both that "we live in a society absolutely dependent on science and technology" and "yet we have cleverly arranged things so that almost no one 
understands science and technology. That's a clear prescription for disaster".

Thoughtful discussions have, therefore, both loosely pondered and also really in much detail examined "how is it possible that such parascientific blunders may involve such vast multitudes of both learned (members of national academies, honored fellows of elite societies) and professionally-trained participants (nuclear plant siting consultants) without collectively a screeching brake to a halt! - or other lifesaving remedy: i.e. Seismic Ghostbusters eradicating psha's paranormal distributions? More simply put, per Ralph Waldo Emerson - if "men love to wonder, and that is the seed of science," then why hasn't PSHA planted any seed since the time of Plato, when "science was nothing but perception"? It was found in both Rugarli (2014; 2016) and in Kossobokov (2017) that: (a) "there is nothing new under the sun, but there are lots of old things we still don't know"; (b) "there are some people who, if they don't already know, you can't tell 'em"; and (c) "it is difficult to get a man to understand something when his salary depends upon his not understanding it"!

"Even if you are a minority of one, the truth is still the truth"

- Mahatma Ghandi

There seems to us to be a real conundrum of confusion (our polite term for total befuddlement, lack of ethical responsibility and a distanced disregard for a secured public safety) in the engineering practices between what is scientifically accepted and what is accepted by the majority in power. ${ }^{2}$

\footnotetext{
${ }^{2}$ Engineering Societies: ASCE, EERI, LATBSDC; Seismological Societies: SSA, GEM, AGU, EGU; Building Code Organizations: NEHRP, BSSC, ICBO, EUROCODE; National, Federal and State Earth Science related formal Agencies and Institutions: INGV, USGS, USNRC, NSF, UCB, UCLA, UCSD, Stanford, PEER, NAS, NAE, CDMG - to name some of the more major seismic roulette players responsible.
}

This conundrum reflects two very distinct realities, wherein: (1) science is the inquiry into finding the best explanation for a physical event or phenomenon; while (2) politics is what people want! While it's certainly "better to be right than to be consistent," part of the blame to go around for inadequate public response (e.g., Peterson, 1988) to earthquake hazards (and sadly the huge human losses that have resulted from them) seems to devolve from the fact that, even though we've long recognized that science cannot be democratic (or left to be determined by the political science will of the majority: See e.g., "Science Is Not A Democracy, And Can Never Be One: it isn't arguments or votes or opinion that herald the acceptance of a scientific explanation: it's the evidence." by Ethan Siegel 2016) - communities-wide, we all have not been well-enough educated to intelligently select our leaders... and the standards they produce! (see also "The Role of the Standards in the Invention of the Truth" - Rugarli 2016).

Galileo Galilei, founder of the experimental method and one of the first members of the Italian Academia dei Lincei, was a strong minority among his contemporaries in observing: "In questions of science, the authority of a thousand is not worth the humble reasoning of a single individual."

In fact, there has always been clear evidence from the time it was authoratively first proposed that PSHA is wrong (Panza and Bela, 2019), but particularly within this past decade - with our benefit finally (calendarwise) now of true 2020 hindsight! (Wyss et al., 2012; Bela 2014; Panza et al., 2014; Mulargia et al., 2017; Stark and Freedman, 2016; Stark, 2017; Rugarli et al., 2019a) - we can say for certain that PSHA's "technological inexactitudes", which unfortunately make up its body of knowledge, cannot ever reliably fulfill on either their presumptions or their promises! But, for a better future, this systemic problem remains: 
when parascience has a legal chrisom covering it, removing it can be very difficult!

"Law was always made by the few and in general for the purpose of preserving the 'existing order', or for the reestablishment of the old order and the punishment of the offenders against it"

- Alfred Korzybski, Manhood of Humanity

The legal framework of law sometimes gives body and substance to the most absurd chimeric dreams (outcomes hoped for but illusory and impossible to achieve). The probabilistic method, which again is based on the false presumption that "owing to the uncertainty in the number, sizes, and locations of future earthquakes it is appropriate that engineers express seismic risk, as design winds or floods are, in terms of return periods"... has been proven to be not only an unreliable analysis, but also a fallacious concept as well!

For example, how many times have we waited in the city for a public transport? - for an hour or more? - only then to see more than one of them arrive together? The same thing is true for earthquakes, as shown for example in Figs. 1 and 2, which sometimes occur in groups (or clusters) within a given seismically active area - as has been well documented by Rundle et al. (2000).

- Number of earthquakes for ten years intervals.
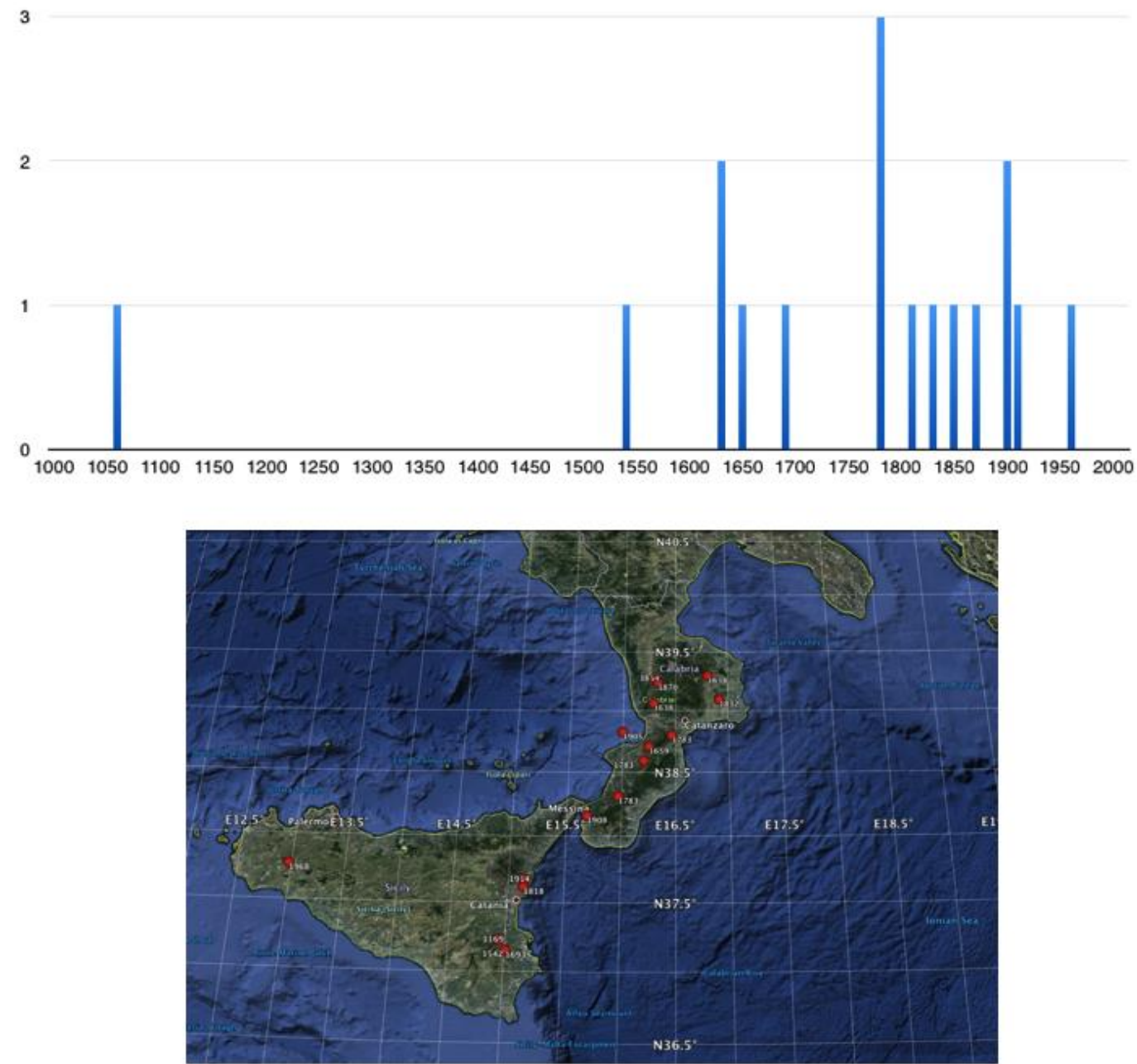
Vietnam Journal of Earth Sciences, 43(2), 111-188

$\leftarrow$ Figure 1. Earthquakes with $\mathrm{I}_{\mathrm{MCS}} \geq \mathrm{X}$, since 1100 , in Messina strait area s.l. (Italy): (a) to be conservative all intermediate Intensity values (see section 4. Macroseismic Intensity, Magnitude and Peak Acceleration) are rounded up to the nearest integer; (b) the sometimes-clustered sporadic locations of epicentres, in space-and-time, threatens at its core the chimeric concept of "average return period" or "return time" - the promoted appropriate cornerstone for expressing seismic risk in PSHA! What is the real practical value that an engineering seismic risk analysis should assign to the Messina strait area for the "average return period" or "return time?" - which here we can calculate at about "60 years" for historic events with $\mathrm{I}_{\mathrm{MCS}} \geq \mathrm{X}$ occurring in the last millennium? (courtesy of D. Bisignano)

- Number of earthquakes for 10 years intervals.

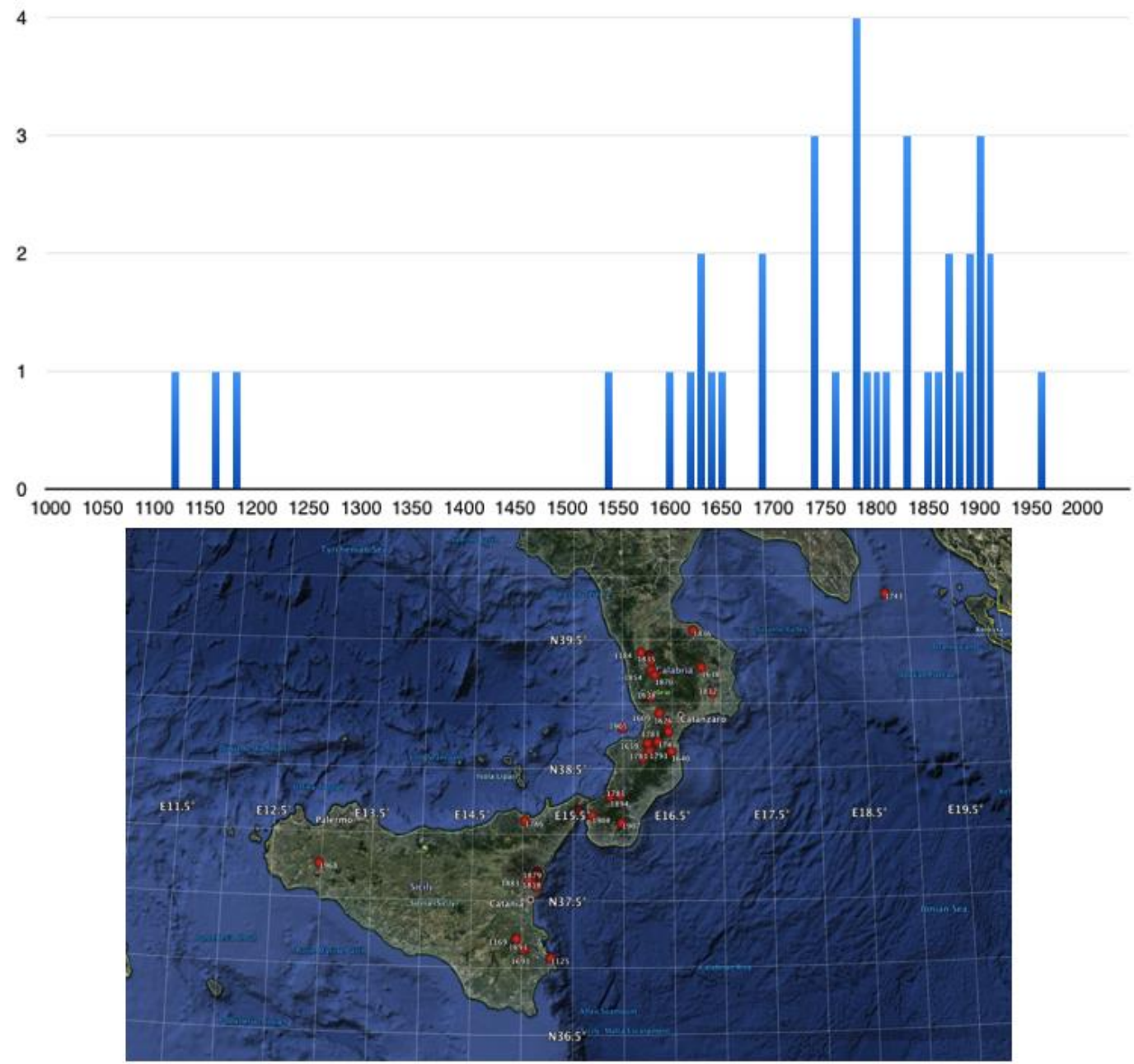

Figure 2. Earthquakes with $\mathrm{I}_{\mathrm{MCS}} \geq \mathrm{IX}$, since 1100, in Messina strait area s.l. (Italy): (a) to be conservative all intermediate Intensity values (see section 4. Macroseismic Intensity, Magnitude and Peak Acceleration) are rounded up to the nearest integer; (b) the clustered sporadic locations of epicentres, in space-and-time, threatens at its core the chimeric concept of "average return period" or "return time" - the promoted appropriate cornerstone for expressing seismic risk in PSHA! What is the real practical value that an engineering seismic risk analysis should assign to the Messina strait area for the "average return period" or "return time?" - which here we can calculate at about " 25 years" for historic events with $\mathrm{I}_{\mathrm{MCS}} \geq \mathrm{IX}$ occurring in the last millennium? (courtesy of D. Bisignano) 
"The Map is not the Territory" *

- Alfred Korzybski

*An abstraction derived from something, or a reaction to it, is not the thing itself.

The PSHA methodology, like the Mythical Beast of Asia Minor in Greek Mythology - the Chimera - is made up of three main parts: (1)"return period"; (2) seismic risk model; and (3) illusory but imposed fault behavior - or what we here humorously (in the mythology and spirit of PSHA's always selfcongratulatory praise) might now refer to as "the beast available science"!

When we apply the formal "body of knowledge", however, for Territories of limited extension, such as those currently considered in its applications (e.g., Seismogenic Zones ZS9 in Italy); it is not readily falsifiable (or proven easily by the evidence to be false!) - and primarily so because such very long time-intervals are required (Panza, Kossobokov et al., 2014). In general, if (in a certain area or territory) the method declares that in the next 50 years the "probability" of an earthquake with seismic shaking severity (danger) greater than $\mathrm{Y}$ is $10 \%$, then the occurrence of a seismic event with much greater shaking than $\mathrm{Y}$ does not falsify the forecast! And in fact, there is disconcertingly still a "probability" of $10 \%$ that even the strongest possible earthquake occurs! If, on the other hand: (a) the event greater than $\mathrm{Y}$ does not occur; or even if (b) no event at all occurs then the method would still be right! In the Greek Mythology of the Chimera: you may encounter the mighty roar of the Lion, the intermediate bleating baa of the Goat, or the slithering slowness (or even hibernation) of the Serpent!

A quite common value for the "return period" at which PSHA computations are made is 475 years (for ground motions which have a $10 \%$ in 50 yr. chance of exceedance). But this is a half-millennium time interval far much longer than the length of our most adequately complete earthquake catalogues - for a very unique exception to this limitation, see CPTI04 Parametric Catalogue of Italian Earthquakes (CPTI Working Group 2004), which spans a time interval of some 1000 years!

Thus, the answer to our opening question of whether "Return period" or Chimera? is obviously that: "Return period" is a Chimera! - i.e., its own mythical and illusory body-of-knowledge beast! We are reminded... as Albert Einstein very timely noted: "The distinction between the past, present and future is only a stubbornly persistent illusion." And since "losing an illusion makes one wiser than finding a truth," for Reliable Seismic Hazard Assessment RSHA, it is always best therefore, we believe, to "never think of [the earthquake as off in] the future - it comes soon enough"!

"When going to a new territory it is best to take a good map, and then to compare that map with the actual territory" (Alfred Korzybski, 1931) "A map," Korzybski says, "is not the territory it represents, but, if correct, it has a similar structure to the territory, which accounts for its usefulness." see also - https://fs.blog/2015/11/map-andterritory/ - Since, therefore, "a prudent question is one-half of wisdom", the naturally wise and consequential question to ask now is: Is any scientifically sounding quantitative seismic risk model based on the "return times" or the "average return period" useful?

Although the concept of "return period" is the basis underlying familiar earthquake hazard maps in Building Codes world-wide, and also upon which most public policy laws and legislation are based; it is unfortunately not adequate for the effective protection of civil populations from the earthquake (Panza et al., 2014).

Moreover, both from an anthropocentric and also an effective public policy perspective, it is essential that at least the strategic and public structures (buildings, facilities, bridges) are designed to withstand 
future strong earthquakes. When an earthquake occurs with a given magnitude $\mathrm{M}$, it generates a seismic ground motion acting on whatever favorable or unfavorable site conditions exist - and that certainly does not depend on how sporadic or infrequent an event of this magnitude is within the area of study. Therefore, the anti-seismic or earthquake-resistant design parameters must not be scaled according to the greater or lesser earthquake likelihood, given the actual sporadic recurrence of earthquakes - but must instead take into account the values of $\mathrm{M}_{\mathrm{EQ}}$ consisting of: (i) the historic seismic and paleoseismic history; and (ii) the seismotectonic terrane (including seismogenic nodes identified by morphostructural analysis, as described in section 5. Methodology - as both are requisitely considered and evaluated by NDSHA, which then uses data-driven realistic and computationally generated scenario earthquakes.

Consequently, to move from our present earthquake paradigm focused on emergency management... to a new one based on prevention and resilience, it is necessary to substantially re-evaluate the scope of not only the applicability, but indeed also of the promised "appropriateness" of the probabilistic approach PSHA (Keilis-Borok, 2018), limiting its use we advise only to the cautionary classification of the "territory" on the basis of the probability that, within a certain relatively large area, an earthquake with a given magnitude $\mathrm{M}_{\mathrm{EQ}}$ may occur within a certain interval of time (e.g., disastrous earthquake - perhaps about 500 years?; large and strong earthquakes - perhaps about 140 years?; and frequent earthquake - perhaps about 70 years?

If we then therefore consider two possible sites that have earthquake hazards of the same magnitude (for example $M=7$ ), or are prone to the same ground motion effects due to their site conditions; then, all other conditions being equal, the site where the sporadic recurrence of earthquakes is greater becomes naturally preferable for new settlements (and vice versa for any required preventive retrofitting actions). However, the reference parameters of an appropriate earthquakeresistant design (Design Ground Acceleration - DGA, Peak Ground Acceleration - PGA, Peak Ground Velocity - PGV, Peak Ground Displacement - PGD, SA - Spectral Acceleration, etc.) must be the same at both sites, since the magnitude $\mathrm{M}_{\mathrm{EQ}}$ from which we must defend ourselves, $M=7$ (or the seismic ground motion of the soil and site conditions), is the same!

Any risk assessment is necessarily different when we consider a purely actuarial perspective for losses. This may be satisfactory for the insurance/reinsurance market system. However, lacking an adequate statistical characterization (generally not possible due to the scarcity of available observations), the usual practice is then to rely on probabilistic risk models - wherein it is recognized that the probabilities in these "black boxes" are subjective (and not real), because there is no truly reliable and indisputable data; and necessary safeguards must therefore be taken to compensate for unacceptable losses - should the model ("the man behind the curtain" - e.g. Stark, 2017) turn out to be wrong! Bummer!

\section{4. "The Great and Powerful Odds"}

The concept of "return period" is related to the idea that a single fault behaves like a spring (elastic rebound theory of Reid 1911; USGS PSHA - UCERF 3, 2015a,b), which can therefore be deterministically fully understood or assimilated to an oscillating system with a single degree-of-freedom (simple pendulum). However, in nature faults are not single, individual and isolated objects, but form more-or-less numerous (collective) systems of faults. So, we are then really dealing with sets of coupled pendulums, whose global behavior is no longer simply 
periodic (closed loop), but which can be wellused to describe deterministic chaos, an apparent oxymoron because it connects two familiar ideas that are generally regarded as incompatible!

Mathematical models of the deterministic type are generally associated with the notions of regular and predictable phenomena (e.g., the oft presumed "earthquake cycle"), which repeat over time; whereas the chaotic term oppositely refers to situations characterized by both an absence of rules and therefore an unpredictability.

The discovery of "deterministic chaos" breaks this dichotomy by showing how deterministic mathematical models (i.e., models lacking any random element in their defining equations) are able to nonetheless generate chaos! That is, they are able to generate extremely complex trends, in many respects unpredictable; so as to be almost indistinguishable from stochastic sequences of events generated through random process - more details e.g., at http://pespmc1.vub.ac.be/CHAOS.html.

Seismic processes are essentially the end result of the Earth's lithospheric dynamics, wherein: (i) the lithosphere is viewed as a self-organized hierarchy of different-sized blocks; (ii) the relative displacements (fault motions) show up as seismic activity at their boundaries; and (iii) interactions can be complex among these many but self-similar systems of faults.

"Prediction is very difficult, especially if it's about the future"

- Nils Bohr

Since the behavior of such a dynamic system is, in general, controlled by nonlinear laws and is therefore chaotic to a great extent - in principle, it is not possible to predict the behavior of such a system in detail. However, the prediction of extreme events resulting from the dynamics of such a system is possible, at least for the relatively near future; and also, after a heavy effort or round of averaging the complex set of observable variables (Keilis-Borok and Soloviev, 2003).

Although accuracy of any prediction can be improved hierarchically by adding into analysis new observable variables from lower levels of averaging, under a refined resolution of the system; it is still rather evident that an efficient prediction in such a complex system can hardly be based on a single phenomenon. Therefore, suppose (i.e., assume), based solely on the seismic history, that a "return period" of 1000 years is estimated for a certain area where there are some faults (a system of faults). However, because we certainly cannot know when the millennium began for each fault - then we can, we advise, legitimately conclude that any quantitative seismic risk analysis that is based singly on the "return times" or "average return period" of earthquakes is neither scientifically valid nor practically useful! The map does not have "a similar structure to the territory", and therefore "safety is not secured"!

An application of "intermediate-term middle-range" earthquake prediction is at the base of the time-dependent hazard briefly described in section 8. Time-dependent earthquake hazard. In the same section the new paradigm intermediate-term narrowrange earthquake prediction is briefly discussed.

\section{Change of Paradigm: From PSHA to NDSHA}

"All generalizations are false, including this one"

- Mark Twain

PSHA relies upon statistics. As the late physicist Richard Feynman (not only Nobel Laureate but also creative genius and even jokester) still reminds us: "Sometimes we make guesses because we wish with our limited knowledge, to say as much as we can about some situation." 
Really, any generalization is in the nature of a guess. Any physical theory is a kind of guesswork. There are good guesses and there are bad guesses. The theory of probability is a system for making better guesses. The language of probability allows us to speak quantitatively about some situation which may be highly variable, but which does have some consistent average behavior.

PSHA relies heavily upon both the language and the prestige of statistics, asserting that (since it self-defines its very own "Hazard Model" inputs as "the best available science") its outputs with regard to the earthquake situation are also science! despite the troubling paradox that the earthquake situation does not even casually "have some consistent average behavior." (See e.g., "What is the Chance of an Earthquake?" - Stark and Freedman, 2016).

As a rule, however, the data considered in a PSHA do not satisfy basic requirements for reliable statistical data processing - that branch of mathematics dealing with the collection, analysis, interpretation, presentation, and organization of data (Båth, 1973). Therefore, then with the subsequent application of that data into probabilistic models that measure the likelihood that an event will occur (i.e. that a certain level of ground shaking will be exceeded within a specified period of time), it is unfortunately found both: (a) that the models are not really science; and (b) that therefore the resulting risk analysis is also unreliable, because (per Castaños and Lomnitz, 2002) "its data are inadequate and its logic is defective."

The general shape of a (pseudo) spectral response acceleration (elastic response spectrum) is popularly applied in seismic codes, where the prescribed design acceleration response spectrum, expressed as a function of natural period, provides "a general procedure to estimate the expected dynamic load on a structure.” Thus, knowing the period response of a structure, design load can be calculated and energy dissipation requirements also considered.

Shapes of standard code spectra, when in specific cases they are obtained by a heavy statistical processing of actual earthquake records [which we note here is in sharp contrast to design response spectra developed from the PSHA framework - which are constructed by their own sets-of-rules argued over by committees] are, so far, the only reliable way to describe earthquake ground motion at low periods $(\mathrm{T}<1 \mathrm{~s})$ that may be of interest for seismic engineering or engineering seismology. However, the response spectrum method is by its nature not precise, because (although derivative shapes of standard code spectra are obtained through a demanding statistical processing of signals) these strong motion records are obtained under quite different background conditions and azimuthal directions; and they therefore cannot always be considered the best tools to assess a specific and individual structural behavior - indeed the scatter can be quite large!

\section{"One finds limits by pushing them"}

- Herbert Simon

Importantly, and as a rule, the NDSHA computations of time-history accelerograms containing accelerations at short periods $(\mathrm{T}<1 \mathrm{~s})$ require a level of knowledge of earthquake source processes and wave medium pathway that so far is unatinable. However, accelerogram computations that are reliable at longer periods may always be extended to $\mathrm{T}<1 \mathrm{~s}$ by using standard elastic acceleration response spectra. And therefore, in absence of normalized spectra derived from specific regionally recorded signals, in NDSHA the recommended procedure then (when within this high frequency range) is to use "Code spectral shapes", e.g. Eurocode 8 (EC8 1993, 2008) - which defines the normalized elastic acceleration response 
spectrum of the ground motion for $5 \%$ critical damping.

However sometimes, where available knowledge may allow us to account for source and pathway details that are required for short periods (less than the standard $\mathrm{T}=1 \mathrm{~s}$ cutoff), then NDSHA is also able to computationally consider these high frequency characteristics (See e.g., NDSHAMCSI, Rugarli et al., 2019a and references therein).

PSHA would not have been plausible or "able to be believed" without the availability and required critical input of earthquake ground motion attenuation relations in formulating a "probabilistic seismic hazard curve," depicting annual frequencies of exceedance - that hazard curve systematically constructed from a presumed composite context of "earthquake magnitudes, locations, and ground motions." (See e.g., Probabilistic seismic hazard analysis: Early history McGuire 2007, 2008) These presumed ground shaking characteristics versus distance still remain the key data ingredient (later remodeled, reinvented and modernized to be called Ground Motion Prediction Equations GMPEs (Douglas, 2020) - and even these subsequently reimagined, with episodic Next Generation GMPE model iterations following) - despite the fact that they cannot shake their scalar and linear property underpinnings, which unfortunately do not and cannot account for the tensor nature of real earthquake ground motions!

Furthermore, because GMPEs are themselves similarly the result of statistical cosmetics, they cannot only sometimes be highly misleading, but they can also have a major destabilizing effect on what seismic design parameters are then codified and implemented in engineering practice. This means that, when those seismic code parameters are derived from PSHA hazard assessments that have been computed using these new, or next generation, or even after next ground motion models - then their resulting imposed uncertainty in the design practice... from decreases, then increases; or increases, then decreases; becomes not only unsettling, but also potentially catastrophic for good engineering judgement, which requires a career of stable practice knowing not only: (a) what you are doing; but also (b) why you are doing it! (See e.g. Hamburger, 2016). For this reason alone, both authors wisely believe that GMPEs cannot be successfully relied upon in any earthquake hazard assessments, since the goals of which must always be the reliable and stable protection of civil populations!

In again asking, therefore: "What is the meaning of using the estimates from GMPEs (a scalar) to assess a probability to the earthquake ground motion, which in reality, is actually a tensorial quantity"? - we note that, for real earthquakes, GMPEs are known to be too linear to be of even any practical use in real-time Shake Map applications, wherein interpolations between strong motion data points, complemented by considerations of both Vs30 and topography, must be relied upon!

NDSHA uses computational (synthetic) accelerograms generated simulating source mechanism and wave propagation pathway through anelastic media: (i) exploiting all available knowledge; (ii) in agreement with basic physical principles of continuum mechanics; and therefore (iii) is totally independent of GMPEs!

PSHA, in order to incorporate the concept of an "average return period," must presume plausible that the Gutenberg-Richter (GR) law is valid at any scale - including e.g. even sometimes at one single fault! The GutenbergRichter (GR) law, which "states that earthquake magnitudes are distributed exponentially as $\log _{10} \quad N(m)=a-b m$, where $N(m)$ is the number of earthquakes with magnitude larger or equal to $m, b$ is a scaling 
parameter and $a$ is a constant... is assumed to be the expression of earthquake selfsimilarity" (Godano et al., 2014). In our view, many of the difficulties complicating the application of the Gutenberg-Richter (GR) law (and the many derivative attempts to deduce local and regional earthquake scaling laws, in particular $b$-values or the proportion of small earthquakes) in seismic hazard assessments can be explained by the fact that its authors (Gutenberg and Richter, 1944; 1949; Panza and Romanelli, 2001) formulated their relation as a law valid only at global scale!

The misapplication of GR relation as a "law" to relatively small areas with detailed fault paleoseismologic studies led the PSHA community to accept the introduction of the Characteristic Earthquake CE model (Schwartz and Coppersmith 1984; Wesnousky 1994), which postulated that "individual faults and fault segments tend to generate essentially same size or characteristic earthquakes having a relatively narrow range of magnitudes near the maximum," because: (i) an alteration was required in order to explain the recurrence intervals and large magnitudes of earthquakes interpreted from paleoseismology; and because (ii) the frequency of occurrence of these large or characteristic earthquakes had been "grossly underestimated" from simple and linear extrapolation of the GR cumulative recurrence curve from smaller earthquake magnitudes.

However, while the Characteristic Earthquake model concept was later solidly proven to be wrong (Molchan et al., 1997; Kossobokov and Mazhkenov, 1994; Bak et al., 2002; Nekrasova and Kosobokov, 2006; Kagan et al., 2012) - since the end result of a PSHA is not design guidance for any specific magnitude of earthquake threat, as was formerly the case when seismic code requirements were based on seismic zones, it is not always possible to intuit the characteristic earthquake model's impact on the final result in any derivative PSHA generated seismic hazard curve (i.e., whether hazard actually increases or decreases)!

NDSHA does not consider GR frequencymagnitude relation as a law, but rather simply as knowledge; or a tool to grossly assess the level of completeness in earthquake catalogues, which historically have always been used to assess hazard.

The CE model and concept, which complicates PSHA's other competing concept of an "average return period" based on the GR law, is immaterial for NDSHA, which simply requires some completeness in earthquake catalogues for earthquakes with $M \geq 5.0$, i.e., a little below the $\mathrm{M} \geq 5.5$ threshold widely associated with observable damage near the epicenter.

PSHA is founded on the chimeric concept of an "average return period". (see section 2 . "Return period" or chimera?) But this is only numerically (not physically) linked to the slope of the Gutenberg-Richter (GR) law. In order to satisfy the presumed objective that engineers should express seismic risk in terms of "return periods" per Cornell 1968, it became necessary to also presume that earthquake recurrence could be treated as a Poissonian process, which characterizes random (but stationary) processes in terms of frequency, time and probability of exceedance. However, since there is neither "annual frequency" of floods, earthquakes nor of public safety (Wang and Ormsbee, 2005; Wang and Rogers, 2014; Wang, 2015), the endgame result of all this presumptive and really haphazard mathematical chess playing has been, after first constructing a hazard model, then to unfortunately compute "something" with neither physical nor statistical meaning! 


\subsection{Confusing and Inappropriate}

It must be underlined here that: (i) the use of a set of misleading terms, like "probability", "return period", "exceedance", "collapse prevention", "performance-based", "best science", as well as the systematic use of complex math symbolically to more authoritatively hide simple baseless rules, has also (using Parascience) pseudo-scientifically deceived the population; and (ii) this population was not told the real truth, that: (a) new building were designed for potentially unsafe earthquake damage; (b) existing buildings that should be strengthened may not be, because earthquakes are believed unlikely; and that (c) rather crude reasoning was applied to their lives (McGuire 2004). Furthermore, to our knowledge there are no observational or theoretical bases for either the guesses, statistical presumptions, or illogical assumptions underlying the PSHA method: namely that the return periods of MCEs along fault segments can be estimated by extrapolation from the seismicity rate and distribution!

Using standard scientific logic, we know that any hypothesis that fails all available tests and is not based on a theory, as is the case for the basic PSHA hypothesis, is considered to be rejected (Wyss 2015).

From the now more than 50 yrs. of PSHA results (a variant of "Extreme Value Statistics" per Gumbel 1958) that presume a composite context for "earthquake magnitudes, locations, and ground motions," we know that not only engineers but also most people have often been confused regarding the differences between an earthquake and ground motion. Ground motion, to clarify, is ground shaking that is a consequence from having an earthquake. In other words, if No earthquake occurs, NO ground motion will be felt and no damage observed!

However, in PSHA hazard models, ground motion occurrence in time could be different from that of a damaging earthquake. How can the composite ground motion that is depicted on the map occur in time intervals from every 500 yrs to only some several years, if the presumed damaging earthquake occurs every 500 years? For example, PGA hazard curves for San Francisco, CA indicate only a $1 / 250$ or 0.004 chance or probability of annually exceeding a certain level of ground motion (as depicted on the curve), which, when translated to engineers or to an unassuming public, becomes reinterpreted as an earthquake with a 250 yrs "return period" or most popularly (but false)... a "250 yr earthquake"! Although PSHA hazard models can derive annual exceedance probabilities as low as 0.0000001 per yr., with a corresponding 10,000,000 years "return period" for ground motions - in nature, both time and ground motion occurrence must be consistently coincident with earthquake occurrence and energy release... "period"! (Romanelli et al., 2013).

A more viable alternative that is capable of minimizing the drawbacks of standard PSHA is represented by the use of scenario earthquakes, as is provided by NDSHA. In the original formulations by Panza et al., 2001, 2012 - NDSHA is solving, in a first approximation, fundamental physics-based problems posed by an adequate description of the physical process of earthquake occurrence. Therefore, NDSHA considers the largest event physically possible, usually termed Maximum Credible Earthquake MCE (from earliest regulatory language: FEMA 65, 2005; USBR 2019), whose magnitude $M_{\text {design }}$ at a given site is then set equal to the maximum observed or estimated magnitude $\mathbf{M}_{\max }$ plus some multiple $\gamma_{\mathrm{EM}}$ of its accepted global standard deviation $\left(\sigma_{\mathrm{M}}\right)$. In areas lacking information on faults, or with very sparse data, both historical and morphostructural analysis methods are used to estimate the MCE (Rugarli et al., 2019a). 
The factor $\gamma_{\mathrm{EM}}$ can be considered a "tunable safety factor" to Earthquake Magnitude to be applied systematically with the other safety factors that are used in structural engineering. So $M_{\text {design }}=M_{\max }+\gamma_{\mathrm{EM}}$ $\sigma_{\mathrm{M}}$, where it is currently assumed $\sigma_{\mathrm{M}} \approx 0.2$ 0.3 (Båth 1973, p. 111) and it is proposed to then use $\gamma_{\mathrm{EM}} \approx 2.0$ per Rugarli et al 2019b. Since the design value $\mathrm{M}_{\text {design }}$ is determined by adding this further tunable increment to the maximum estimated value $\mathbf{M}_{\max }$, it must be considered approximately a one-half Magnitude step to realistically envelope uncertainty, evaluated at the very best of our present-day knowledge and geologic judgement.

\subsection{PSHA and NDSHA: The Similarities are Different!}

(I) PSHA seeks a biased advantage toward lowering first costs of construction (McGuire, 1992; 2004; Hanks, 1997; Somerville, 2000), and it both easily and familiarly fits within the standard business model, whereby: (a) the focus is on production of products and services by fast, efficient and repeatable protocols; (b) the details, science, validity and truth underlying these methods, as well as any accountability for using them, are not as important, if even considered at all; and (c) the decisions made are, therefore, not always either error-free, consistent with past practices, or actually the best decisions! (Egan 1989; Kahneman 2011). It is, therefore, not surprising to us that the code writers maintaining the now institutionalized regional and global dominance of PSHA are, indeed, the very same individuals from business that are (at the same time) also using these methods in their daily practices! What is surprising... is that Universities have now joined-in with business in these efforts?

(II) NDSHA seeks RSHA... as is best described by the historically eminent USGS Geologist "Rock Star" G.K. Gilbert, who offered these observations now more than a century ago (or the equivalent of two $50 \mathrm{yr}$. lifetimes... in PSHA's alternate universe):

It is the duty of investigators seismologists, geologists, and scientific engineers - to develop the theory of local danger spots,to discover the foci of recurrent shocks, to develop the theory of earthquakeproof construction. It is the duty of engineers and architects so to adjust construction to the character of the ground that safety shall be secured. It should be the policy of communities in the earthquake district to recognize the danger and make provisions against it.

- Gilbert 1909

RSHA also incorporates this lesson from the twentieth century poet T.S. Eliot:

"Where is the wisdom we have lost in knowledge? Where is the knowledge we have lost in information?" And now... Where is the information we have lost in PSHA?

What, we wondered, makes the similarities between PSHA and NDSHA so different? while still at the same time so many of its practitioners continue to claim that "there is nothing better"? And we found in Celeste Adams' thoroughly enjoyable reflections on "The Vision of Buckminster Fuller" some both amusing and also very realistic answers! Buckminster Fuller (1895-1983) "was one of the world's first futurists and global thinkers," and "he set forth ideas that would overthrow all the old paradigms" (Adams 2002):

(a) Buckminster Fuller, like NDSHA, focused on large scale patterns, rather than details, like PSHA.

(b) PSHA is "educated to death," such that it is "only able to communicate that in which it is educated," but

(c) Fuller's most applicable insight came from what he described as the "scandal of pi." That is, he said:

Generations of 'circle-squarers' attested to the persistent intuition that it $[\pi]$ ought to have a rational value, but nobody ever found one! 
Eventually it was proven that none was findable. The decimal sequence for pi is $3.14592653589793 \ldots$ and will go on forever $\ldots \ldots \ldots \ldots \ldots \ldots$. . . . . . . . . . . . decision right at that moment that nature didn't use pi . . . and I decided then, in 1917, that what I'd like to do was find nature's geometry.

NDSHA, we believe, is more soundly rooted in nature's geometry ... and therefore, as widely proven... provides Reliable Seismic Hazard Assessment RSHA!

PSHA has been going on forever (pi sha, if you will), adding integer - after other integer after other integer, but still without any "rational value"... or any end in sight that one can see, even if now with super-computing! And what cosmetic statistical gamesmanship (Kossobokov, 2017) may seem logical for "one single engineering site" - gambling with nature to achieve (as the numbers seem to promise) a "maximum utility"... then completely falls apart when required to be scaled-up to include every single building with all of its supporting infrastructure, heritage buildings and community resilience also at stake! In that circumstance (e.g., "The Seismic Future of Cities"- Bilham 2009)... "taking a chance on a guess"... well, it just doesn't seem rational anymore!

A further implicit and important confirmation (through granting of legal authorization as a seismic building code procedure) of the validity of adopting NDSHA as the most realistic and effective available preventive tool is given in Norme Tecniche per le Costruzioni 2018 (NTC 2018), which deepens and expands the concept contained in chapter 3.2.3.6 of NTC 2008 as follows:

L'uso di storie temporali del moto del terreno generate mediante simulazione del meccanismo di sorgente e di propagazione $\grave{e}$ ammesso a condizione che siano adeguatamente giustificate le ipotesi relative alle caratteristiche sismo genetiche della sorgente e del mezzo di propagazione e che, negli intervalli di periodo sopraindicati, l'ordinata spettrale media non presenti uno scarto in difetto superiore al $20 \%$ rispetto alla corrispondente componente dello spettro elastico.

The use of accelerograms generated simulating source mechanism and wave propagation is allowed, provided the hypotheses about the seismogenic characteristics of the source and the properties along the pathway are duly justified and that, in the considered period intervals, the average spectral ordinate is not less than $20 \%$ of the corresponding component of the elastic spectrum.

Further details can be seen in Rugarli et al., 2019a.

PSHA, because it has too often delivered not only erroneous but also too deadly results (Wyss et al., 2012; Panza et al., 2014; and Bela, 2014), has remained a "conundrum," despite it having been extensively debated and also challenged over these last three decades. A comprehensive sample of contributions is contained in the PAGEOPH Topical Volume 168 (2011) and references therein. In the evidence against PSHA: too many damaging and deadly earthquakes (like the 1988 M 6.8 Spitak, Armenia earthquake; the 2011 M 9 Tohoku, Japan Megathrust and Tsunami; and the 2012 M 6 Emilia, Italy events) have all occurred in regions rated to be "low-risk" by PSHA Seismic Hazard Maps (e.g., Peresan and Panza, 2012; Danciu and Giardini, 2015).

In concluding this chapter, let us briefly consider how strong earthquakes (M 6.0 - 6.9) that have been induced or "triggered" by oil production have impacted our approaches to seismic hazard assessment. Hough and Page (2016) found that during the 1900-1935 oil boom in the Los Angeles Basin, four out of the five major earthquakes in the region may have been caused by oil and gas production including the M 6.4 1933 Long Beach 
earthquake (the largest), which killed 120 people, caused $\$ 50$ million damage, and was the impetus for California instituting public policies to address earthquake hazards.

However, as California already is an active tectonic region that is prone to $M \geq 6$ earthquakes regardless of any additional triggering, these sorts of induced earthquakes would not change the NDSHA estimates of hazard. That is because there is nothing to say that the oil production is not simply bringing forward in time the energy release from earthquakes that would have happened eventually anyway.

Summarizing, if the area of interest is, as in California: (i) active tectonically; (ii) known already to be seismically active; and has (iii) reliable catalogues - then there is no problem with NDSHA in reliably assessing its seismic hazard!

Finally, human induced earthquakes (Foulger et al., 2018) would, however, introduce an additional problem to the application of the PSHA method anywhere globally, as they would perturb the recurrence time interval of earthquakes (i.e., if the numbers of smaller $M$ earthquakes increase, the hazard model presumes likewise an increase in the numbers of larger $\mathrm{M}$ events, which presumably shortens the "return period"). And therefore, the answer to this further induced earthquake question is the same: the "return period" remains a Chimera!

\section{Macroseismic intensity, magnitude and peak ground acceleration}

A shaking of $30 \% \mathrm{~g}(0.3 \mathrm{~g})$ is about the level of shaking that would make it difficult for you to walk down the airplane aisle without holding onto a seat during turbulence, because $30 \%$ of your mass is pushing you sideways. In the M 7.8 Nepal earthquake in 2015, the shaking intensity (Peak Ground Acceleration: PGA $<0.2 \mathrm{~g}$ ) in Kathmandu was only moderate, but the strong motion recordings of $\sim 0.5 \mathrm{~g}$ spectral acceleration at $\sim 5$ s period (e.g. Pokharel and Goldsworthy 2015) seem to indicate that practically any modern high-rise building (say > 40 stories) would have been vulnerable to collapse in these long period motions.

Familiar scales of moderate to strong earthquake shaking intensity (e.g. European Macroseismic Intensity Scale EMS-98) that can be both perceptibly felt by humans and also cause from slight to completely devastating damage to buildings are, however, often not very informative for the earthquake response of long-period structures - such as taller buildings and long span bridges, particularly during large magnitude earthquakes.

Although a single parameter is insufficient to completely describe an event, the first number any structural engineer should want to know is Peak Ground Velocity - PGV (for at recorded levels $>50 \mathrm{~cm} / \mathrm{s}$, there is typically damage). The second number is Peak Ground Displacement PGD; for when greater than 1 $\mathrm{m}$, then tall buildings are also likely to be in trouble.

A detailed historical review of earliest seismological attempts to quantify sizes of earthquake sources through a measure of their energy radiated into seismic waves, which occurred also in connection with the parallel development of the concept of earthquake magnitude, is supplied by Gutenberg and Richter (1949); Panza and Romanelli (2001) and Okal (2019).

Large earthquakes are produced by large slips on large faults, and they therefore differ from small earthquakes in that they produce large velocities and large displacements at large distances from the earthquake source which can result in significant to sometimes catastrophic effects and damages. Obviously then, it necessarily falls to macroseismic intensity data (perceptible earthquake shaking that can be felt without the use of instruments) to supply the longest time period record of 
damaging earthquake effects, since the first earthquake magnitude scale from instrumentally recorded ground displacements was not developed until 1935 by Charles F. Richter - in close cooperation with Beno Gutenberg (Richter 1935). This means that for some seismic regions like Italy fortunately there is a $1000+$ years' long and exceptionally reliable earthquake catalogue available, while in most other parts of the globe (where the data is mostly reflecting magnitudes estimated from seismograms), the catalogue record is only close to $\sim 100$ years.

Macroseismic intensity is considered a "classification of the severity of ground shaking on the basis of its observed effects" (EMS-98, Grünthal 1998, Grünthal and Musson 2020). EMS-98 (European Macroseismic Scale) (gfz-potsdam.de).

From this definition of the Intensity Scale, it is evident that, for a given earthquake magnitude $\mathrm{M}$, the intensity I can be different in different places.

\subsection{General Considerations}

The most important general consideration in applying such a scale is that it brings together both: (a) long-period; and (b) shortperiod effects. The latter are in the majority and may be roughly correlated with acceleration, or PGA - whereas the longperiod effects represent large displacements, which often occur accompanied by comparatively only moderate levels of ground shaking acceleration. (see e.g. Gupta 1980) Importantly, with increasing magnitude $\mathrm{M}$, the proportions of long-period to short-period phenomena tend to increase at all distances from the epicenter; and since the macroseismic scale historically has in general placed the long-period effects where they appear most frequently during earthquakes of moderate magnitude, serious confusion has sometimes arisen when dealing with the greater territorial ranges observed with large shocks. (See "The long and the short of it" below).

In the now more than one century since the first macroseismic intensity scale was put forward by Mercalli in 1902 (at first with ten grades of intensity, later with twelve following a suggestion by Cancani 1904, who attempted to express these grades in terms of acceleration), many different scales have come into widespread existence. The shear existence of many different scales is a demonstration of the complexity of the problem in describing earthquake effects. This resulting multiplicity of scales generates some problems in practical applications, which therefore must rely upon very conservative assumptions.

Any macroseismic intensity scale (e.g., Mercalli, Cancani, Sieberg - $\mathrm{I}_{\mathrm{MCS}}$; Modified Mercalli - I $\mathrm{MM}_{\mathrm{M}}$; Medvedev, Sponheuer, Karnik - $\mathrm{I}_{\mathrm{MSK}}$; European - $\mathrm{I}_{\mathrm{EMS}}$ ) is individually distinct and discrete, having unit incremental steps. This means accordingly: (a) intermediate values, even though arbitrarily often used, are not defined; and (b) the long-period and shortperiod effects are comingled, as previously discussed.

\subsection{Defining patternicity}

Analyzing two independent data sets of Maximum Macroseismic Intensity values for Italy, namely (1) Mappa della Massima Intensità Macrosismica Risentita in Italia (Scalera et al., 1995) and (2) Massime intensità macrosismiche osservate nei comuni italiani (Molin et al., 1996) - Panza et al., 1997 proposed correlations between macroseismic Intensity patterns (I) and seismic Ground Motion Parameters (GMPs) that differ by one degree $\mathrm{I}_{\mathrm{MCS}}$. Based on these past efforts and analyses (which required not only a holistic approach, but also judgment based on comprehensive and detailed knowledge of earthquake phenomena and their effects) we feel that a further comment on the use of intermediate values ("half- 
degrees" per Kárník and Algermissen, 1978 or "Intensity factors" per Klügel, 2015) in any macroseismic intensity scale is important and warranted, because these intermediate values have caused several drawbacks when subsequently used to obtain: (a) quantified estimates of hazard; and then (b) derived seismic design parameters (GMPs) which can be characterized as follows:

"The problem is not precise language. The problem is clear language"

- Richard Feynman

(i) Ambiguity - we wonder whether the derivative intensity estimation realistically actually captures, reflects and envelopes the MCE, which is a requirement for a Reliable Seismic Hazard Assessment RSHA, in order to protect civil populations and their cultural heritage buildings. The ambiguity here is coming because the "half degree" or "Intensity factor" is simply not telling the whole truth since "the magnitude assigned is characteristic of the shock as a whole, and it thus differs from the intensity, which varies from point-to-point of the affected area (Richter 1935)". See also Hays (1980), Somerville (2000) and Gomez-Capera et al. (2020).

(ii) PGA - Intensity Relations and Ground Motion Intensity Conversion Equations GMICEs (used to compute instrumental intensities on ShakeMaps) are used in many applications to translate pre-instrumental earthquake observations (macroseismic intensities) to instrumental recordings of earthquake ground motions, primarily PGA and PG... and vice-versa;

(iii) Magnitude and Intensity - (Io at the epicenter, Imax, and I) can be expressed as an equation transfer function from empirical observations. In some engineering-practice applications, the correlation between Intensity factors (expressed decimally as .1 - .2 - .3, etc.) and PGA - as an anchor starting point in setting Earthquake Resistant Design EQ-RD Criteria, and one log-linear relation for converting Intensity (here EMS-98) to PGA (in gals) is via the equation $\log 10$ (PGA) $\approx 1.6682 \times \mathrm{I}+1.2821$. Here, of course: (a) the intensity grades must be treated as true numerical quantities, which they are not! And (b) peak values of both ground motion parameters GMPs and intensity I are often poorly correlated in the correlation hypothesis $\log (y) \approx b_{0}+b_{1} I$ - and their scatter is considerable! (e.g., Ambraseys, 1974 and Decanini et al., 1995).

(iv) Intensity Factor Wild Card - an "intermediate values" intensity card can easily be played (without challenge) in the deckshuffling that is currently practiced with the touted money-saving applications available in Performance-Based Earthquake Engineering PBEE, which (also not telling the whole truth) ignores at its convenience the fact that earthquake phenomena (not numbers of earthquakes) are a "power law" Pareto distribution, or a distribution with "fat tails" i.e. outside the normal bell-shaped or Gaussian distribution for PGV and PGD. Earthquakes are the Wild Card, and they should be dealt with! See e.g. "Will Performance-based Earthquake Engineering Break the Power Law?" (Heaton, 2007);

(iv) Confirmational Bias - persuading us to believe our guess with perhaps a great deal more conviction than it rightly deserves, simply because we are biased by our presumed precision of having employed "half degree" or "Intensity factors" at decadal incremenal scale; without now an equally close-enough attention paid to the more fundamental and important aspects of selecting earthquake-resistant design criteria (Miranda and Bertero, 1994, Miranda, 1997; Bertero, 1996), whose primary functions are, as Bertero (1996) emphasizes: "to restate a complex problem that has unknowns and uncertainties in an unambiguous, simplified form having no ambiguities." (Housner and Jennings, 1977; 1982). 


\subsection{Magnitude Power Broadcast}

Richter compared Magnitude "to the power output in kilowatts of a radio broadcasting station" and likened the Intensity at a site location then "to the signal strength noted on a receiver at a given locality. Intensity, like signal strength, will generally fall off with distance from the source; it will also depend on local conditions at the point of observation, and to some extent on the conditions along the path from source to that point."

Magnitude $\mathrm{M}$ and Macroseismic Intensity Io at the epicenter can be accurately equated mathematically: $\operatorname{Io}(\mathrm{m})=1.5(\mathrm{M}-1)$ and inversely $\mathrm{M}=2 / 3$ Io +1 . And there are also empirical relations for linking Io and PGA, e.g., Io $=2.97 \log 10(P G A)+6.71$. So, when one performs the math in these conversions (or consults early comparative MMI - to PGA tables as in Hays, 1980), one in fact does get an Intensity Value (integer) followed then by a decimal. When still further one does a literature search through time, one also finds: (a) a wide range of scales and indices describing natural hazards and their impacts (Blong 2003); (b) studies on "PGA-intensity relations with applications to damage estimation" (McCann et al., 1980; Li et al., 2020); and (c) an "instrumental intensity scale" format that is now reported on near-real time ShakeMaps (Wald et al., 1999a, b; Wald et al., 2019); and even now Ground Motion to Intensity Conversion Equations GMICEs. (Caprio et al., 2015, Cilia and Baker, 2015, 2018; Cilia et al., 2017).

In then summing up, we want to begin by first returning to the definition of any intensity scale: "A sequence of Natural Ordinal Numbers, i.e., a scale in which each number tells the position of something in a discrete scale of integers, such as I, II, III, IV, V, etc." And within our combined experience, we cannot locate any problem for which "the artefact of introducing half-values of intensity" is both a solution and a benefit!
Simply put this illusion of precision does little to improve accuracy in the final product resulting from using this pre-instrumental system for recording the sizes of damaging earthquakes as witnessed by their effects!

Accuracy, we believe, has more to do with both a knowledge-based consideration and also a comprehensive integration of all the other judgements that have to be made, because "science is a way of thinking much more than it is a body of knowledge." (Carl Sagan). For RSHA, "we aim above the mark to hit the mark." (Emerson).

The critical issue then, for earth science and natural hazards awareness and planning, is more elegantly revealed in this well explained observation from Richard Feynman:

The real problem in speech is not precise language. The problem is clear language. The desire is to have the idea clearly communicated to the other person. It is only necessary to be precise when there is some doubt as to the meaning of a phrase, and then the precision should be put in the place where the doubt exists. It is really quite impossible to say anything with absolute precision, unless that thing is so abstracted from the real world as to not represent any real thing.

One of the co-authors, James Bela, explored the ranges of greatest applicability for some of the familiarly available empirical conversion equations relating Magnitude $\mathrm{M}$, Intensities I, Io, Imax and PGA - specifically by examining four damaging earthquakes between M 5.6 - M 7 (and within earthquake magnitude step intervals at $1 / 4 \mathrm{M}$ between M 5.6 - M 9.5). Conversely, and corollary to Richard Feynman's comment above, it was found that "the doubt is put where the precision exists"!

"As far as the laws of mathematics refer to reality, they are not certain; and as far as they are certain, they do not refer to reality"

- Albert Einstein, "Geometry and Experience" January 27, 1921 
The "Table for Thought" that tabulated these results revealed that: (a) the range of greatest applicability for these empirically generated numbers is M 5.5 - M 7.0, noting in particular that above M 8 they are not reliable; (b) PGA is probably useful (perhaps even robust) up to $\mathrm{M} 7$, but only to one decimal point; (c) ASCE 7-10 computed results for "expected maximum intensities" $\left(\mathrm{PGA}_{\mathrm{M}}\right)$ were problematic and unreliable as a basis of determining reliable EQ-RD criteria (Housner and Jennings, 1977, Bertero, 1996); and (d) "If you do not expect the unexpected, you will not find it, for it can't be found by [very precise calculations of what you expect!]".

So, again we can say with additional confidence that we feel that the undissected and unperturbed Macroseismic Intensity Scale has been really useful... and a step in the right direction... for now $1000+$ years!

As noted previously above, with increasing magnitude $\mathrm{M}$, the proportion of long-period to short-period energy tends to increase at all distances from the epicenter (a point for small slips) or fault rupture (for large slips). However, since the Macroseismic Intensity Scale in general places these long-period effects where they geographically appear during earthquakes of moderate magnitude, serious confusion has sometimes arisen when dealing with large magnitude and distant shocks. For example, large landslides (particularly those of the earth-slump type) are one typically long-period phenomenon that is triggered more readily by large displacement and slow velocity motion than by rapid high frequency shaking closer to the source. This long-period triggering phenomenon then favors assigning larger slides to Macroseismic Intensity $\mathrm{X}$ in $\mathrm{I}_{\mathrm{MM}}$, while smaller slides (many of them of the earth-avalanche type) are more commonly, as indicated, assigned at Macroseismic Intensity VII. However, great earthquakes $(M \geq 8)$ sometimes precipitate large slumps in distant regions where the felt intensities may otherwise only be indicated perhaps as low as VI $\left(\mathrm{I}_{\mathrm{MM}}\right)$. The formation (triggering) of cracks and fissures, especially those due to earth lurches, behaves similarly; and therefore, the Macroseismic Intensity level based on such evidence has to be seismologically reviewed and then carefully assigned with some reference and consideration given to both magnitude and distance.

This same judgement applies to site effects on works of construction where a long-period coupling or resonance with seismic waves occurs - as in the swaying and distortion of tall buildings or towers, and also in the overturning of elevated tanks.

A special grouping of long-period effects is presented under Intensity Level I $\left(\mathrm{I}_{\mathrm{MM}}\right)$ : (i) dizziness or nausea; (ii) birds or animals uneasy or disturbed; (iii) swaying of trees, structures, liquids, bodies of water; and (iv) doors swing slowly - the swinging of chandeliers may also be added. This sensory confusion comes about from the fact that all of these phenomena may be observed even when no actual felt shaking is perceptible: (i) many are pendulum effects - chandeliers and large branches of trees acting as longperiod seismoscopes; (ii) oscillations of bodies of water are termed seiches; and (iii) the increased number of such observations with higher magnitude earthquakes is reflecting the greater proportion of longperiod motion as magnitude increases.

Reliable information about long period ground motion is automatically recognized as particularly relevant for the correct planning of seismic isolation systems (e.g., Martelli et al., 2014), but it is also an equally important (but often overlooked) consideration for tall buildings located at some far distance from large magnitude earthquake sources, as we illustrate in the two following examples.

As shown in Fig. 3 from Bertero et al. (2018), tall buildings in Buenos Aires (1280 km away from the epicenter), although a great distance away from the $2015 \mathrm{Mw} 8.3$ 
Illapel, Chile earthquake, experienced horizontal acceleration time-series of motion that were significantly higher than the "motion perception threshold" limit for wind-induced vibrations as specified in ISO 10137 (2007) for human comfort, productivity and well-being because motions at frequencies less than $1 \mathrm{~Hz}$ can provoke fear, discomfort and symptoms of motion sickness in buildings occupants.
"International Standard 10137 specifies peak acceleration magnitudes over the frequency range $(0.06 \mathrm{~Hz}-0.5 \mathrm{~Hz})$ expected to be satisfactory for people living and working in tall buildings during wind storms with a 'return period' of one year." Additionally, the recorded motions also indicated that some level of nonstructural damage (such as light cracking) was also a possibility.

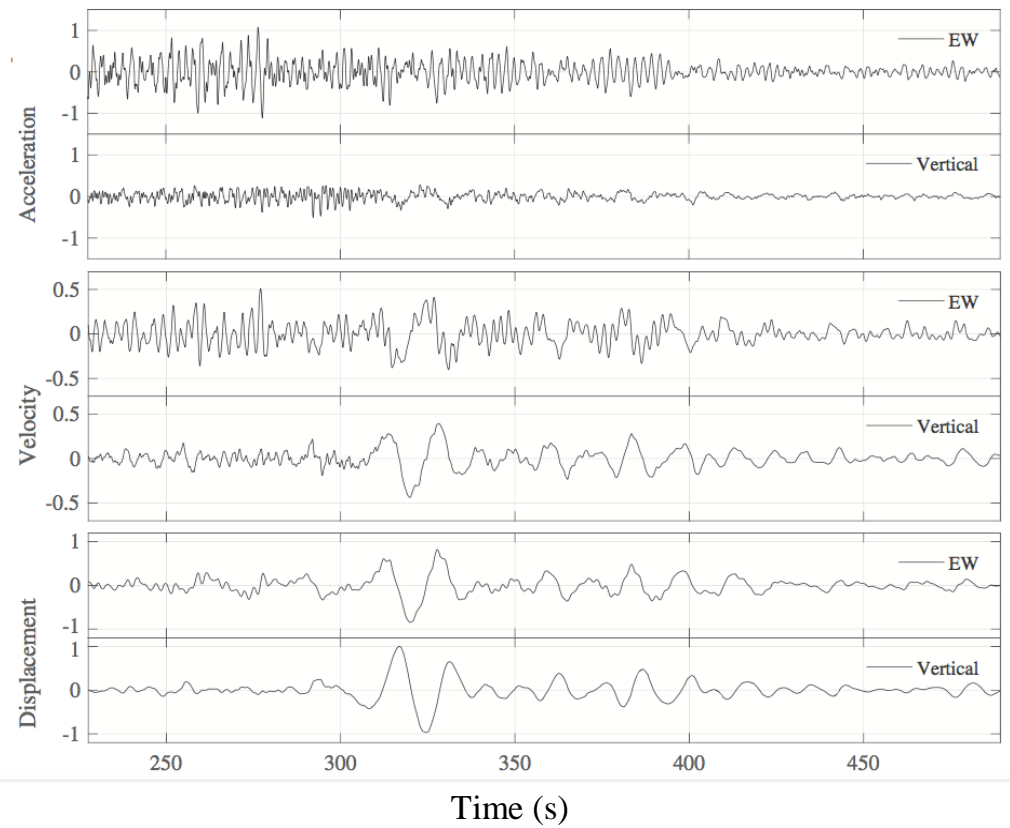

Figure 3. Vertical and East-West (EW) Motions (North-South component is not available) in Buenos Aires $\left(1280 \mathrm{~km}\right.$ away from the epicenter) of acceleration $\left(\mathrm{cm} / \mathrm{s}^{2}\right)$, velocity $(\mathrm{cm} / \mathrm{s})$, and displacement $(\mathrm{cm})$ time series for the strong shaking portion of the $\mathrm{Mw}=8.32015$ Illapel, Chile earthquake: Sept 16, 2.015, at 22:54:32 UTC, originating $48 \mathrm{~km}$ offshore from Illapel, Chile (modified from Bertero et al., 2018)

Although these low frequency motions induced by high winds will generally meet building strength and safety requirements, concerns have always been that they may nevertheless cause a wide range of adverse effects on building occupants, including: alarm or fear, discomfort, difficulty concentrating and symptoms of motion sickness (See e.g., "Human Exposure to Wind-Induced Motion in Tall Buildings: An Assessment of Guidance in ISO 68987 and ISO 10137”, Howarth, 2015).
Per these "motion perception threshold" limits for buildings, which are based on activities of occupants and frequencies of events, we amusedly find some irony in the fact that, since PSHA is founded on the presumption that earthquakes ("like wind") should be designed based on "return period," nevertheless engineering wind design is all-over-the-wind-map regarding concerns reflected in (we guess) obligatory wind "return periods": (i) peak acceleration magnitude limits over a low frequency range expected to be satisfactory for people living 
and working in tall buildings during wind storms with a "return period" of only one year; (ii) worst $10 \mathrm{~min}$ of infrequent events having a "return period" of at least 5 years; as well as (iii) zone maps for "high wind regions" and "hurricane prone regions" as well. Similar to the earthquake problem, Nature may not always offer up "Gaussian" wind distributions nor acceleration "crest factors" as assumed. In short, "return period" is likewise a Chimera in the wind universe ... to which PSHA astrologers first looked (Cornell 1968) to foretell (they say) the most universally appropriate way to handle "the uncertainty in the number, sizes, and locations of future earthquakes"!

Finally, it is important to point out that both wind-resistant and seismicresistant design considerations (although fundamentally different) identically share the same vulnerability to fatigue strength degradation of welded joints in steel frame buildings: due to low cycle fatigue phenomena (Kim and Hwang, 2019) The caveat: the tall building performance in the extreme wind event, or alternatively in the MCE earthquake (Parvez et al., 2011)... may not be per the design intent - but rather actual performance will reflect the integrated sum of all (both wind and seismic) low cycle events affecting degradation of the fatigue strength of welded joints - meaning that the building is now more realistically "what it is cracked-upto-be"!

Bertero's results show that design practices for tall buildings that are located at far distances from high-seismicity areas with large faults need to be revised - in order to consider both comfort criteria and nonstructural damage control - because of the energy input from an extraordinarily large number of cycles of vibration at very low frequencies (over the frequency range $0.06 \mathrm{~Hz}$ - $0.5 \mathrm{~Hz}$ ) and occurring over an exposure duration of well more than 5 minutes!
Just such kind of a warning is confirmed by Rong-Gong Lin II's August 15, 2019 report in Los Angeles Times: "Earthquake shook L.A. skyscrapers so hard some got vertigo." https://www.latimes.com/california/story/201908-14/ridgecrest-earthquake-produced-minutesof-shaking-new-story.

In the newspaper report: acceleration time series recordings (supplied by Monica Kholer, Caltech) were published for both the 2 nd floor $(\sim 0.02 \mathrm{~g})$ and the 50th floor $(\sim 0.04 \mathrm{~g})$ of a high-rise building in Los Angeles that felt the Mw 7.1 Ridgecrest earthquake of July 5, 2019 (Celebi et al., 2020). In this record the long period (low frequency) energy dominates the waveform on the 50th floor, leading to longduration displacements persisting for 2-3 minutes following the earthquake (M. Kholer, personal communication).

Therefore, it is abundantly clear that both site-specific design spectra and also scenario earthquakes are required for purposes of addressing both occupant comfort and damage control from large magnitude and distant earthquake sources, whose long period energy may couple with and excite tall buildings, causing them to sway for many minutes:

On the 48th floor of another building in downtown Los Angeles, Beth M. Foley said she felt vertigo, and her husband motion sickness, after what seemed like minutes of swaying. Eventually, the building creaked and came to a stop. The couple said they plan to pack anti-nausea medications in their earthquake kit. 'These things swayed like loblolly pines in a storm,' Foley said.

Furthermore, this tall building energy coupling to long period seismic waveforms from distant earthquake sources can neither be accounted for nor addressed using familiar site effects parameters such as Vs30 (Peng et al., 2020).

As further noted in Bertero et al. (2018), regarding these distantly generated long period effects in Buenos Aires - where firm 
soil is found in the upper layers: site "amplification" resulting from polarization of seismic wave motion in the horizontal plane is produced because of the large depth of soil deposits.

These local observations of site amplification in Buenos Aires, which highlight the inadequacy of relying solely upon Vs30 for defining response spectra for large magnitude and long-distance earthquakes, can be extended more generally to all earthquake phenomena. And in all such cases our recent experiences are showing that: (a) the tensor and nonlinear nature of earthquake ground motion is much more frequent than commonly believed; and (b) therefore it cannot be neglected!

For familiar cases: where both site amplification and basin response effects are persistent (e.g., Molchan et al., 2011; Panza et al., 2014; The SCEC Phase III Report, 2000. http://scecinfo.usc.edu/phase3/) often the best preferred parameter to define the design spectra can be the soil site period. However, as a rule, comprehensive and detailed performance evaluation must make use of the actual (and non-modified) recorded ground motions from far-distant earthquakes; and/or realistic synthetic scenario simulations, as is naturally done by NDSHA.

\section{Methodology}

The procedure for the Neo-Deterministic Seismic Hazard Assessment NDSHA (Panza et al., 1996; 2001; 2012; Panza, 2017; Panza and Bela, 2019) is based on the computation of realistic and physics-based synthetic seismograms (earthquake scenarios) - and the end products of NDSHA are therefore synthetic ground motion accelero-grams, veloci-grams and displacement-grams. In NDSHA, seismic hazard is defined as "the envelope of the values of earthquake ground motion parameters": (a) considering a wide set of scenario events (including Maximum Credible Earthquakes MCE); and (b) calculated by means of physically-rooted models formulated using the available physics-based knowledge on earthquake source and wave propagation processes. NDSHA therefore does not rely on empirical attenuation models (GMPEs), as these are: (i) often weakly constrained by the available pertinent observations and (ii) unable to account for the tensor nature of earthquake ground motions, which are formally described as the "tensor product" of the earthquake source tensor with the Green's functions of the transmitting medium (Aki and Richards, 2002).

NDSHA (Fig. 4) employs numerical modeling codes that are based upon: (1) the physical description of the earthquake rupture process; and then upon (2) the seismic wave propagation pathways to then reliably predict resulting ground motion parameters resulting from the many considered potential seismic sources. (See e.g., Panza et al., 2001; 2012; Magrin et al., 2016; Panza et al., 2013 and the references therein).

Regional geologic and seismic wave velocity structural models of the lithosphereasthenosphere system (thickness, S- and Pwave velocities of the crust and uppermost mantle layers) can be defined in several ways, starting from available information in the literature. Particularly suitable are: the cellular models introduced by Panza and Pontevivo (2004), Pontevivo and Panza (2006), and as later optimized by Boyadzhiev et al., 2008. These models are already used in many NDSHA applications worldwide: Bangladesh; China; Cuba; Egypt; India; Indonesia; Italy; Iran; Macedonia; Vietnam. (Al-Hussaini et al., 2017; Zhang et al., 2012; 2013a; 2013b; 2014a; 2014b; Gonzales et al., 2007; 2012a; 2012b; 2018; El-Sayed et al., 2001; Hassan et al., 2017; Irwandi 2017; 2020; Parvez et al., 2003; 2017; Motaghi et al., 2015; Rastgoo et al., 2018; Brandmayr et al., 2010; Milkova et al., 2018; Cao et al., 2008b; Bisignano et al., 2011). 
Vietnam Journal of Earth Sciences, 43(2), 111-188

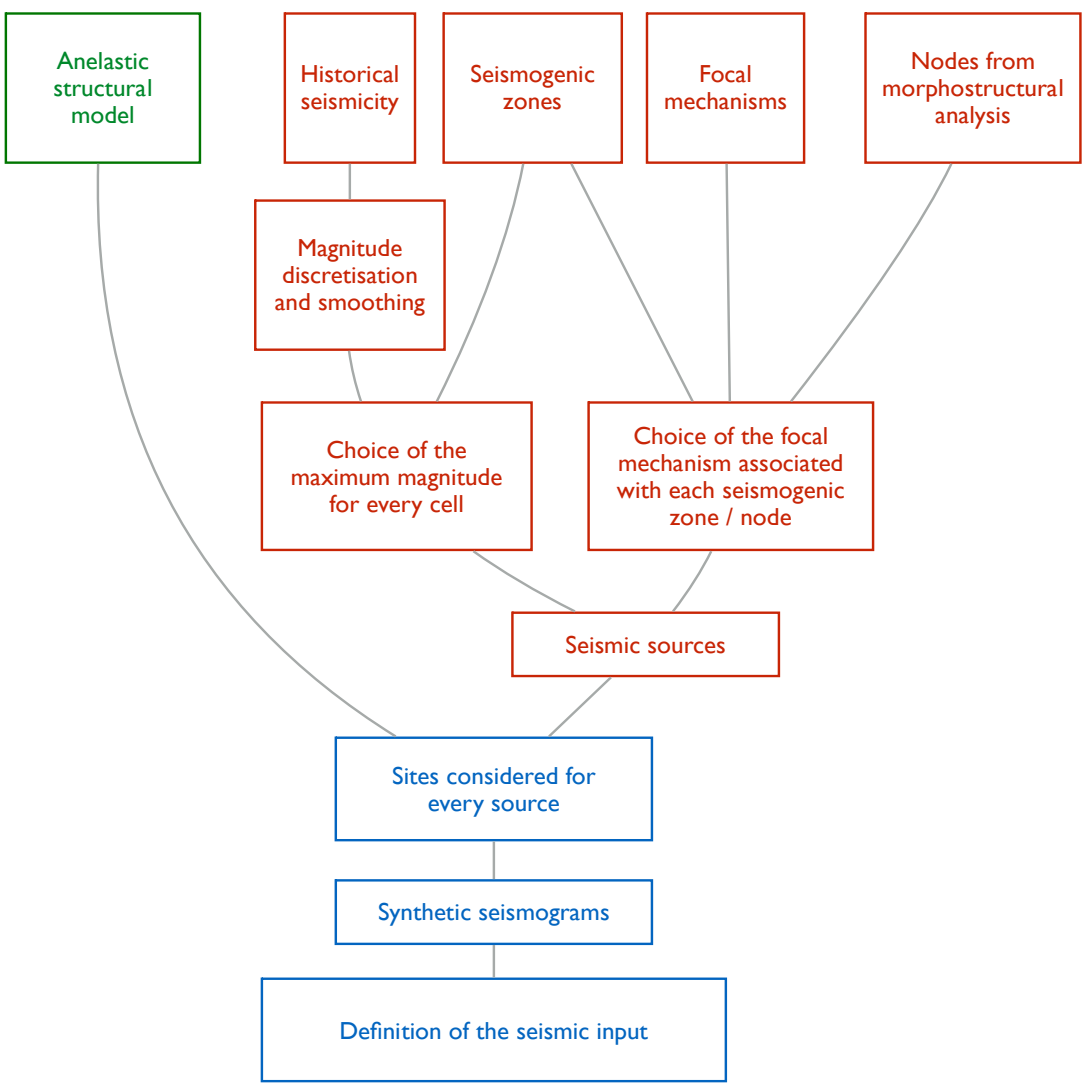

Figure 4. Flow Chart of NDSHA at Regional Scale: details for computations at local scale of the Maximum Credible Seismic Input - NDSHA-MCSI - are given in Rugarli et al. (2019a) and references therein

The definition of seismic sources is based not only on available reliable parametric earthquake catalogues, including source focal mechanisms, but also, and equally important, on: (a) the identification of seismogenic zones per Meletti et al. (2000); and (b) the identification of seismogenic nodes. Since by definition seismogenic nodes, which can be identified by pattern recognition via morphostructural zonation (MZ), per Gorshkov et al. (2003) - accommodate earthquakes with a magnitude above a fixed threshold M (Gorshkov et al., 2002; 2004; Peresan et al., 2015; Gvishiani et al., 2020) therefore their use is recommended in the NDSHA procedure whenever either historical parametric catalogues are unavailable or, although available, they cannot be considered sufficiently complete. A comprehensive validation of seismogenic nodes as a viable alternative to both seismogenic zones and observed seismicity, for the definition of seismic hazard at regional scale, is given by Rugarli et al. (2019b).

Since 1972 the methodology of the pattern recognition of Earthquake-Prone Areas (EPA) has been systematically applied (for different values of $\mathbf{M}$ ) in many seismic regions throughout the world: the Tien Shan and Pamir (Gelfand et al., 1972); Balkans, Asia Minor, Transcaucasia (Gelfand et al., 1974a,b); California and Nevada (Gelfand et al., 1976); Italy (Caputo et al., 1980; Gorshkov et al., 2002); Andean South America (Gvishiani and Soloviev, 1984); Kamchatka (Gvishiani et al., 1984); Western 
Alps (Cisternas et al., 1985); Pyrenees (Gvishiani et al., 1987); Greater Caucasus (Gvishiani et al., 1988); Lesser Caucasus (Gorshkov et al., 1991); Himalaya (Bhatia et al., 1992); Carpathians (Gorshkov et al., 2000); Alps and Dinarides (Gorshkov et al., 2004); Alborz (Gorshkov et al., 2010); Ecuador (Chunga et al., 2010); Iberian Plate (Gorshkov et al., 2010); North Vietnam (Tuyen et al., 2012); Kopet Dagh (Novikova and Gorshkov, 2013); Caucasus Region (Soloviev et al., 2013); and Northeast Egypt (Gorshkov et al., 2018). Various validations of seismogenic nodes as identified by pattern recognition in morphostructural zonation (MZ) are given by: Gorshkov et al. (2005); Gorshkov and Novikova (2018); and Gvishiani et al. (2020); and other applications of pattern recognition techniques, intended for use in seismic hazard analysis, were similarly evaluated and reviewed by Mridula et al. (2013).

\subsection{Scenario Earthquakes}

NDSHA generated earthquake scenarios are determined consistent with: (i) the available knowledge about the earth's structure (through which seismic waves propagate); (ii) the earthquake sources, and (iii) all previously known seismicity within the study area. Therefore, it is then possible to compute realistic synthetic seismograms that are suitable for engineering applications.

It is thus possible to quantify peak values of Acceleration (PGA), Velocity (PGV) and Displacement (PGD) or any other ground motion parameter relevant to seismic engineering. The Design Ground Acceleration (DGA) can be computed consistently with the shape of any preferred Design Spectrum (Panza et al., 1996), as shown in Fig. 5. DGA is the "Spectral Acceleration" SA(g) anchoring the Elastic Acceleration Response Spectrum (RS) at a period of $\mathrm{T}=0 \mathrm{~s}$. This quantity is comparable to PGA, since an infinitely rigid structure (i.e., a structure having a natural period of $0 \mathrm{~s}$ ) moves exactly like the ground: the Maximum Acceleration of the Structure (MSA) is the same as that of the ground, which is the PGA. Moreover, DGA is practically equivalent to Effective Peak Acceleration (EPA), which is defined as the "average of the maximum ordinates of elastic acceleration response spectra within the period range from $0.1 \mathrm{~s}$ to $0.5 \mathrm{~s}$, divided by a standard factor of 2.5, for 5\% damping (Panza et al., 2004)".

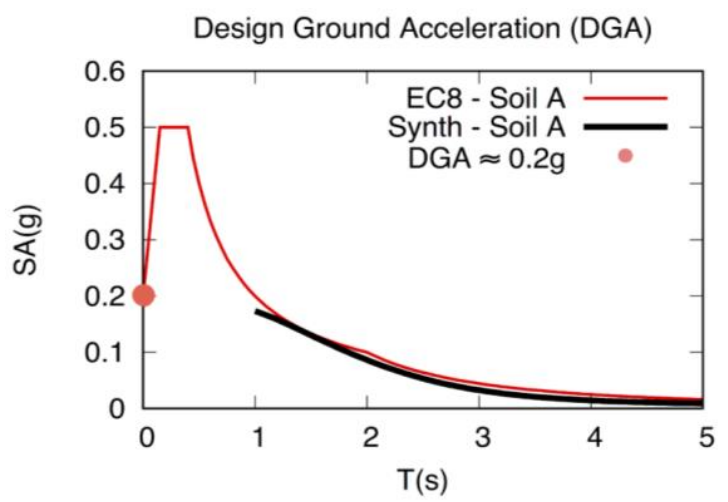

Figure 5. Elastic Acceleration Response Spectrum. To obtain an estimate of $P G A \approx D G A \approx E P A$ (Panza et al., 2004), overcoming the $\mathrm{T}=1 \mathrm{~s}$ or $1 \mathrm{~Hz}$ cutoff (consistent with the available detail in the input data used for the modeling at national scale) the "shape" of any code design spectrum can be used. The thin (red) line represents the shape of the chosen Standard Seismic Code Normalized RS (EC8 - Soil A), scaled here with the long period ( $\mathrm{T}>1 \mathrm{~s}) \mathrm{RS}$, thick (black) line: determined with NDSHA computed time histories (Synth) at the site of interest (Panza et al., 1996). These approximations $\mathrm{PGA} \approx \mathrm{DGA} \approx \mathrm{EPA}$ hold as follows: (a) DGA = PGA for elastic Design Spectra; (b) DGA $\approx$ EPA at bedrock - although, importantly, it is also controlled by the earthquake source time-history; EPA (although it is correlated with the real Peak Value) is then, as a rule, actually not "equal to," nor even "proportional to" it. (Panza et al., 2003) 
Importantly, and as a rule, the computations of time history accelerograms containing accelerations at short periods $(\mathrm{T}<1 \mathrm{~s})$ require a level of knowledge of earthquake source processes and wave medium pathway that so far is unattainable; but accelerogram computations that are reliable at long periods may be extended to $\mathrm{T}$ $<1 \mathrm{~s}$ by using elastic acceleration response spectra (Fig. 5). In absence of normalized spectra derived from specific regional recorded signals, the recommended procedure is to use "Code Spectral Shapes", e.g., Eurocode 8 (EC8 1993, 2008), which defines the normalized elastic acceleration response spectrum of the ground motion for $5 \%$ critical damping. Thus, it is possible now to obtain DGA by: (i) computing the RS for each synthetic accelerogram computed for periods of $1 \mathrm{~s}$ and longer; and (ii) by then extending this spectrum to shorter periods using any normalized elastic acceleration $\mathrm{RS}$ of the ground motion (e.g. corresponding to soil A, as in Fig. 5). DGA estimation has been validated in many instances: both regionally and at regional and local scale (See Fasan et al., 2016; Panza, 2017; Parvez et al., 2017; De Natale et al., 2019; Panza, 2020).

The normalized code elastic RS method, although physically rooted in structural dynamics, is by nature of its origin from many different earthquakes and the required smoothing of data, not precise. The smoothed shapes of standard Code Elastic RS (which prescribe strength base shear requirements for new structures) are obtained, as a rule, through a demanding statistical processing of signals - obtained however under quite different earthquake conditions, and they cannot therefore always be considered the "best tool" to assess structural behavior.

These limitations result from, among other things: (a) our inability to duly consider both the wavelength phases; and also (b) the durations of the recorded earthquake signals. However, it is still today the most frequently used method for application in seismic design codes, because of its relative ease in estimating the peak or maximum elastic response of a building, which forms the basis for calculating the "forces" that a structure must be designed to resist. For engineering purposes, the seismic hazard is still today defined by a code prescribed normalized elastic design response spectrum, which perhaps takes indirectly into account the variability of the possible signals. These response spectra, however, in most of the cases, do not have true direct links to the site under examination, but rather refer to average national shapes. Malhotra (2015) found that the latest empirical ground motion prediction equations (GMPEs) do not always preserve the shape of the normalized RS and he recommends: (i) that ground motion prediction models should only be developed for PGA, PGV and PGD; and (ii) that the response spectra for various damping ratios should be generated from PGA, PGV and PGD by using the normalized RS.

\subsection{NDSHA Grid Cells: A Honeycomb of Seismic Sources | Computed Seismograms}

In NDSHA, as a general rule: (a) a regular grid $\left(0.2^{\circ} \times 0.2^{\circ}\right)$ is placed over the study region; (b) the earthquake sources are centered in the grid cells that fall within the adopted seismogenic zones; (c) the receiver or computation sites (points where the seismograms are computed) are centers of a companion grid that is offset from the source grid by $0.1 \times 0.1$ degrees - the maximum distance receiver site from a double-couple point source centered in the grid is "usually $150 \mathrm{~km} "$ or about 7 grid square distances 
away; while the computation sites are placed at the nodes of a grid that is staggered by $0.1^{\circ}$ with respect to the sources' regular grid; (d) a smoothing procedure for the definition of earthquake location and magnitude $M$ is then applied to partly account for spatial uncertainty, catalogue incompleteness and for earthquake source extension; (e) after smoothing, only the cells (earthquake sources) located within the seismogenic zones and/or within each seismogenic node, as identified by pattern recognition techniques, are retained; (f) a double-couple point source is placed at the center of each cell, with a representative focal mechanism, which is consistent with the known present-day dominant tectonic regime of the corresponding seismogenic zone (cellular source) - (i) to define the magnitude of each source (cellular magnitude), the NDSHA procedure makes use of information about the space distribution of large-magnitude earthquakes $(M>5)$, which can be defined from historical, instrumental and geological observations; and (ii) the source depth is taken into consideration as a function of magnitude, in agreement with literature. (e.g., Caputo et al., 1973; Molchan et al., 1997; Doglioni et al., 2015).

In addition, NDSHA permits (if really necessary, as claimed by PSHA addicted practitioners fearful of "overdesign" because a damaging earthquake is unlikely) an accounting for earthquake occurrence rate (Peresan et al., 2013; Nekrasova et al., 2013; Magrin et al., 2017; and references therein): first, the characterization of the FrequencyMagnitude (FM) relation for earthquake activity in Italy is performed, according to the "multi-scale seismicity model" (Molchan et al., 1997), such that a robust estimated occurrence (not recurrence) rate is associated to each of the NDSHA modeled sources; and second, the occurrence rate assigned to the source is thus associated to its pertinent synthetic seismogram, coherently with the physical nature of the problem. Accordingly, then, two separate maps are obtained: (1) one for the "ground shaking" and (2) another for the corresponding perceived "average occurrence rate", as shown in Fig. 6. From the Figure it is evident that even the availability of the CPTI04 parametric earthquake catalogue (CPTI04 Working Group 2004), reliable for events with $M \geq 5.0$ since year 1000 , does not allow the computation (over the entire territory of Italy) of reliable "average occurrence rates" - "open circles" in (B); and there are many "?" symbols appearing for DGA in (C): i.e., sites where the occurrence estimate of maximum ground motion is unreliable due to the lack of sufficient data in Fig. 6.

Since, in policy decisions to protect civil populations, the authors believe that the engineering use of these "average occurrence rates" (per Cornell 1968) is not only questionable... but also both unsafe and unsound; they can neither recommend nor even suggest their use! Therefore, "in policy decisions to protect civil populations" (a) when considering two sites prone to earthquakes with the same Earthquake Hazard $\mathrm{M}$, given that all the remaining conditions are the same; (b) the parameters for seismic design must be equal at the two sites - since the magnitude we have to defend against is the same $\mathrm{M}$, independently from the sporadic nature (i.e., perceived likelihood) of the earthquake's occurrence (not recurrence). 

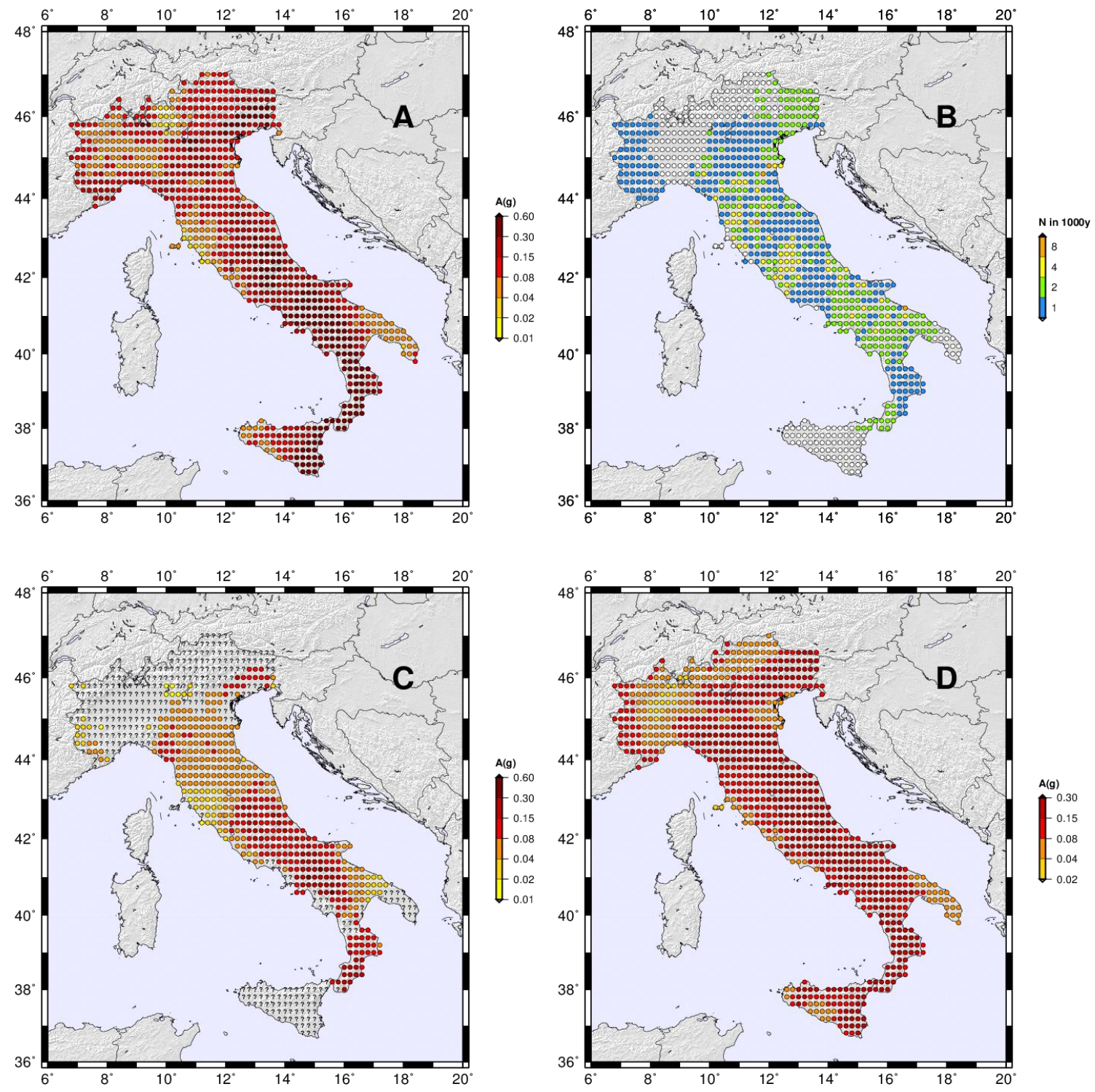

Figure 6. Maximum DGA (A) computed considering both seismogenic zones and seismogenic nodes; and, also, its Occurrence (B) expressed, to be conservative, as the upper bound of the "integer" number of times the ground motion is likely to be observed in 1000 years; Neo-Deterministic DGA (C); and Probabilistic PGA (D) for a time interval $\mathrm{T}=475 \mathrm{yr}$. Question Marks "?" represent sites where occurrence estimate of maximum ground motion is unreliable, due to the lack of sufficient data. (modified after Magrin et al., 2017)

\section{3. "Information is not knowledge}

- Albert Einstein

When available knowledge may sometimes permit reliable accelerogram computations comprising frequencies $>1 \mathrm{~Hz}$ (higher frequencies at periods less than the standard $\mathrm{T}=1 \mathrm{~s}$ cutoff in Fig. 5), such accelerograms can be considered. Remembering: (a) $\mathrm{T}=1 / \mathrm{f}$; and that (b) building period can be approximated at $0.1 \mathrm{~s}$ per story - the physics- 
based ground motion modeling is however, as a rule, limited within the frequency range from 1 to $10 \mathrm{~Hz}$, because any estimates of ground motions at higher frequencies (shorter periods) would require a comprehensive knowledge of: (i) source heterogeneity, (ii) physical properties of the rock/soil, and (iii) ground motion attenuation parameters all with a resolution realistically not attainable (Rugarli et al., 2019a and references therein).

This is well in agreement with Aki's (2003) conclusion: results about (i) the sourcecontrolled $\mathrm{f}_{\max }$; (ii) non-linear soil response; and (iii) the studies of seismic attenuation from borehole data - all indicate that there is no need to consider frequencies higher than about $10 \mathrm{~Hz}$ in strong motion seismology.

In fact, the quality of the results obtained by physics-based ground motion modeling depends on the quality of the input data. The NDSHA procedures allow for sensitivity analyses to evaluate evidence and also to address the uncertainties using different input data and varying levels of knowledge about seismic sources and attenuation velocity structural models. Proper presentation and evaluation of uncertainties, associated with the ground motion computation, will help the potential users determine how much confidence to place on the NDSHA computed seismic hazard map.

Further insight into the hierarchical interrelationships of NDSHA procedures considers the following: (a) the strength of the source is determined as the maximum between a lower bound and the magnitude defined by the smoothing procedure. The lower bound for magnitude inside the seismogenic zones is $\mathrm{M}=5$, that also is conventionally (D'Amico et al., 1999) taken as the lower bound magnitude of damaging earthquakes; (b) the lower bound of earthquake magnitude within the seismogenic nodes is the magnitude threshold identified for that node by the morphostructural analysis (Gelfand et al., 1972); (c) the orientation of the double-couple point source is the one representative of the parent seismogenic zone or seismogenic node; (d) hypocentral depth, in fairly good agreement with existing literature, is taken as a discrete function of magnitude $\mathrm{f}(\mathrm{M})=(10$ $\mathrm{km}$ for $\mathrm{M}<7)(15 \mathrm{~km}$ for $7 \leq \mathrm{M}$ $<8)$ and $(25 \mathrm{~km}$ for $\mathrm{M} \geq 8)$. A quite complete description of the NDSHA methodology, including the joint use of earthquake sources within seismogenic zones and seismogenic nodes, can be found in Panza et al. (2001), and its updates and validations in Panza et al. (2012), Fasan et al. (2016), Magrin et al. (2016), Parvez et al. (2017) and Hassan et al. (2017). Specific 3D NDSHA applications can be found in La Mura et al. (2011) and Panza et al. (2013).

\subsection{Validations by the facts}

NDSHA, unlike PSHA, is "falsifiable", and therefore it can be tested! Since PSHA is false, it is not falsifiable and it cannot be tested! A detailed review of the traditional PSHA method (see Supplementary material in Panza and Bela, 2019) revealed that the method itself is inadequate to describe the physical process of earthquake occurrence, because of its built-in and required assumption of a "memoryless" stochastic process, or Poisson process. (e.g., Ferraes, 1967, Panza et al., 2014).

It is obvious that strain and stress renewal needs time, and therefore the process of rebuilding the conditions for the next earthquake is "time-dependent". Furthermore, the locations of earthquakes (even at and along the same faults) are changing with time, as well as are fault strength mechanical properties, in particular after each event. Each magnitude range of earthquakes, as defined by USGS - (Moderate: M 5 - M 5.9); (Strong: M 6 - M 6.9); (Major: M 7 - M 7.9); and (Great: $M \geq 8$ ) - is modifying the boundary conditions for the next earthquake. http://www.geo.mtu.edu/UPSeis/magnitude.html. 
Recent evidences of an earthquake-induced transformation of the crust are described in some detail by Jamtveit et al. (2018) and Zhang et al. (2019). This means that a mathematical probabilistic model has to be at least bivariate, and probably also bimodal. This is outside of the scope of our human knowledge due to: (a) lack of data; and (b) also the shortness of human observation time in comparison with geological time scales. Furthermore, the theoretical discrete model by Carlson (1991) shows that the smaller events are consistent with the Gutenberg-Richter statistical law, whereas the larger and same-size characteristic events have a separate statistical distribution. Carlson's 1991 model has been extended to a continuum by Cattania (2019), who explored: (a) why small earthquake sources can produce quasiperiodic sequences of identical events; whereas (b) earthquakes on large faults are intrinsically more variable - and showed that simple, isolated faults do not necessarily produce regular and periodic earthquakes, especially when the faults are relatively large. Both models illustrate the absolute fallacy of the "return period" concept! (see also section 2. "Return period" or chimera?).

As does any physical earthquake model, NDSHA must deal with uncertainties intrinsic in the basic model input data, here chiefly coming from: (a) earthquake catalogues; and (b) lack of satisfactory theories about earthquake source (slip distribution at initiation of rupture, and slip distributions in cascading multi-fault ruptures). For this reason, the hazard values at both national and regional scale supplied by NDSHA are given as ranges over geographic areas - whose values are consistent with the information content of the basic data. (See section Macroseismic Intensity, Magnitude and Peak Acceleration).

Typical values are displayed on a geographic grid mesh of about $25-50 \mathrm{~km}$ spacing (e.g. see Fig. 6), and hazard values are color-coded in discrete ranges of geometrical progression close to $2 \mathrm{X}$ (Fig. 7). More specific hazard estimates can be obtained at local scale by means of ad hoc studies, e.g. Rugarli et al., 2019a.

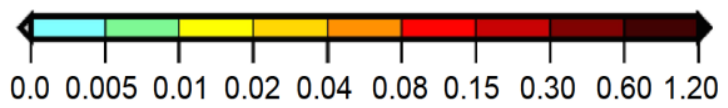
A (g)

Figure 7. Typical Discrete Ranges of Hazard Values (units of $\mathrm{g}$ ): shown in geometrical progression (close to $2 \mathrm{X}$ ), consistent with the real resolving power of the worldwide available data (e.g., Cancani 1904 and Lliboutry 2000)

In the original formulation of NDSHA (Panza et al., 2001; 2012), physics-based computer computation was: (i) combined with a comprehensive geologic and geophysical overview of the regional tectonic setting and earthquake history to; (ii) solve, in a first approximation, the fundamental problems posed by an adequate description of the physical process of earthquake occurrence (which in the real earth is a tensor phenomenon). It examined the "largest" potential seismic event - termed Maximum Credible Earthquake (MCE) - whose cellular magnitude $\mathbf{M}_{\text {design }}$ at a given site can be tentatively, until proven otherwise, set equal to the Maximum observed or estimated earthquake magnitude $\mathbf{M}_{\max }$, plus some multiple of its accepted global standard deviation $\sigma_{\mathrm{M}}$. In areas where information on faults and other input data are sparse, the historical data and morphostructural analysis are relied upon to estimate this Maximum Magnitude $\mathrm{M}_{\max }$.

For estimating $\mathbf{M}_{\text {design }}$ specifically, we presume statistically that no more than $1 / \mathrm{k}^{2}$ of a distribution's values can be more than $\mathrm{k}$ standard deviations away from the mean (or equivalently, at least $1-1 / \mathrm{k}^{2}$ of the distribution's values are within $\mathrm{k}$ standard deviations of the mean). If $\mathrm{k}=2$, then at least $75 \%$ of the values fall within $2 \sigma_{\mathrm{M}}$; and if 
$\mathrm{k}=3$, then at least $89 \%$ of the values fall within an interval of $3 \sigma_{\mathrm{M}}$ centered on the mean. This factor $\mathrm{k}$ can therefore be considered a "tunable safety factor", e.g. $\gamma_{\mathrm{EM}}$ (EM = Earthquake Magnitude), which may be applied systematically jointly with the other safety factors that are used in structural engineering. So $M_{\text {design }}=M_{\max }+\gamma_{\mathrm{EM}} \sigma_{M}$ where it is currently presumed $\sigma_{\mathrm{M}} \approx 0.2-0.3$ (Richter 1935; Gutenberg and Richter 1956; Båth 1973, p. 111; 1979, 1981), and it is proposed to use $\gamma_{\mathrm{EM}}=1.5-2.5$ (Rugarli et al., 2019a).

Since the design value $\mathbf{M}_{\text {design }}$ is determined by adding this further tunable increment to the maximum estimated value $\mathbf{M}_{\max }$, it must be considered an envelope evaluated at the best of our present-day knowledge. This choice is consistent with Chebyshev's theorem: "for a very wide class of probability distributions, no more than a certain fraction of values can be more than a certain distance away from the mean" (but here a Maximum estimated $\mathrm{M}$ value, $\mathrm{M}_{\max }$, is used by analogy).

As an instructive example illustrating NDSHA's global applications: (i) when considering the upper limit of $\gamma_{\mathrm{EM}} \sigma_{\mathrm{M}}$; and then (ii) applying this "tunable safety factor" to the Maximum observed $\mathrm{M}\left(\mathrm{M}_{\max }=7.5\right)$ in southern California within the time interval from 1932-2011 (Chiou and Miao, 2013); we can then determine here that $\mathrm{M}_{\text {design }}=\mathrm{M}_{\max }+$ $\gamma_{\mathrm{EM}} \sigma_{\mathrm{M}}=7.5+0.7=8.2$; this result is well in agreement with Kijko (2004), where $\mathrm{M}_{\max } \approx$ 8.3; and with Field et al. (1999), wherein $\mathbf{M}_{\max }$ $\approx 8.0$.

It is, however, also important to first: (1) remember that the purpose of estimation is to first and foremost inform judgement; and then secondly; (2) to therefore realize that good engineering and seismological judgement is required whenever $\mathrm{M}_{\text {design }}$ should exceed magnitude levels that can range from perhaps "too high" to even "physically unrealistic", as is discussed below.
For example, when examining $\mathbf{M}_{\text {design }}$ computed values for the following countries, the results are high: Chile (10.2); Alaska (9.9); Sumatra (9.8 - 10.0); Japan (9.8); Cuba (8.3) and Iran (8.0). While the results for both Cuba and Iran are compatibly close to $\mathbf{M}_{\max }$ events already experienced in those countries; the very high values for the major subduction zones in Chile, Alaska and Sumatra, while perhaps possible, are all greater than the largest Megathrust event ever so-far recorded (Mw 9.5 - Chile 1960)!

Therefore, the selection and application of the $\mathbf{M}_{\text {design }}$ definition to site-specific locations and ultimate selection of design values within each country then requires targeted ad hoc studies, keeping in mind that, for example: (a) the fault length for earthquakes with $\mathbf{M} \sim 9$ is of the order of $1000 \mathrm{~km}$ or more (Wells and Coppersmith, 1994); and (b) ground motion amplitudes saturate at $\mathrm{M} \sim 8$ - and do not necessarily increase linearly with Moment Magnitude $\mathrm{Mw}$ (which for these very large faults is more physically reflecting the amount of energy the rocks can store before they break, than it is what the individual record of any strong motion recording station might be).

"One must never say anything too specific about earthquakes"

- Perry Byerly

As long as these caveats are fully understood and then sufficiently factored into our judgments, nevertheless a physically sound way to estimate and assess the magnitude of the largest event physically possible, usually termed Maximum Credible Earthquake MCE, is to set its magnitude equal to $\mathbf{M}_{\text {design, }}$ i.e., the maximum observed or estimated magnitude $\mathrm{M}_{\max }$, plus some multiple of its accepted global standard deviation $\sigma_{\mathrm{M}}$, as given in parentheses $\left(\sigma_{\mathrm{M}} \approx 0.2-0.3\right)$ :

$\mathrm{MCE}=\mathrm{M}_{\text {design }}=\mathrm{M}_{\max }+\gamma_{\mathrm{EM}} \sigma_{\mathrm{M}} \approx \mathrm{M}_{\max }+0.5$

Since NDSHA's computations then supply a bounding or envelope value (in other words, 
a value that should not be geologically or seismologically exceeded in nature) - this value is immediately falsifiable: (1) if an earthquake occurs with a magnitude $\mathrm{M}_{\mathrm{eq}}$ larger than that indicated by NDSHA's $\mathrm{M}_{\text {design }}$ $\left(\mathrm{M}_{\mathrm{eq}}>\mathrm{M}_{\text {design }}\right)$, then $\Delta \mathrm{M}=\mathrm{M}_{\mathrm{eq}}-\mathrm{M}_{\max }>$ $\gamma_{\mathrm{EM}} \sigma_{\mathrm{M}}$, and $\gamma_{\mathrm{EM}}$ should then be increased. Given the way $\mathbf{M}_{\text {design }}$ is defined, however, this is expected to be a rare circumstance!

The tunable increment to $\mathrm{M}_{\max }, \gamma_{\mathrm{EM}}$, could similarly be increased, should recorded peak ground motion values (e.g., PGA, PGV, or PGD) on the bedrock (at the occurrence of an earthquake $\mathrm{M}_{\mathrm{eq}}$ after the compilation of NDSHA maps) exceed, within error limits, those values given in these same maps. By way of improving usefulness and applicability of future strong ground motion recordings, this would suggest targeting installation of additional strong motion network stations over stiff soils, so as to avoid the local amplifications due to site effects - since the majority of the strong ground motion stations of the Italian strong motion network are sited upon soft soils.

While the selection of the multiplier $\gamma_{\mathrm{EM}}$ to be applied to $\sigma_{\mathrm{M}}$ cannot be derived by equations (indeed, it would be misleading to try), today it is partly heuristic, or a "rule-ofthumb" practical method of approximation learned from experience. See also Tversky and Kahneman (1974). Nonetheless, should this heuristic be falsified by natural experiments, this multiplier can be gradually reset to the new minimum safe value. This is what has already been done with all the already safety factors used in engineering: (i) the 1.5 safety factor for material limit stresses was used well before the availability of reliable statistical measures; and (ii) the semi-probabilistic methods used in structural engineering are de facto tuned to confirm these already validated-by-experience values (Rugarli et al., 2019a).

In an important recent finding, Rugarli et al. (2019b) have shown, using the unique
1000 + years' catalogue available for Italy, that seismogenic nodes may represent a viable alternative to seismogenic zones and observed seismicity for the reliable definition of seismic hazard at regional scale. Their paper provides both a validation of the seismogenic nodes method, and it also further supplies a tentative tuning of the safety factor $\gamma_{\mathrm{EM}}$ at about $\approx 2$. Therefore, they recommend to start both the seismic hazard assessment and also the derivative earthquake resistant design planning process with the generalized use of:

$$
\mathrm{M}_{\text {design }}=\mathrm{M}_{\max }+\gamma_{\mathrm{EM}} \sigma_{\mathrm{M}}=\mathrm{M}_{\max }+2.0 \sigma_{\mathrm{M}}
$$

\section{A warning about site effects}

The experimental approach to the estimation of the site response ("large modifications of seismic waves produced by variations of material properties in superficial geological layers near the Earth's surface") is based on the instrumental measures of the amplitudes and frequencies of ground motions at different sites (Boore, 2004a; Panzera et al., 2017). This necessarily implies the recording, with a network of strong motion instruments, of multiple seismic sources - all impacting the site from various azimuthal directions, as well as under seismological influences of pathway (including buried and surface topography) and seismic wave velocity of the transmitting geologic medium.

If a network of $\mathrm{N}$ sites has recorded $\mathrm{J}$ events, the amplitude spectrum, $\mathrm{O}$, of the $\mathrm{j}$-th event recorded at the $\mathrm{n}$-th site is usually represented as (e.g. Field and Jacob, 1995) as $\mathrm{O}_{\mathrm{nj}}(\omega)=\mathrm{E}_{\mathrm{j}}(\omega) \cdot \mathrm{P}_{\mathrm{nj}}(\omega) \cdot \mathrm{S}_{\mathrm{n}}(\omega)$, where $\mathrm{E}$ is the source term, $P$ is the path term, and $S$ is the site-effect term. In the time domain: $\mathrm{O}_{\mathrm{nj}}(\mathrm{t})=$ $E_{j}(t) P_{n j}(t) S_{n}(t)$, where indicates the convolution operator, a mathematical way of blending two signals to form a third signal.

The most traditional techniques for site effect estimation of the $S_{n}$ term, known as convolutive methods, are based upon computation of the ratio between: (a) the spectrum of the signal (or a portion of it) at 
the (sedimentary) site of interest; and (b) the spectrum of a reference signal, preferably recorded at a nearby (bedrock) site. Similarly, Nakamura $(1989 ; 2008)$ and Nakamura and Gurler (2001) analyzed site effects by a method based on the computation of the spectral ratio between horizontal (usually the square root of the product between the spectra of the NS and EW components is used) and vertical components $(\mathrm{H} / \mathrm{V})$ obtained from seismic noise (microtremors).

Theoretical investigations (e.g., Lachet and Bard, 1994; Dravinski et al., 1996) as well as experimental studies (e.g., Field and Jacob, 1995; Field 1996) have further shown that, while Nakamura's method can reveal the fundamental resonant frequency of a site, it is usually not able to give the correct amplification level. Furthermore, Nakamura's 1989 original assumptions now seem questionable, since several later studies (e.g., Lachet and Bard, 1994; Konno and Ohmachi, 1998) have demonstrated that the horizontalto-vertical spectral ratio HVSR is more strictly correlated with the polarization of Rayleigh waves - these tending to be more concentrated in the horizontal plane whenever there is an increasing thickness of sediments with poor mechanical properties (Panza et al., 1972; Rugarli et al., 2019a). Of course, poor mechanical properties may be responsible for an increase of wave train duration, always within the principle of energy conservation. Recent studies have shown that the difference between the HVSR and the actual amplification during an earthquake can be extremely large (Perron et al., 2018).

A comprehensive comparison of: (i) the various empirical techniques for describing and characterizing site effects, found in Bard (1997); (ii) "Advances in seismic site response: Usual practices and innovative methods," in Panzera et al. (2017); and (iii) "Emergence of seismic metamaterials: Current state and future perspectives," in Brûlé et al. (2020) - all testify to their importance. Additionally, the paper by Dal Moro et al. (2019) is of particular interest to us, since it critically illustrates a series of "technical aspects" regarding the holistic acquisition and analysis of Rayleigh waves acquired by a single 3-component geophone.

\subsection{Can site response be predicted?}

Boore (2004b), in posing this question, points out that "because the soil amplifications can be as large as a factor of ten, they are important in engineering applications that require the quantitative specifications of ground motions... What is often missing in these studies, however," as he points out, "are discussions of the uncertainty of the predicted response." Observational studies of site response (site effects) have demonstrated that ground motions have both: (a) "large site-to-site variability for a single earthquake"; and (b) "large earthquake-location-dependent variability for a single site." - and that therefore (c) "this variability makes sitespecific, earthquake-specific predictions of site response quite uncertain, even if detailed geotechnical and geological information is available near the site". Alternatively, however, "predictions of site response for average classes of sites exposed to the motions from many earthquakes can be made with much greater certainty if sufficient empirical observations are available." (e.g., Clemente-Chavez, 2014 and Poggi et al., 2017).

\subsubsection{Warning I: Calculated ambiguities are not so easily understood}

Although the most frequently used techniques for the empirical estimation of site effects, based on $\mathrm{O}_{\mathrm{nj}}(\omega)=\mathrm{E}_{\mathrm{j}}(\omega) \cdot \mathrm{P}_{\mathrm{nj}}(\omega) \cdot \mathrm{S}_{\mathrm{n}}(\omega)$, supply reliable information about the site response to non-interfering seismic phases or to single modes of vibration; they are not adequate in most real cases when the seismic sequel of seismic phases or modes is formed 
by either: (a) several interfering waves; or (b) equivalently by several modes - generated, e.g. by a rupture on a finite dimension fault buried within a deep sedimentary basin.

Also, in a mathematically very simple situation, i.e., in the far field region (where one can consider a "point source" approximation for the initiation of seismic wave energy) - the 1-th component of seismic ground displacement is given by $\mathrm{u}_{\mathrm{l}}(\mathrm{t})=\Sigma_{\mathrm{ijj}} \mathrm{M}_{\mathrm{ij}}(\mathrm{t}) * \mathrm{G}_{\mathrm{lij}}(\mathrm{t})$, where: (i) $\mathrm{G}$ is the Green's function that represents the transmitting medium (pathway) response: and (ii) $\mathrm{M}_{\mathrm{ij}}$ are moment tensor functions representing the source properties (e.g. Šílený and Panza, 1991; Š́lený et al., 1992).

If $\mathrm{G}$ and $\mathrm{M}_{\mathrm{ij}}$ are considered to be independent in their descriptions of the source, the above equation is linear and represents a mechanism generally varying with time. However, if we constrain their independence and ask for a constant mechanism (even one that is unconstrained, i.e. the full moment tensor); i.e. if we impose the constraint $M_{\mathrm{ij}}(\mathrm{t})=\mathrm{M}_{\mathrm{ij}} \cdot \mathrm{m}(\mathrm{t})$, then the problem becomes non-linear because of the product $\mathrm{M}_{\mathrm{ij}} \cdot \mathrm{m}(\mathrm{t})$, where both $\mathrm{M}_{\mathrm{ij}}$ and $\mathrm{m}(\mathrm{t})$ are the model parameters controlling source properties.

Thus, the inverse problem (i.e., the separation of source and medium terms), is therefore non-linear in the time domain; even without the double-couple constraint usually assumed for seismic sources. An additional non-linearity derives, in fact, from the doublecouple constraint, which imposes a non-linear combination of the components of the moment tensor - namely a zero value of its determinant.

\subsubsection{Warning II: Site Effects are dependent upon source properties}

Alternatively, within the frequency domain - where $M_{i j}(\omega)=M_{i j} \cdot m(\omega)$ - the inverse problem may seem simpler, because: (i) the convolution is converted to pure multiplication; and (ii) the equation is solved for each frequency separately. Since within linearity we can determine $\mathrm{M}_{\mathrm{ij}}(\omega)$, we can further see from $O_{n j}(\omega)=E_{j}(\omega) \cdot P_{n j}(\omega) \cdot S_{n}(\omega)$ that site effects are dependent upon source properties! To separate the source time function transform $\mathrm{m}(\omega)$ and the space tensor $\mathrm{M}_{\mathrm{ij}}$, again a non-linear constraint is needed so therefore the advantage of the frequency domain is fictitious.

\subsubsection{Site Effect Ground Motions computed from Scenario Earthquakes}

A complementary alternative to the questionable empirical approach to site response estimation, evidenced for example by De Ferrari et al. (2010) and Molchan et al. (2011), is based on computer codes, developed from the detailed knowledge of the seismic source process and the propagation of seismic waves. (e.g., Romanelli and Vaccari, 1999; Field 2000; Olsen 2000; Panza et al., 2001; Rugarli et al., 2019a; Panza and Bela, 2019). This approach can simulate the ground motion associated with a given earthquake scenario, as done by NDSHA. Thereby using available geological and geotechnical information, a low-cost parametric analysis of site responses can be performed - without using the empirical $\mid$ convolutive methods that are based on $\mathrm{O}_{\mathrm{nj}}(\omega)=E_{\mathrm{j}}(\omega) \cdot \mathrm{P}_{\mathrm{nj}}(\omega) \cdot \mathrm{S}_{\mathrm{n}}(\omega)$.

Summarizing - the Warnings for the empirical | convolutive models are: (a) uncertainty, which remains unknown for any site-specific application (as previously discussed); and most importantly (b) validity is also proven not general - since site effects are, as a rule, dependent upon source propertie that are a direct consequence of the telluric and tensor nature of the motion equation: $\mathrm{u}_{\mathrm{l}}(\mathrm{t})=\Sigma_{\mathrm{ij}} \mathrm{M}_{\mathrm{ij}}(\mathrm{t}) \cdot \mathrm{G}_{\mathrm{li}, \mathrm{j}}(\mathrm{t})$, where: (i) $\mathrm{G}$ is the Green's function, that represents the transmitting medium (pathway) response and (ii) $\mathrm{M}_{\mathrm{ij}}$ are moment tensor functions representing the source properties. 


\section{Case studies}

A very natural question to ask, as a consequence of what has already been proven in earlier sections Change of paradigm and Methodology, is: "What is the appropriate way to estimate seismic hazard for our historical buildings and monuments"? - since we must now be considering time intervals of hundreds of years (or perhaps even more, since, even if naturally perishable, we want to keep cultural heritage as long as possible).

It is our best judgment that probabilistic methods of seismic hazard assessment, i.e., PSHA, must be rejected when considering cultural heritage, because of their severe shortcomings deriving from: (i) erroneous mathematical presumptions; (ii) defective logic; (iii) incorrect and unverifiable earthquake science assumptions; and (iv) too simplistic physical considerations of earthquake occurrence. Summarizing: PSHA turns out by far to be failingly inapplicable for cultural heritage and monuments!

Since PSHA quantitatively displays results in terms of peak ground acceleration PGA and spectral response acceleration SA, both design professionals and the public inhabitants of buildings have often been rather confused between: (a) what an "earthquake" actually is? - and (b) what exactly the PSHA modeled "ground motion" derivations represent?

Ground motion is ground shaking that is simply a physical consequence from having an earthquake! In other words: NO earthquake occurs! - NO ground motion will be observed! However, in the PSHA earthquake hazard model, "ground motion" occurrence in time is a "concept" that is tied to regulatory earthquake-resistant design requirements - and therefore the PSHA hazard model "ground motion" could be (and too often is) different from that felt in experiencing an actual earthquake (Klügel et al., 2006).
"Whenever you think that you are facing a contradiction, check your premises. You will find that one of them is wrong"

- Ayn Ran

A viable alternative capable of minimizing the drawbacks of ground motion and other systemic confusions of standard SHA is given by the use of scenario earthquakes, which can be characterized in terms of: (i) magnitude including MCE; (ii) distance; (iii) faulting style; and (iv) by the treatment of complex source processes (Klügel et al., 2006; Rugarli et al., 2019a, b; Panza and Bela, 2019).

Scenario-based seismic hazard maps: (a) are purely based on geophysical and seismotectonic features of a region; and (b) take into account the occurrence of earthquakes only for their classifications into descriptive hazard categories: exceptional (catastrophic); rare (disastrous); sporadic (very strong); occasional (strong); and frequent - therefore they may provide an upper bound for the ground motion levels that can potentially be expected for most regions of the world. Knowledge of an upper bound is first and foremost more appropriate than probabilities of exceedance, in view of the longer time scales required for the protection of historical buildings. Secondarily, and as was pointed out in section 6 . A warning about site effects, a calculated ambiguity (which in PSHA sometimes can also be counterintuitive) is often difficult to communicate so as to be understood!

Since the NDSHA approach naturally supplies realistic time-series of ground motion, it can also provide reliable estimates of ground displacement that are readily applicable to seismic isolation techniques (e.g., Martelli et al., 2014 and references therein) - techniques that are very useful in preserving historical monuments and other culturally important man-made structures. The relevance of the realistic modeling provided by NDSHA, which permits the generalization 
of empirical observations by means of physically sound theoretical considerations, cannot be overstated - as it allows for the optimization of the structural design with respect to the site of interest, especially in Italy.

Presently, the new and comprehensive book "Earthquakes and Sustainable Infrastructure: neodeterministic (NDSHA) approach guarantees prevention rather than cure", now (in early 2021) in advanced stage of preparation (edited for Elsevier by Panza G, Kossobokov V, Laor E and De Vivo B) aims to communicate in one very complete volume our "state-of-the-art" scientific knowledge on earthquakes and related seismic risks.

\subsection{Albania}

The NDSHA scenario studies so far performed for Albania are those by Muço et al. (2001; 2002) and Marku et al. (2014). In the area most severely affected by the M 6.4 earthquake of 26 November 2019, the NDSHA DGA ( PGA) value at the bedrock is around $0.3 \mathrm{~g}$, which well envelopes the observed ground motions https://earthquake.usgs.gov/earthquakes/event page/us $70006 \mathrm{~d} 0 \mathrm{~m} / \mathrm{shakemap} / \mathrm{pga}$ - with larger values being observed where strong "site effects" are to be expected; and a model (Stein and Sevilgen 2019) shows "amplification" factors of 4-5 greater than the shaking that was experienced at bedrock sites. Predicted PSHA values, however, do not exceed $0.18 \mathrm{~g}$ ! (Muço, 2013).

Last but not least, the tsunami hazard in the Adriatic Sea had been modeled by Paulatto et al. (2007) following NDSHA approach; and their pioneering results had also been later confirmed by Tiberti et al. (2009). Notwithstanding that both the conservative NDSHA estimates, as well as the subsequent confirmation by Tiberti et al. (2009), excluded any significant tsunami generation hazard caused by the M 6.4 earthquake of 26
November 2019 - the Italian Istituto Nazionale di Geofisica e Vulcanologia (INGV)'s Center for Tsunami issued (7 minutes after the quake) an alert to Civil Protection for tsunami hazard in Albania, Montenegro and Italy. That alert was appropriately rescinded the following morning of November 27, based on records of tide gauge measurements.

https://www.agi.it/estero/terremoto_albania6620218/news/2019-11-26/

\subsection{Bangladesh}

Bangladesh lies within a historical earthquake-prone region, with evidence pointing to past major earthquakes within or close to the country. There is now general consensus among national and international experts about the possibility of a large magnitude earthquake occurring in Bangladesh (and the surrounding region) at any time. Historical records of "major" earthquakes in and around Bangladesh, including: 1930 M 7.1 Dhubri Earthquake; 1918 M 7.6 Srimangal Earthquake; 1897 M 8.3 Great Indian Earthquake; 1885 M 7.0 Bengal Earthquake; 1762 M 7.5+ ChittagongArakan Earthquake - all bear testimony to the threat of major and even M 8+ great earthquakes for Bangladesh (Al-Hussaini et al., 2017). However, an absence of strong earthquakes affecting Bangladesh for quite a long period has left the current generation complacent about the possibility of a strong earthquake (M 6 - 6.9). Therefore, for example, in Dhaka, during the September 2324, 2017 International Conference on Disaster Risk Mitigation: the first results of a focused NDSHA application to get reliable hazard assessment values for Bangladesh were illustrated and discussed (Panza, 2017; Al-Hussaini et al., 2017).

In response to the then recent publication by Steckler et al. (2016), about an anticipated "mega-earthquake" risk in Bangladesh, on an active, shallowly dipping and locked 
megathrust fault (Magnitude ranging from $\mathrm{M}$ 8.2 - M 9.0) - NDSHA computations were performed (Chakraborty 2017) for some hypothetical scenario mega earthquakes (M 8.5 and M 8.0), with their epicenters $40 \mathrm{~km}$ east of Dhaka. For M 8.5 earthquake scenario, DGA in Dhaka can be $0.3 \mathrm{~g}-0.6 \mathrm{~g}$; while it can be $\sim 1.0 \mathrm{~g}$ near the earthquake epicenter in Comilla. These values, not surprisingly, far exceed the code specified values of $0.2 \mathrm{~g}$ for Dhaka and Comilla. Obviously, for the lesser M 8.0 scenario earthquake, acceleration in Dhaka is lower, reaching only $0.15 \mathrm{~g}-0.3 \mathrm{~g}$ - while within the more limited epicentral region it can still reach $1.0 \mathrm{~g}$.

\subsection{China}

China's pioneering application of NDSHA dates back to 1998 (Sun et al., 1998), and Sun's work has been followed now by two decades of international publications: Panza et al., (2002); Ding et al., (2004a, b); Wang et al., (2010); Wang and Shi (2010); Zhang et al. (2018) - all dealing with NDSHA's application to both seismology and structural engineering. At present a major international endeavor is developing: "China Seismic Experimental Site - Natural laboratory of earthquake science for seismic disaster resilience." - http://www.cses.ac.cn/en/ - And one of this endeavor's projects is focusing on "Application research of the neo-deterministic seismic risk assessment (NDSHA) method in China Seismic Experimental Site." http://www.ief.ac.cn/home/index.html http://www.ief.ac.cn/ylaw/info/2020/22510.ht $\mathrm{ml}$ -

http://www.ief.ac.cn/ylaw/info/2020/22512.ht $\mathrm{ml}$ -

http://www.ief.ac.cn/eic/info/2020/22511.html

\subsection{Cuba}

Pioneering work has been done focused on Santiago de Cuba city, the capital of southeastern Cuba's Santiago de Cuba Province, with special attention examining earthquake source influence on "site effects". (see section 6. A warning about site effects). Analysis of the influence of both depth and distance of the source on the "site effects" shows that standard traditional methods (based on deconvolution analysis of nearby rock outcrop motions) can lead to erroneous results (Alvarez et al., 2001) - consistent with the fact that the deconvolution analysis is unable to specifically account for the tensor nature of realistic earthquake ground motions.

In other words, as a natural consequence of the tensor nature of earthquake ground motion, "site effects" are not persistent, when changing the relative positions of site-tosource - as has been confirmed both by modelling (e.g. Olsen 2000 for the Los Angeles basin) and also by formalized empirical observations in Molchan et al. (2011).

In Santiago de Cuba city, there are three different main zones identified, in addition to a small sector characterized by major resonance effects (due to the particular structural conditions). Each zone is characterized in terms of its expected ground motion parameters for both $\mathrm{M} 7$ and $\mathrm{M}=$ $M_{\text {design }}=8.0$. (Alvarez et al., 2004). In their later paper Alvarez et al. (2005) supply microzoning for Santiago de Cuba - where 11 zones are delimited, combining: (a) geological information; and (b) results of the classification based on formal analyses of the modeling of earthquake ground motion. Since the strongest earlier historical event in the region (06 Nov. 1766) reached $M$ 7.6, the use of $\mathrm{M}_{\text {design }}=\mathrm{M}_{\max }+\gamma_{\mathrm{EM}} \sigma_{\mathrm{M}}=8.3$ is recommended (see also section 5 . Methodology) - not so different, within experimental errors, from the value of $\mathbf{M}_{\text {design }}$ $=8.0$ that was considered by Alvarez et al. (2004).

\subsection{Venezuela}

Three synthetically generated scenario earthquakes were chosen (located within the Guarenas - Guatire sedimentary basin) along 
San Sebastian, Pichao (system La Victoria) and Tacagua Faults: with Mw 7, Mw 6 and Mw 5 respectively (Morfe et al., 2015). The following ground motion parameters were obtained: 2D/1D spectral ratio of the horizontal and vertical components $\mathrm{H} / \mathrm{V}$, and 2D/1D acceleration response spectrum ratio for the transverse, radial and vertical components. Response spectra of horizontal acceleration for the ground surface were developed from average relations of response spectra (considered as transfer functions) and response spectrum at bedrock obtained from a regional seismic hazard study.

In a similar study evaluating how the destructive effects of earthquakes may increase within sedimentary basins (not only due to the presence of sediments, but also because of basin geometry), Alvarado et al (2020) analyzed the results of 2D numerical simulations of seismic wave propagation from Mw 6.0 and Mw 7.0 scenarios: to estimate the soil response in the cities of Barquisimeto and Cabudare, located in the vicinity of Boconó fault, western Venezuela. The results obtained showed that the presence of sedimentary basins affect the amplitude, time duration and frequency content of the seismic source signal.

\subsection{Egypt}

In the last century, Egypt has experienced earthquakes with magnitudes ranging from $\mathrm{m}_{\mathrm{b}} 5.8$ up to $\mathrm{Mw}$ 7.3. The original pioneering work in the general framework and perspective of NDSHA in Egypt dates back to the work by El-Sayed et al. (2001). The computations of peak Displacement (DMAX), peak Velocity (VMAX) and Design Ground Acceleration (DGA) are chosen and then plotted to construct the Egyptian seismic hazard maps. These results have been validated against the few strong motion recordings available. Significantly, the areas of high seismic hazard are also of great socioeconomic importance.

While results obtained from the deterministic and probabilistic approaches are often comparable, the considerable differences observed in some areas may be related to the following factors that are peculiar to probabilistic methods. These methods: (a) are very sensitive to the completeness of the catalogue; and (b) use simple attenuation relations that oversimplify the wave propagation environment, which intrinsically is a tensor phenomenon. The most current reliable update on the seismic hazard maps available for Egypt incorporated the results of many recent studies, including: (i) revised historical earthquake catalogues: (ii) Morphostructural Zonation (MSZ) data; (iii) revised focal mechanism solutions; and (iv) revised mechanical models of the lithospheric structure - and was all completed within the framework of the NeoDeterministic Seismic Hazard Assessment (NDSHA) procedure (Hassan et al., 2017).

In a recent hazard assessment that is based upon scenario earthquakes, Mostafa et al. (2019) use a "ground motion prediction equation" selected from already developed attenuation relationships, since there is no scaling attenuation relationship adopted in Egypt, due to the scarcity of strong ground motion observations - with obvious severe limitations on the reliability of results!

The set of relevant scenario earthquakes considered by Hassan et al. (2017) provides a large dataset of synthetic seismograms, particularly important for the areas like Egypt that suffer from an endemic lack of useful strong motion time-histories. This data set then comprises the basis for completing, in the future, more detailed and comprehensive seismic microzonation studies, like the one now in progress in the framework of the Suez Canal Economic Zone (SCZone). Availability of a wide spectrum of hazard maps is an 
important prerequisite to making available the valuable information necessary for the significant improvements to current practices in seismic engineering codes.

The SCZone is a mega-project launched to both increase the role of the Suez Canal region in the international trading arena, and to also develop the urbanization of that region. Reliable Seismic Hazard Assessment, therefore, is crucial input information for the designers and planners of all facilities within this area. Accordingly, an updated seismic hazard map for the Suez Canal region has been compiled within the framework of the NDSHA procedure. To consistently both assess the uncertainty of the understanding of the seismic hazard, and also that uncertainty's effect on critical structures, a sensitivity analysis is performed varying, for example: (i) source focal mechanism; (ii) directivity; (iii) rupture process; and (iv) seismotectonic model. With a suite of ground shaking scenarios computed at the selected profile crossing the Suez Canal, variations of the ground shaking scenarios are then carefully evaluated by considering: (a) the amplitudes measured on the waveforms and the response spectra; (b) the changes in the shaking duration; and (c) the modifications in the amplification patterns.

Two recent papers by Hassan et al. (2020) and El Gabry et al. (2020) provide a specific focus on the NDSHA procedure, as applied to: (a) the seismic hazard assessment for the historical city of Cairo, which contains a large number of cultural heritage buildings; and (b) the seismic input definition (e.g., response spectra, time-histories) at a site of the tunnel that undergoes the Suez Canal to connect Sinai Peninsula with the western side of the country. Last but not least, ElGabry and Hassan (2020) have produced NDSHA estimates of design ground motion parameters - in the form of accessible online digital maps or databases (e.g., DGA, PGV, PGD, RS and time-histories) to be used as input for the next generation of the Egyptian Building code.

\subsection{India}

Parvez et al. (2003) published the first ever neo-deterministic seismic hazard map of India. Then, in 2017, by taking advantage of several enhancements to the original formulation of NDSHA, Parvez et al. (2017) supplied a revised NDSHA map for India. With respect to the original work by Parvez et al. (2003): (i) the velocity structural model for the entire Indian subcontinent was now redefined at a higher resolution of $1^{\circ} \times 1^{\circ}$ - amounting now to 387 cellular structures; (ii) the earthquake catalogue and the seismogenic zones were updated; and (iii) a more realistic source model, the Size and Time-Scaled Point Source (STSPS) described by Parvez et al. (2011), was adopted in the computations.

The highest seismic hazard, expressed in terms of DGA, lies in the range of $0.6 \mathrm{~g}-1.2 \mathrm{~g}$, and is mainly distributed: (i) in Western Himalayas and Central Himalayas along the epicentral zone of the 25 April 2015 Mw 7.8 Nepal earthquake: (ii) in part of NE India; and (iii) in the Gujarat (Kachchh region). In these same areas, a similar pattern has been found for PGV and PGD values.

A comparison of NDSHA estimates with the maximum observed intensities $\mathrm{I}_{\mathrm{MAX}}$ reported in EMS scale by Martin and Szeliga (2010) indicates that the modeled intensities are rarely exceeded by maximum observed intensities. That is, the underestimation of $\mathrm{I}_{\mathrm{MAX}}$ is greater than one degree of intensity only: (a) in $2 \%$ of the NDSHA cells for $\mathrm{I}_{\mathrm{MAX}}$ between VI ( $\left.\mathrm{I}_{\mathrm{EMS}}\right)$ and VIII ( $\left.\mathrm{I}_{\mathrm{EMS}}\right)$; and (b) in $7 \%$ of the cells for $\mathrm{I}_{\mathrm{MAX}}=\mathrm{IX}\left(\mathrm{I}_{\mathrm{EMS}}\right)$; while (c) there is no underestimation for $\mathrm{I}_{\mathrm{MAX}}=\mathrm{X}$ ( $\mathrm{I}_{\mathrm{EMS}}$ ).

These gratifying and naturally supplied robust results (well consistent with the information content of the available data Panza et al. (2013), and as also illustrated by Parvez et al. (2017), represent not only a major contribution to the reliable assessment 
of the seismic hazard in India and neighboring areas, but they should also be used to update the building code IS 1893 of the Bureau of Indian Standards.

\subsection{Indonesia}

From a detailed comparative analysis considering the reliability of seismic hazard assessments given by PSHA and NDSHA, Irwandi (2017) stressed the need for a systematic application of NDSHA methodology to Indonesia, with particular attention paid to critical infrastructure at risk from seismic hazard. The Indonesian government has consistently provided updates of seismic hazard maps of PGA - releasing a series of official PSHA maps in 1978, 2002, 2010 and 2017. Most recently, Irwandi et al. (2020) compared the official PSHA 2010 and 2017 map values with those obtained by means of NDSHA.

The spatial resolution of the PSHA maps $\left(0.01^{\circ} \times 0.01^{\circ}\right)$, i.e., a ten-times finer resolution than the more realistic NDSHA maps $\left(0.1^{\circ} \times 0.1^{\circ}\right)$, is, we believe, an evident numerical artifact - totally inconsistent and at odds with the real resolving power of available data! The NDSHA comparison is naturally made by smoothing the PSHA values, thereby adjusting them to the same resolution $\left(0.1^{\circ} \times 0.1^{\circ}\right)$ as the NDSHA data points.

In general, the resulting PGA value of the newer PSHA 2017 map is significantly greater than the previous PGA value of the preceding PSHA 2010 effort - except along the Sumatran fault in Central and South Sumatra. But in contrast, the PGA values estimated by using standard NDSHA (with $10 \mathrm{~Hz}$ cut-off frequency) are higher than those of the PSHA computed PGA - at a PE (Probability of Exceedance) of $2 \%$ in 50 years for both of the official PSHA maps released in 2010 and 2017.

Since NDSHA's ground motion values for Sumatra are based on the realistic physical simulation of seismic wave generation and propagation, they provide reasonable, realistic and conservative envelopes of the complete suite of potential earthquake ground motions therefore they should be seriously considered in those areas of Indonesia where critical infrastructure is at substantial risk from seismic hazards.

\subsection{Iran}

Seismic hazard maps for the Alborz region in northern Iran and adjacent areas have been compiled accordingly with NDSHA procedures by Rastgoo et al. (2018). The input data set consists of: (i) attenuation-velocity structural models (representing bedrock conditions); (ii) seismogenic zones; (iii) focal mechanisms; and (iv) the catalogue of past seismicity. The seismic hazard is mapped on a regular grid of $0.2^{\circ} \times 0.2^{\circ}$ over the entire region.

The results of this first order NDSHA mapping computation indicate a high seismic hazard in the Alborz region, and this may represent an important fundamental knowledge basis - essential for future and more detailed and comprehensive seismic microzonation studies.

A major validation of NDSHA results has been made against the records of the 20 June $1990 \mathrm{Mw}$ 7.4 Manjil-Rudbar earthquake, which occurred in the Alborz region - and was both an unexpected left-lateral strike-slip motion on a previously unknown fault, and also the most destructive documented earthquake in Iran in the last century (Fig. 8). On account of the fact that earlier strongest events in the region had reached $M$ 7.3, the use of $M_{\text {design }}=M_{\max }+\gamma_{\mathrm{EM}} \sigma_{\mathrm{M}}=8.0$ is to be recommended (see section 5. Methodology) - also exploiting, among other modeling techniques, the experience acquired with $3 \mathrm{D}$ NDSHA computations made so far (Gholami et al., 2012; 2014). 


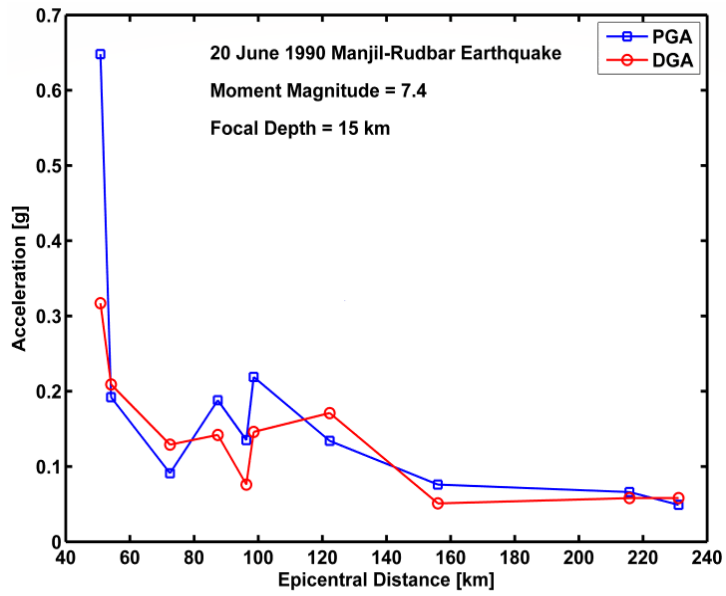

Figure 8. Alborz region, Iran: 20 June $1990 \mathrm{Mw}$ 7.4 Manjil-Rudbar Earthquake. Plot of recorded PGA and estimated DGA versus epicentral distance. Apart from the closest station (which is at near-source condition), the DGA and PGA values are well aligned (modified from Rastgoo et al., 2018)

\subsection{Italy}

The first NDSHA maps for Italy were published by Panza, Romanelli, and Vaccari in 2000. Subsequently, there were many earthquake "surprises" in Italy (as listed in Table 1), that not only contradicted but also invalidated the regulatory PSHA maps that were published in 2004 - and on which the current seismic code is based (e.g. Rugarli 2014).

Table 1 provides a detailed list of four significant earthquake-chapter "surprises" that contradicted the 2004 PSHA Map of Italy after the 2000 NDSHA Map was published:

Table 1. List of Earthquake "Surprises" for the 2004 PSHA Map of Italy - After 2000 NDSHA Map

L'Aquila 2009 (6 April M 6.3; 309 victims) Occurred in a defined area with high seismic hazard, but the acceleration values observed exceed those foreseen by the anti-seismic code Emilia 2012 (20 May M 5.9; 29 May M 5.8; 17 victims) Occurred in a defined area with low seismic hazard, but the acceleration values observed exceed those foreseen by the antiseismic code

Central Italy Earthquake Crisis 2016 (24 August M 6.0; 30 October M 6.5; 299 victims) Sequence occurred in a defined area with high seismic hazard, but the acceleration values observed exceed those foreseen by the antiseismic code

Ischia 2017 (21 August M 4.0 - 4.2; 2 victims)

\begin{tabular}{|c|c|}
\hline $\begin{array}{c}\text { Expected PGA (475 years) } \\
0.250-0.275 \mathrm{~g} \\
\text { (map MPS04) }\end{array}$ & $\begin{array}{l}\text { PGA observed: } \\
\quad>0.35 \mathrm{~g}\end{array}$ \\
\hline $\begin{array}{c}\text { Expected PGA (475 years) } \\
<0.175 \mathrm{~g} \\
\text { (map MPS04) }\end{array}$ & $\begin{array}{l}\text { PGA observed: } \\
\quad>0.25 \mathrm{~g}\end{array}$ \\
\hline $\begin{array}{c}\text { Expected PGA (475 years) } \\
0.250-0.275 \mathrm{~g} \\
\text { (map MPS04) }\end{array}$ & $\begin{array}{l}\text { PGA observed: } \\
\qquad>0.4 \mathrm{~g} \\
\text { value }>0.35 \mathrm{~g} \\
\text { in L'Aquila } 2009\end{array}$ \\
\hline $\begin{array}{l}\text { Expected PGA (475 years) } \\
\text { Bedrock D: 0.14-0.15 g (H), } \\
0.0951 \mathrm{~g}(\mathrm{~V}) \\
\text { Soil B:1.20D }=0.17-0.18 \mathrm{~g} \\
1.0 \mathrm{D}_{\mathrm{V}}=0.0951 \mathrm{~g}(\mathrm{Z}) \\
\text { Soil C: } 1.50 \mathrm{D}=0.21-0.23 \mathrm{~g} \\
1.0 \mathrm{D}_{\mathrm{V}}=0.0951 \mathrm{~g}(\mathrm{Z}) \\
\text { IOCA Station } \\
\text { 40.7458 N; Long. } 13.9008 \mathrm{E} \\
\text { Sited on Soil B }\end{array}$ & $\begin{array}{c}\text { IOCA Station PGA } \\
\text { (observed) } 0.280 \mathrm{~g}(\mathrm{E}-\mathrm{W}) \\
0.272 \mathrm{~g}(\mathrm{~N}-\mathrm{S}), 0.192 \mathrm{~g}(\mathrm{Z}) \\
\quad \text { are > PSHA Map: } \\
\text { Surprises for PSHA Map: } \\
\text { Obs. }(\mathrm{H})>60 \% \text { (Soil B) } \\
\text { Obs. }(\mathrm{H})>30 \% \text { (Soil C) } \\
\text { Obs. }(\mathrm{V})>101 \%(\mathrm{Z})\end{array}$ \\
\hline
\end{tabular}

NDSHA Map 2000 (for all events) computes values that include the observed ones. In example of the Ischia 2017 quake: [NDSHA] estimates values in the range [0.15-0.30g]; then when including the local site effects Soil B at Latitude 40.7458 and Longitude 13.9008, as determined by NTC08 (Norme techiche - PSHA), NDSHA estimates [0.18-0.36g] - within which the observed value of $0.280 \mathrm{~g}$ falls! If Soil C is assumed, the NDSHA range is then $[0.23-0.45 \mathrm{~g}]$. More details in De Natale et al. (2019) Surprise and Contradiction to the 2004 Map did befall! PSHA missed them all! 


\subsubsection{Emilia 2012}

20 May 2012 - M 5.9; 29 May 2012 - M 5.8; PSHA PGA (475 years) $<0.175 \mathrm{~g}$.

In studying these two rapidly repeating sequential M 5.9 and 5.8 Emilia events, Tramelli et al. (2014) noted that: (a) quite similarly the "seismicity recorded in Italy in the last decades occurred frequently in sequences"; and (b) "on the other hand, the current practice of probabilistic seismic hazard analysis based on the Cornell approach assumes statistically independent seismic events"; and further cautioned that (c) "the occurrence of a consecutive seismic sequence may result in an enhanced PSA and Sd with respect to the values obtained for any single earthquake that composes the sequence," where PSA and Sd are response spectral values for acceleration and displacement.

Therefore, these same authors have strongly encouraged the earthquake engineering design community to more comprehensively consider design spectra which also take into account the occurrence of a consecutive sequence of earthquakes, at least for designing strategic structures, claiming that "a broader and modern approach (in line with the present knowledge of active faults locations, mechanisms, and interaction) would be more advantageous for seismic risk mitigation" - and they further implicitly encourage the more widespread use of NDSHA's methodology, since that is physically and systematically capable of addressing the endemic fundamental problems infecting PSHA, that they correctly have mentioned.

\subsubsection{Central Italy}

Norcia had been retrofitted after the Umbria-Marche Earthquake Crisis (a long sequence of moderate to strong earthquakes that began September 26, 1997.

http://www.geo.mtu.edu/UPSeis/magnitude.html All earthquake damage reconstruction work used as a benchmark the PSHA map ("return period" $475 \mathrm{yr}$.), on which the Italian building code seismic requirements were based.

Those maps, however, proved totally misrepresentative and erroneous upon the occurrence of the 30 October $2016 \mathrm{Mw} 6.5$ earthquake, where in Norcia the earthquake ground motion was much larger than what had been predicted previously by PSHA! The resulting damage was verylarge, corresponding to $\mathrm{I}_{\mathrm{MCS}}=\mathrm{IX}$. Instituto Nazionale di Geofisica e Vulcanologia reports $\mathrm{I}_{\mathrm{MCS}} \approx$ VIII - IX.

http://www.afs.enea.it/poggif/amatrice/docs/Q UEST_rapporto_15nov.pdf. But it should be kept in mind that any Intensity Scale is defined by discrete integer values, thereby having unit-incremental-steps; and therefore, intermediate values are not defined (Grünthal 1998). On the NDSHA map, the hazard value indicated is slightly above the experienced ground motion generated by the 30 October 2016 earthquake. In all likelihood, if the reconstruction and retrofitting that followed the 1997 Umbria-Marche earthquake crisis would have been undertaken in due account of the NDSHA demand estimates, then the damage would have been much less (if not negligible), when compared with that actually observed after the 30 October 2016 M 6.5 event.

\subsubsection{Italian Seismic Codes}

To have simply and blindly followed PSHA designated design strength and detailing requirements for new buildings, while at the same time neglecting the fact that the Italian antiseismic code further provides:

L'uso di accelerogrammi generati mediante simulazione del meccanismo di sorgente e della propagazione è ammesso a condizione che siano adeguatamente giustificate le ipotesi relative alle caratteristiche sismogenetiche della sorgente e del mezzo di propagazione (NTC 2008 chapter 3.2.3.6). 
The use of accelerograms generated simulating source mechanism and wave propagation is allowed provided the hypotheses about the seismogenic characteristics of the source and the properties along the pathway are duly justified.

Certainly allowed some (marginal) cost saving during the reconstruction and retrofitting following the 1997 events, when compared to the higher earthquake-resistant requirements indicated under NDSHA. Nonetheless, any apparent "savings" has been unrealized and ultimately seismologically frustrated by the 30 October $2016 \mathrm{Mw} 6.5$ earthquake - and now it is necessary to consider in the reconstruction and retrofitting the NDSHA values, which were so unwisely ignored after the 1997 earthquakes.

In the planning work performed by Cimellaro et al in both 2011 and 2015, a departure from the standard building code hazard assessment approach was found to be more advantageous. In the town of Calascibetta (Sicily), for example, the NDSHA scenario proposed by Panza et al. (2012) gives the value of the peak ground velocity in the range $\mathrm{PGV} \approx 15-30 \mathrm{~cm} / \mathrm{s}$. Following the alternative use of computed synthetic ground motions authorized under use of chapter 3.2.3.6 of NTC 2008 and NTC 2018 - the neo-deterministic approach has been preferred over the familiar and codified probabilistic seismic hazard analysis (per Cimellaro et al., 2015), because the latter provides non-conservative results (Panza, Kossobokov et al., 2014), when systematically applied to Urban Water Distribution Networks. Cimellaro et al. (2015) performed a comprehensive study about a new "Resilience Index" for urban water distribution networks, using therein the average NDSHA value of $\mathrm{PGV}=22.5 \mathrm{~cm} / \mathrm{s}$ and this value can be assumed constant over the entire water distribution network, because of the network's limited extent.

\subsubsection{Historic Napoli}

Very recently Nunziata and Costanzo (2020), using local scale NDSHA procedures Rugarli et al. (2019a) modeled the ground motion at the historical center of Napoli for the 5 December 1456 and 5 June 1688 earthquakes - responsible for a maximum felt intensity VIII (MCS). The NDSHA propagation model is validated through the comparison of its computational synthetic signals with strong motion records obtained from within the historical center of Napoli, of a moderate earthquake on 29 December 2013 $\mathrm{M}_{\mathrm{W}}$ 5.2, whose epicenter is close to the seismogenic fault responsible for the 1688 earthquake. Remarkable agreement exists between computed PGA and reported epicentral intensity values if the 1688 earthquake is modeled with: (i) magnitude $\mathrm{M}_{\mathrm{W}}=7$, as reported in CPTI15 (2015) catalogue; (ii) normal fault sources striking $296^{\circ}$ and $311^{\circ}$ (i.e., either Calore river or Tammaro basin faults); and (iii) epicentral distance and focal depth varying in the range $45-62 \mathrm{~km}$ and $8-15 \mathrm{~km}$, respectively. However, if the 5 December 1456 earthquake is modeled with the strike-slip fault source proposed by Fracassi and Valensise (2007), then the magnitude reported in CPTI15 2015 must be increased to at least M 7.3 - still, however, well within measurements error.

Keeping in mind the uncertainties of both the macroseismic intensities and the estimated magnitudes of these historical earthquakes, as well as the degraded conditions of the masonry heritage, the earthquake responsible for the highest ground motion parameters can necessarily be chosen for both the proper restoration and also future protection of the historical heritage of Napoli, whose historical center is also a UNESCO World Heritage site. 
These NDSHA computational simulations, therefore, represent basic input data to be further considered in assessing the seismic response of these heritage buildings and to also further provide useful guidelines to improve building seismic resistance. Moreover, because it is not the "last" earthquake that should concern us, but rather the earthquake that comes after the next one many now believe that it is both well validated and also scientifically justified to claim that NDSHA is not only a more reliable but also a ready alternative to the presently widespread use of PSHA.

\subsubsection{Reliable Seismic Hazard Assessment}

This is because NDSHA provides not only practical but also more realistic and Reliable Seismic Hazard Assessment (RSHA), particularly since PSHA's continued use has been so widely proven in the professional journals and publications to be a totally unjustified and unreliable procedure, i.e., a fabulation dependent upon magical realisms. (e.g. Saxe 1873; Krinitzky 1993a, b, c, 1995; 2003; Klügel 2008; PAGEOPH Topical Volume 168, 2011; Mualchin 2011; Wang and Cobb 2013; Klügel 2015; Mulargia et al., 2017; Stark, 2017).

A further implicit and important confirmation of the validity of considering NDSHA as a robust and effective preventive tool is given in the decadally updated Norme Tecniche per le Costruzioni 2018 (NTC 2018) that deepens and expands the concept contained in chapter 3.2.3.6 of (NTC 2008) as follows:

L'uso di storie temporali del moto del terreno generate mediante simulazione del meccanismo di sorgente e di propagazione è ammesso a condizione che siano adeguatamente giustificate le ipotesi relative alle caratteristiche sismo genetiche della sorgente e del mezzo di propagazione e che, negli intervalli di periodo sopraindicati, l'ordinata spettrale media non presenti uno scarto in difetto superiore al $20 \%$ rispetto alla corrispondente componente dello spettro elastico.

The use of accelerograms generated simulating source mechanism and wave propagation is allowed provided the hypotheses about the seismogenic characteristics of the source and the properties along the pathway are duly justified and that, in the considered period justified and that, in the considered period intervals, the average spectral ordinate is not less than $20 \%$ of the corresponding component of the elastic spectrum.

(For more details see Rugarli 2018).

\subsubsection{Regione Emilia Romagna, Bologna}

The NDSHA computational synthetic ground motion procedure has been applied to many manufactured-goods situations as well as works of construction - both public and private, e.g. http://www.studioaltin.com/work/ - and selected examples of engineering applications of NDSHA to strategic buildings and cultural heritage are shown in the following Figures 9-13. (see also VADEMECUM SVEB, 2015 - for the seismic verification of existing buildings).

The engineer Gian Carlo Giuliani, President of Redesco (Research-DesignConsulting) Progetti - http://www.redesco.it/ - an internationally recognized consulting firm in Structural Engineering, in his message dated 26 October 2016, following publication of "Difendersi dal terremoto si può L'approccio neo-deterministico" (Panza and Peresan, 2016), wrote about torre Regione Emilia Romagna in Bologna, shown in Fig. 9: 
J. Bela, G.F. Panza/Vietnam Journal of Earth Sciences 43(2021)

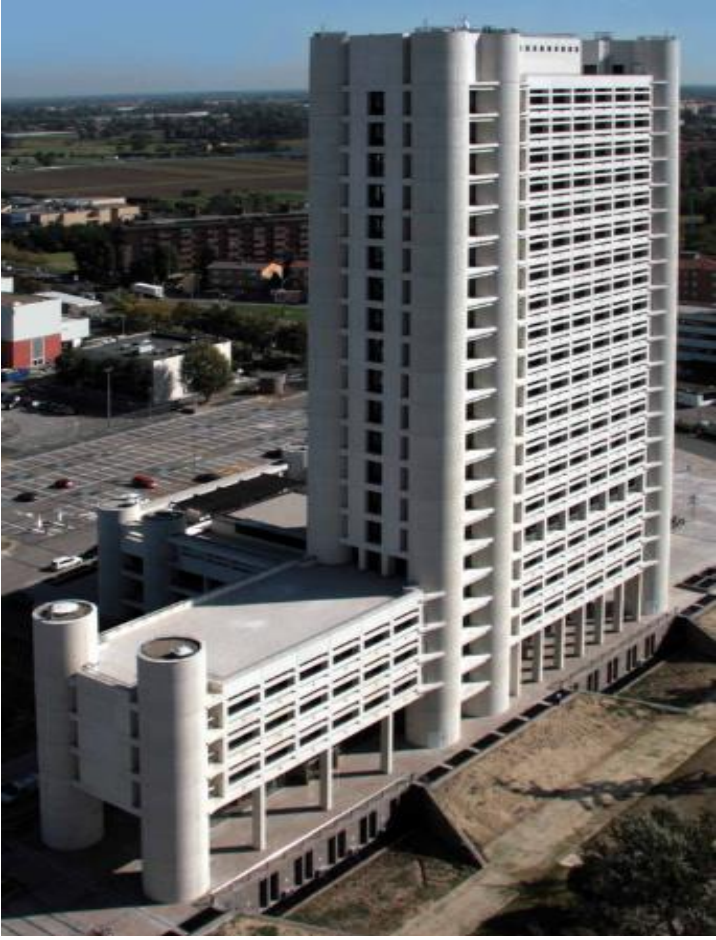

Figure 9. Bologna: torre Regione Emilia-Romagna

Caro Giuliano [Panza], ho preso nota di quanto tu e la dott. Peresan avete riportato nel vostro libro che corrisponde ai miei pensieri. Ho ordinato il volume perché è di sicuro interesse. Ti ricordo che, per il nostro progetto della torre della Regione Emilia Romagna a Bologna, abbiamo utilizzato le tue previsioni sui possibili eventi sismici condensate in 6 accelerogrammi, derivanti da altrettante sorgenti sismogenetiche $e$ quindi questa applicazione del NDSHA (anno 2001) dovrebbe essere aggiunta a quelle citate nel libro 'Difendersi dal terremoti si può - L'approccio neodeterministico.'

\section{Ad Majora! Gian Carlo}

Dear Giuliano [Panza], I have taken note of how much what you and Dr. Peresan have reported upon in your book corresponds very much to my own thoughts. I ordered the volume because it is surely of interest. I remind you that, for our project of the tower of the Emilia Romagna Region Headquarters in Bologna, we used your predictions on possible seismic events, condensed in 6 accelerograms, and deriving from as many seismogenic sources; and therefore, this application of the NDSHA (year 2001) should be added to those already mentioned in the book 'Difendersi dal terremoti si può L'approccio neo-deterministico.'

Ad Majora! Gian Carlo

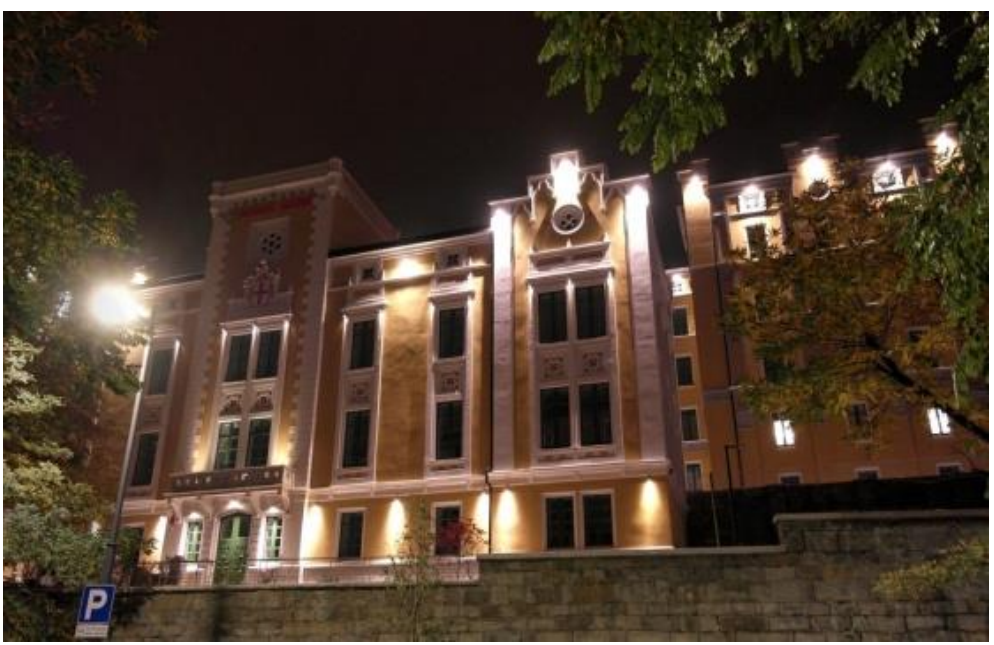

Figure 10. University College Luciano Fonda - Trieste. Seismic verification made before the inauguration of the student college can be summarized as follows: NDSHA $(0.16 \mathrm{~g})$ compatible with standard (475 yr) PSHA $(0.12 \mathrm{~g})$ at bedrock 
Vietnam Journal of Earth Sciences, 43(2), 111-188

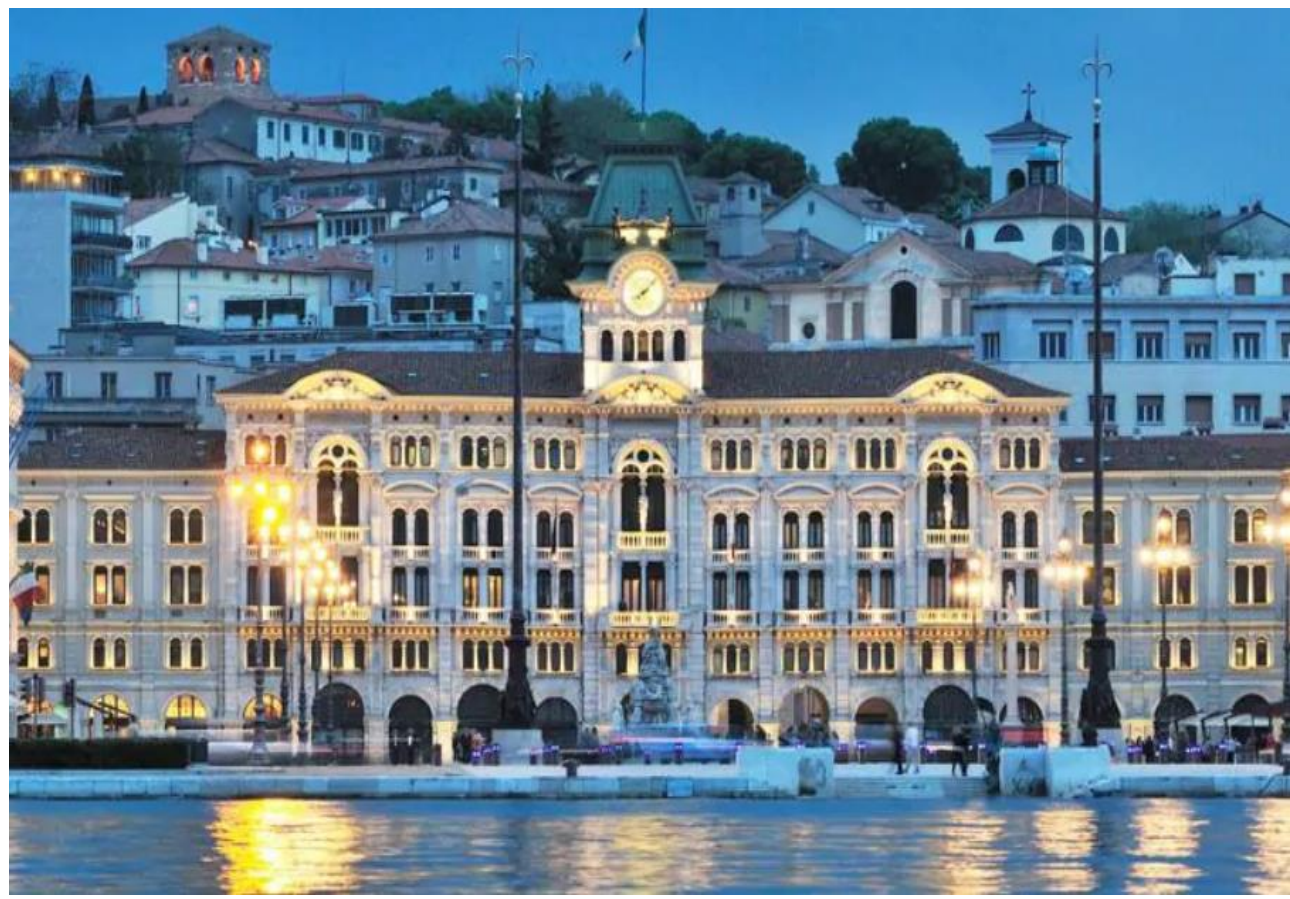

Figure 11. City Hall - Trieste. Built in an eclectic style between 1873 and 1875 on a project by the Trieste architect Giuseppe Bruni. The NDSHA study, supported by the municipality, has been performed in agreement with NTC 2008 and NTC 2018 chapter 3.2.3.6. http://www.studioaltin.com/service/

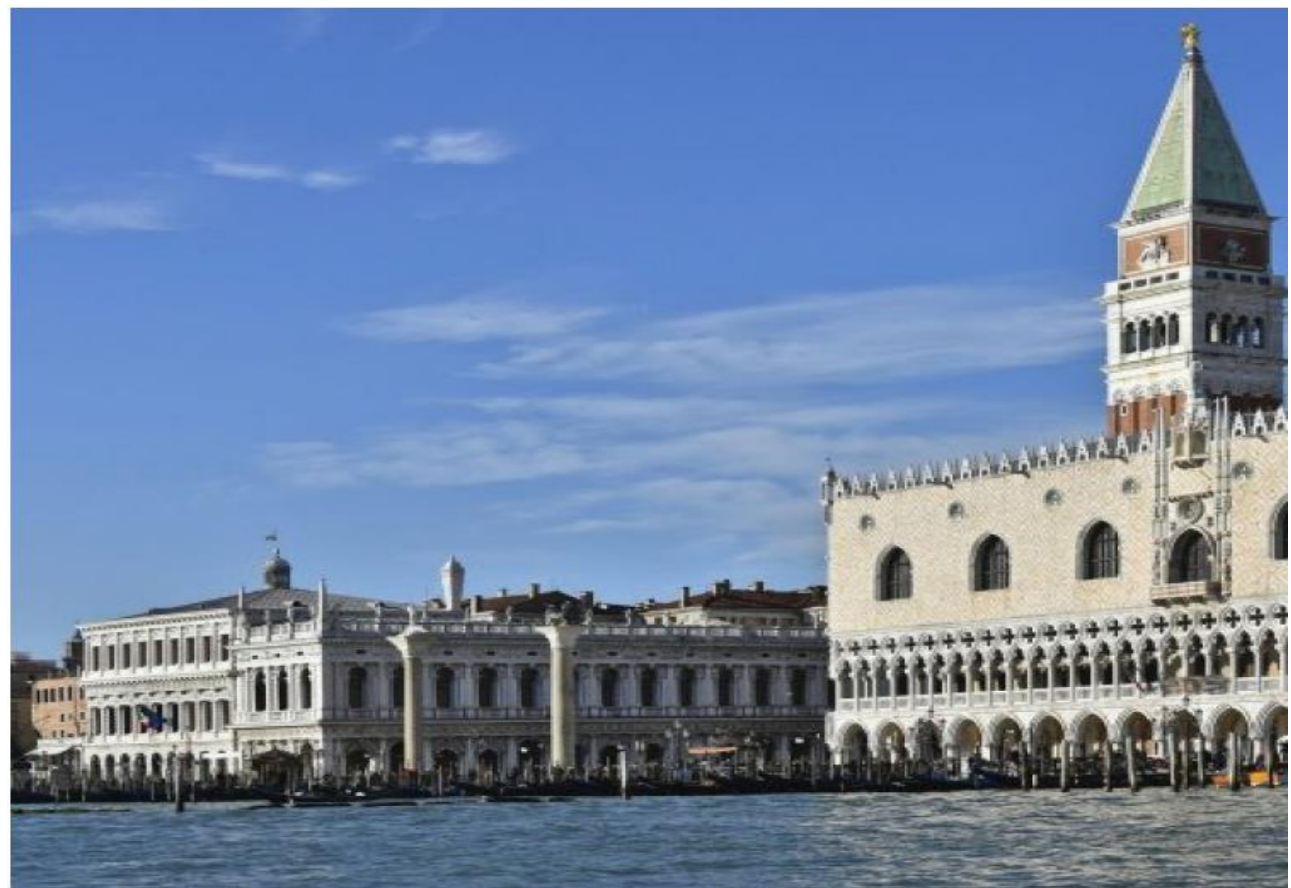

Figure 12. Marciana Library - Venice. The NDSHA study, performed in agreement with NTC 2008 and NTC 2018 chapter 3.2.3., has been supported by Segretariato Regionale of MIBACT. https://www.veneto.beniculturali.it/prevenzione-sismica-area-veneta 
J. Bela, G.F. Panza/Vietnam Journal of Earth Sciences 43(2021)
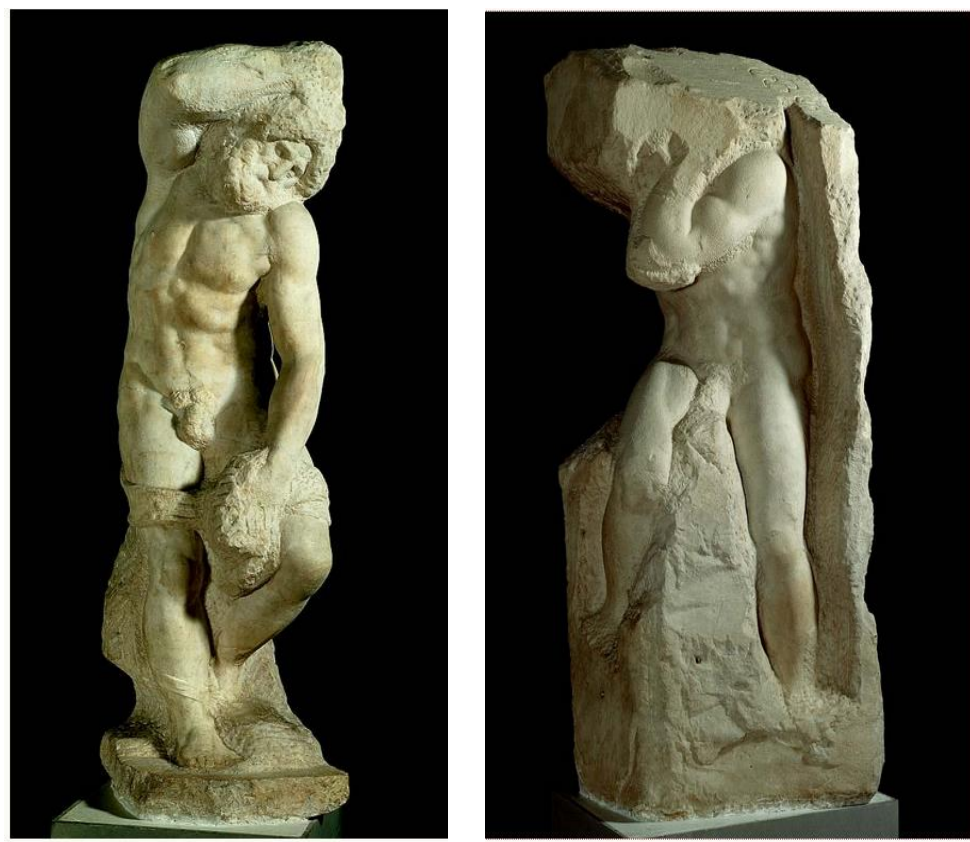

Figure 13. Prigioni by Michelangelo Buonarroti (Accademia Gallery, Florence); Prigione barbuto (bearded) on the left, Prigione Atlante (/Atlas) on the right. The stability test values, performed by non-linear kinematic analysis accordingly with the NDSHA approach, are satisfied for all the four statues in Accademia Gallery, while the stability tests carried out according to the standard PSHA approach values are not satisfied for the statues of the prigione barbuto and the prigione Atlante shown here. Therefore, in the Florence area, the use of PSHA hazard values leads to an overestimation of real hazard. (Negro et al., 2013)

\subsection{Pakistan}

The seismic hazard in both Pakistan and the adjoining regions has been assessed by Sarwar et al. (2018) using the NeoDeterministic Seismic Hazard Assessment (NDSHA) approach. The peak Displacement $\mathrm{D}_{\mathrm{MAX}}$, peak Velocity $\mathrm{V}_{\mathrm{MAX}}$ and Design Ground Acceleration (DGA) are extracted from synthetic signals generated from simulations of both source mechanism and wave propagation - thus duly justifying the seismogenic characteristics of the source and the physical properties interacting along the pathway.

The peak computational values have been plotted on a $0.2^{\circ} \times 0.2^{\circ}$ grid to construct the seismic hazard map of the study areas. The most severe hazard zone occurs within the epicentral area of the Mw 7.6 Muzaffarabad earthquakes of 2005 in Kashmir, which regionally affected Pakistan, India and Afghanistan - where the DGA estimate falls within the range of $0.6 \mathrm{~g}-1.2 \mathrm{~g}$. The peak velocity and displacement within the same grid region are estimated as $\mathrm{V}_{\mathrm{MAX}}=60$ $120 \mathrm{~cm} / \mathrm{s}$ and $D_{\text {MAX }}=30-60 \mathrm{~cm}$. In the other regions of high seismicity, such as Islamabad, capital of Pakistan, and in Quetta (site of the deadly Mw 7.71935 earthquake), estimates of DGA values are as high as DGA $\approx 0.3 \mathrm{~g}-$ 0.6 g. Similarly, the peak Velocity $\mathrm{V}_{\mathrm{MAX}}$ and Displacement $\mathrm{D}_{\mathrm{MAX}}$ are also high in these same earthquake-prone regions.

Since these estimated ground shaking values are definitely high for the existing infrastructure, they could result in great damage and huge socio-economic losses for the region, due to the high economic importance of these areas. This research and 
the data it has produced have substantially enhanced our understanding of the seismic hazard from these repeating large major earthquakes in Pakistan and the adjoining regions, e.g., the M 7.6 Muzaffarabad and M 7.8 Awaran earthquakes of 2005 and 2013; and we believe it will be of great help to civil and earthquake engineers, whom (because of the region's very high seismic risk) we hope will be eager to launch future thorough and detailed studies of regional earthquake hazard.

\subsection{Vietnam}

In Vietnam's capital city of Hanoi, results of NDSHA synthetic seismograms generated from scenario-based seismic hazard analysis (Nguyen et al., 2000) show that the largest potential MM macroseismic intensity $\left(\mathrm{I}_{\mathrm{MM}}\right)$ varies in a range between VI $\left(\mathrm{I}_{\mathrm{MM}}\right)$ - IX $\left(\mathrm{I}_{\mathrm{MM}}\right)$ : (a) acceleration spectral ratios reach largest values in the frequency range from 1.0 $3.0 \mathrm{~Hz}$; and (b) the largest site amplification effects are observed in loose soils and for thick sediment areas.

The generation of synthetic seismograms from scenario-based seismic hazard analysis is particularly important in those earthquake areas that may be lacking a catalogue record of both strong and major earthquake events, and it further provides realistic magnitudespecific earthquake input data that is required for the prediction of nonlinear dynamic response of structures under the potential suite of future earthquakes (Romanelli et al., 2013).

Therefore, the timely development of a set,of synthetic seismograms, both in the NDSHA and NDSHA-MCSI approximations, for the prediction of seismic response of structures in Vietnam (beginning with the more strategic ones), can be a productive future research effort, both reliably and effectively oriented towards prevention. In achieving this important goal, the pioneering work by: Cao et al. (2008b); Nguyen et al. (2008); Tuyen et al. (2012; 2018); Bisignano et al. (2011); Romanelli et al. (2012) - all represents not only a major contribution, but also a feasibility study for future international cooperation!

\section{Time-dependent earthquake hazard}

Although damaging earthquakes cannot yet be predicted with ultimate precision and accuracy, intermediate-term (several months) and middle-range (few 100s $\mathrm{km}$ scale) predictions of main shocks above a preassigned threshold - based on seismicity "alarms" generated by interpretive algorithms (Keilis-Borok and Soloviev, 2003; KeilisBorok, 2018) - may be properly used for the implementation of low-key preventive safety actions for affected at-risk populations.

Progressive reduction of the prediction uncertainty in both space-and-time is an ongoing and challenging task. Towards this aim, algorithms (like CN, M8 and M8S) based on objective recognition of seismicity patterns have been tested (already now for some decades) for: - intermediate-term - middlerange - prediction of strong earthquakes above a pre-assigned magnitude threshold (e.g. Peresan et al., 2005).

Through a retrospective analysis of both the 2012 Emilia sequence and also the 20162017 seismic crisis in Central Italy (Panza et al., 2018; Crespi et al., 2019), space-time precursory features have been already highlighted within both GPS ground velocities and instrumentally monitored seismicity. Overall, it is demonstrated now that the proper integration of both seismological and geodetic information can achieve what here is called intermediate-term-narrow-range - earthquake prediction. The extent of the alarmed areas, identified for the strong earthquakes by earthquake prediction algorithms based on seismicity patterns (e.g. Kossobokov and Shebalin, 2003), can be significantly reduced from linear dimensions of a few hundred to now a few tens of kilometers, leading to an improved and more specific implementation 
of low-key preventive actions, like those recommended by UNESCO as early as in 1991.

Therefore, then, a new paradigm is defined for time-dependent hazard scenarios, based on the results of - intermediate-term - narrowrange - earthquake prediction (Panza, 2019). In this precautionary framework, GPS data are systematically used to reconstruct the station velocities and strain patterns along preselected transects, which are properly oriented according to information about the known tectonic setting. The goal then (and plan now presently in progress), is: (a) to generalize and apply the "seismo-geodetic" analysis to the Italian territory and, consistently with the availability of reliable data; (b) to supply the identification of relatively narrow areas where we would expect the occurrence of a strong earthquake within a specified timeinterval, as indicated by Algorithms CN, M8 and M8S.

Some work has already been done so far in Vietnam regarding time-dependent hazard scenarios, as summarized in the paper by $\mathrm{Cao}$ et al. (2008a) that is echoing earlier works by Kossobokov in (2003) and (2004). Cao's work, along with this and the results mentioned previously in the section 7. Case studies: Cao et al. (2008b); Nguyen et al. (2008); Tuyen et al. (2012, 2018); Bisignano et al. (2011); Romanelli et al. (2012) together represent a feasibility study for a project that could be immediately begun in Vietnam, within the framework of international cooperation, like the joint project cooperation presently in progress in China under "Application research of the neodeterministic seismic risk assessment (NDSHA) method in China Seismic Experimental Site" -

http://www.ief.ac.cn/ylaw/index.html -

which is part of "China Seismic Experimental Site - Natural" - laboratory of earthquake science for seismic disaster resilience. Exchange and Collaboration: http://www.ief.ac.cn/home/index.html

\section{Discussion and Conclusion}

"Errors are not in the art but in the artificers"

- Issac Newton

Our world-wide experiences (expressed in terms of unacceptable losses) of now more than half-a-century of equating earthquake risk models with earthquake hazard (or likelihood of an earthquake) have proven unreliable and prompted the development of data driven hazard estimation to replace model driven PSHA.

Building upon the familiarity and long experience of successful practice with Deterministic Seismic Hazard Assessment, NDSHA, a robust and intrinsically data driven evaluation, now convolves a comprehensive physical knowledge of: (i) the seismic source process; (ii) the propagation of earthquake waves; and (iii) their combined interactions with site conditions - and thus effectively accounts for the tensor nature of earthquake ground motions.

By computationally using all available information about the spacial distribution of large Magnitude earthquake phenomena, including: (a) geological and geophysical data; and (b) Maximum Credible Earthquake (MCE) - Mdesign is set equal to the maximum observed or estimated magnitude Mmax (plus some multiple of its accepted global standard deviation $\sigma_{\mathrm{M}}$ ). NDSHA is a data driven assessment, since it does not rely on scalar empirical ground motion attenuation models GMPEs, as these are often both: (a) weakly constrained by available observations; and (b) fundamentally unable to account for the tensor nature of earthquake ground motions. Therefore, it provides both robust and safely conservative hazard estimates for engineering design and mitigation decision strategies. Importantly, these are broadly and systematically accomplished without invoking the chimeric (illusory) and physically rootless Hazard Curve: "annual frequency of 
earthquakes" and "earthquake return period" generally depicted as a "475 yr. earthquake" or the more rare " 2475 yr. earthquake."

The validity of NDSHA estimates of the last 20 years and the description of the perspective and planned activity is documented in the section 7. Case studies. A series of papers that reviews and updates the NDSHA research and the results obtained so far in Africa, America, Asia and Europe now provides a collection of evidences that hopefully will induce responsible people and authorities to consider more reliable procedures for SHA evaluation like NDSHA and is the topic of the forthcoming book "Earthquakes and Sustainable Infrastructure: neodeterministic (NDSHA) approach guarantees prevention rather than cure". Edited by Panza G., Kossobokov V., Laor E. and De Vivo B. for Elsevier (2021 in press).

\section{Nomenclature}

CE Characteristic Earthquake introduced to artificially justify the frequent exceptions to the log-linear GR law observed when considering study areas of limited extension.

$\mathrm{CN}$ Intermediate-term (several months) and middle-range (few $100 \mathrm{~s} \mathrm{~km}$ scale) interpretive algorithm to be used for the implementation of low-key preventive safety actions.

DGA Design Ground Acceleration.

GPS / GNSS Global Positioning System / Global Navigation Satellite System.

GR Gutenberg-Richter relation - valid as a log-linear law only at global scale.

$\mathrm{I}_{\mathrm{EMS}}$ European Macroseismic Intensity Scale issued in 1998

European macroseismic scale https://en.wikipedia.org/wiki/European_macro seismic_scale.

$\mathrm{I}_{\text {MAX }}$ Maximum observed macroseismic intensity - as a rule coincident with epicentral macroseismic intensity.

$\mathrm{I}_{\mathrm{MCS}}$ Macroseismic Intensity Scale as defined by Mercalli, Cancani and Sieberg; also indicated I(MCS).
$\mathrm{I}_{\mathrm{MM}}$ Modified Mercalli Macroseismic Intensity Scale - see also MM.

M Magnitude.

M Magnitude Threshold - lower magnitude bound for seismogenic nodes

M8 Intermediate-Term (several mos.) and Middle-Range (few $100 \mathrm{~s} \quad \mathrm{~km}$ scale) interpretive algorithm to be used for the implementation of low-key preventive safety actions.

$\mathrm{m}_{\mathrm{b}}$ body waves magnitude.

MCE Maximum Credible Earthquake.

$\mathbf{M}_{\text {design }}$ Cellular Magnitude at a given site tentatively set equal to the maximum observed or estimated earthquake magnitude $\mathrm{M}_{\max }+$ some multiple of its accepted global standard deviation $\sigma_{\mathrm{M}} \mid \mathrm{M}_{\text {design }}=\mathrm{M}_{\max }+\gamma_{\mathrm{EM}} \cdot \sigma_{\mathrm{M}}$.

MIBACT Ministero per i Beni e le Attività Culturali e per il Turismo, Italy.

MM Modified Mercalli Intensity scale (Wood and Neumann, 1931).

$\mathrm{M}_{\max }$ Maximum Observed or Estimated Earthquake Magnitude.

Ms Surface Waves Magnitude.

MSZ Morphostructural Zonation.

Mw Magnitude derived from Seismic Moment $\mathrm{M}_{0}$ acting at the fault.

NDSHA Neo-Deterministic Seismic Hazard Assessment.

NDSHA-MCSI (or more simply MCSI) NDSHA Maximum Credible Seismic Input can be defined (both at bedrock and considering site specific characteristics) as RS; or as a set of Accelerograms .

$P$ "Annual Probability of Exceedance".

PGA Peak Ground Acceleration.

PGD Peak Ground Displacement.

PGV Peak Ground Velocity.

PSA Pseudospectral Acceleration.

PSHA Probabilistic Seismic Hazard Analysis /Assessment.

RS Response Spectrum.

SA Spectral Acceleration.

Sd Spectral displacement.

SHA Seismic Hazard Assessment.

Vs30 Average Seismic Shear-Wave 
Velocity from the surface to a depth of 30 meters.

$\gamma_{\mathrm{EM}}$ Tunable Safety Factor related to the partial factor $\gamma_{\mathrm{q}}$; in standard practice for the so-called "ultimate limit states", and for typical actions like those of wind or snow, $\gamma_{\mathrm{q}}$ $=1.5$. See $\mathrm{M}_{\text {design }}$ above.

$\gamma_{\mathrm{q}}$ Currently accepted Safety Factor (Eurocode Paradigm), in order to get the design value for variable actions, applied to the characteristic value of an action $\mathrm{Q}_{\mathrm{k}}$, so that the design value applied for the action is $\mathrm{Q}_{\mathrm{d}}=\gamma_{\mathrm{q}} \mathrm{Q}_{\mathrm{k}}$.

$\sigma_{\mathrm{M}}$ Standard Deviation of Magnitude at global scale.

\section{References}

Abers G.A., 2020. Subduction Zones. In: Gupta H. (Ed) Encyclopedia of Solid Earth Geophysics. Encyclopedia of Earth Sciences Series. Springer, Cham. First online: 22 January 2020. https://doi.org/10.1007/978-3-030-10475-7.

Adams C., 2002. The Vision of Buckminster Fuller. Spirit of Ma'at: "Living Off the Grid" - Vol. 2, April 2002. https://spiritofmaat.com/archive/apr2/bucky.htm.

Aki K., 2003. A perspective on the history of Strong Motion Seismology. Phys. Earth Planet. Int., 137(1-4), 5-11. https://doi.org/10.1016/S0031-9201(03)00004-9.

Aki K., Richards P.G., 2002. Quantitative Seismology. University Science Books, Sausalito, CA, USA. ISBN 978-0935702965.

https://www.ldeo.columbia.edu/ richards/Aki_Richa rds.html.

Al-Hussaini T., Chakraborty S., Chowdhury I.N., Vaccari F., Romanelli F., Magrin A., Panza G.F., 2017. Neo-Deterministic seismic hazard assessment research programs for Bangladesh. Proc. International Conference on Disaster Risk Mitigation Sept. 23-24, Dhaka, Bangladesh, pp.5. https://www.researchgate.net/publication/327940490

Alvarado L., Rojas O., Carrasco-Jimenez J.C., Schmitz M., Rendon H., Alvarez L., 2020. Clustering of the synthetic response spectra of sh waves for barquisimeto and cabudare cities using machine learning techniques. Revista Facultad de Ingeniería 34(1).

http://saber.ucv.ve/ojs/index.php/rev_fiucv/article/vi ew/19296.

https://www.researchgate.net/publication/343351106 _Agrupamiento_de_los_espectros_de_respuesta_sint eticos_para_las_ondas_SH_en_las_ciudades_de_Bar quisimeto_y_Cabudare_usando_tecnicas_de_aprend izaje_automatico.

Alvarez L., Garcia J., Vaccari F., Panza G.F., Gonzalez B., Reyes C., Fernandez B., Pico R., Zapata J.A., Arango E., 2004. Ground Motion Zoning of Santiago de Cuba: An Approach by SH Waves Modelling. Pure Appl. Geophys, 161, 1041-1059. https://doi.org/10.1007/s00024-003-2500-3.

Alvarez L., Panza G.F., Vaccari F., Gonzalez B.E., 2001. Modelling of Seismic Ground motion in Santiago de Cuba City from Earthquakes in Oriente Fault Seismic Zone. Pure Appl. Geophys, 158, 17631782. https://doi.org/10.1007/PL00001242.

Alvarez L., Vaccari F., Panza G.F., Pico R., 2005. Seismic microzoning from synthetic ground motion parameters: case study, Santiago de Cuba. Soil Dynamics and Earthquake Engineering, 25, 383-401. https://doi.org/10.1016/j.soildyn.2005.02.006.

Ambraseys N., 1974. Notes on engineering seismology. In J. Solnes (Ed) Engineering Seismology and Earthquake Engineering, NATO Advanced study, 33-54. ISBN 978-94-011-7576-0.

https://www.springer.com/gp/book/9789401175760.

Anderson J.G., Brune J.N., 1998. "Non-ergodic probabilistic seismic hazard analysis (abstract)", 1998 SSA Annual Meeting Mar. 16-18, 1998, Boulder, CO. Seis. Res. Lett., 69(2), 171-172. https://doi.org/10.1785/gssrl.69.2.127sr1069002_012 7.pdf (silverchair.com).

Bak P., Christensen K., Danon L., Scanlon T., 2002. Unified Scaling Law for Earthquakes. Phys. Rev. Lett., 88, 178501-178504. https://doi.org/10.1103/PhysRevLett.88.178501; Erratum Phys. Rev. Lett. 90, 109901 (2003).

Bard P.-Y., 1997. Local effects on strong ground motion: basic physical phenomena and estimation methods for microzoning studies. In SERINA Seismic Risk: An Integrated Seismological, Geotechnical and Structural Approach. ITSAK 
(Ed.), Proceedings of the Advanced Study Course on Seismic Risk, 21-27 Sept. 1997, in Thessaloniki, Greece, 229-299.

https://www.researchgate.net/publication/235623266 _Local_effects_of_strong_ground_motion_Basic_ph ysical_phenomena_and_estimation_methods_for_mi crozoning_studies.

Båth M., 1973. Introduction to Seismology, John Wiley, New York, pp. 395. ISBN: 978-0470056608.

Båth M., 1979. Introduction to Seismology, Springer, Basel AG, pp. 394. ISBN 978-3764309565. https://www.springer.com/gp/book/9783034852852.

Båth M., 1981. Earthquake magnitude - recent research and current trends. Earth-Science Reviews, 17(4), 315-398. ISSN 0012-8252, https://doi.org/10.1016/0012-8252(81)90014-3.

Bela J., 2014. Too generous to a fault? Is reliable earthquake safety a lost art? Errors in expected human losses due to incorrect seismic hazard estimates. Earth's Future, 2, 569-578. https://doi.org/10.1002/2013EF000225.

AGU, 2014 Science Policy Conference - ePoster: https://agu.confex.com/agu/spc2014/webprogram/Pa per1558.html.

Bertero V.V., 1996. State-of-the-art repoirt on: design criteria. Proc. 11WCEE, Acapulco, Mexico, June. Elsevier Science Lt. Osford, UK, pp.16. ISBN: 008 0428223.

https://www.iitk.ac.in/nicee/wcee/article/11_2005.P DF.

Bertero R.D., Vaquero S., Mussat J.M., Bertero A., 2018. Seismic hazard in Buenos Aires, Argentina: A preliminary study on the effects of long-distance earthquakes on tall buildings. Earthquake Engng. Struct. Dyn., 47, 2333-2339. https://doi.org/10.1002/eqe.3052.

Bhatia S.C., Chetty T.R.K., Filimonov M., Gorshkov A., Rantsman E., Rao M.N., 1992. Identification of potential areas for the occurrence of strong earthquakes in Himalayan Arc Region. Proc. Indian Acad. Sci. (Earth Planet. Sci), 101, 369-385. https://doi.org/10.1007/BF02893012.

Bilham R., 2009. The seismic future of cities. Bull. Earthquake Eng., 7, 839-887. https://doi.org/10.1007/s10518-009-9147-0.

Bisignano D., Romanelli F., Peresan A., 2011. Modeling scenarios of earthquake-generated tsunamis for
Vietnam coasts. Proceedings of The International Symposium on Grids and Clouds and the Open Grid Forum, Academia Sinica, Proceedings of Science. Taipei, Taiwan - March 19-25, pp.10. https://pos.sissa.it/133/078/pdf.

Blume J.A., 1965. Earthquake ground motion and engineering procedures for important installations near active faults. Proc. Third World Conf. on Eq. Engr. (New Zealand), IV-53.

https://www.iitk.ac.in/nicee/wcee/article/vol3_IV53.pdf.

Bodin P., 2020. Seismicity, Intraplate. In: Gupta H. (Ed) Encyclopedia of Solid Earth Geophysics. Encyclopedia of Earth Sciences Series. Springer, Cham. First online: 29 December 2019. https://doi.org/10.1007/978-3-030-10475-7_162-1.

Boore D. 2004a. Estimating Vs(30) (or NEHRP Site Classes) from Shallow Velocity Models (Depths30 m). Bull. Seismol. Soc. Am., 94, 591-597.

Boore D.M., 2004b. Can site response be predicted? Journal of Earthquake Engineering, 8(SI1), 1-41. https://doi.org/10.1080/13632460409350520. http://www.daveboore.com/pubs_online/rose_keyno te_jee_2004.pdf.

Bormann P., 2020. Earthquake, Magnitude. In: Gupta H. (Ed) Encyclopedia of Solid Earth Geophysics. Encyclopedia of Earth Sciences Series. Springer, Cham. First online: 18 December 2019. https://doi.org/10.1007/978-3-030-10475-7_3-1.

Boyadzhiev G., Brandmayr E., Pinat T., Panza G.F., 2008. Optimization for non-linear inverse problems. Rendiconti Lincei, 19, 17-43. https://doi.org/10.1007/s12210-008-0002-z.

Brandmayr E., Raykova R., Zuri M., Romanelli F., Doglioni C., Panza G.F., 2010. The lithosphere in Italy: Structure and seismicity. In: M. Beltrando, A. Peccerillo, M. Mattei, S. Conticelli and C. Doglioni (Eds.), The Geology of Italy, Journal of the Virtual Explorer, Electronic Edition, 36, paper 1, ISSN: 1441-8142.

https://virtualexplorer.com.au/article/2010/224/lithos phere-structure-seismicity/index.html. https://doi.org/10.3809/jvirtex.2010.00224.

Brûlé S., Enoch S., Guenneau S., 2020. Emergence of seismic metamaterials: Current state and future perspectives, Physics Letters, A, 384(1), 126034. Part of SI: Physics Letters A - Perspective articles. 


\section{J. Bela, G.F. Panza/Vietnam Journal of Earth Sciences 43(2021)}

ISSN:0375-9601.

https://doi.org/10.1016/j.physleta.2019.126034

Physics Letters A | Physics Letters A - Perspective articles ScienceDirect.com by Elsevier. https://arxiv.org/ftp/arxiv/papers/17 12/1712.09115.pdf.

Cancani A., 1904. Sur l'emploi d'une double échelle sismique des intensités, empirique et absolue. In Verh. II. Internat. Seismol. Konf. zu Straßburg, 2428 July 1903, Gerlands Beiträge zur Geophysik, 2, 281-283.

Nguyen Hong Phuong, Cao Dinh Trieu, F. Romanelli, F. Vaccari, 2008. Realistic estimation of seismic ground motion in Hanoi city using synthetic seismograms. Dept. Geology \& Minerals of Vietnam Journal of Geology, Series B, 31-32, 181-191. http://www.idm.gov.vn/111P59N178PI1T/enUS/Chi-Tiet-Linh-Vuc/Center-for-Information-andArchives-of-Geology.aspx. Center for Information \& Archives of Geology (idm.gov.vn).

Cao Dinh Trieu, G.F. Panza, A. Peresan, F. Vaccari, F. Romanelli, Nguyen Huu Tuyen, Pham Nam Hung, Le Van Dung, Mai Xuan Bach, Cao Dinh Trong, 2008b. Seismic hazard assessment of Viet Nam territory on the basis of deterministic approach. Dept. Geology \& Minerals of Vietnam Journal of GEOLOGY, Series B(31-32), 220-230.

https://www.researchgate.net/publication/335339914 _seismic_hazard_assessment_of_viet_nam_terrttory _on_the_basis_of_deterministic_approach.

Cao Dinh Trieu, G.F. Panza, A. Peresan, F. Vaccari, F. Romanelli, Nguyen Huu Tuyen, Pham Nam Hung, Le Van Dung, Mai Xuan Bach, Thai Anh Tuan, Cao Dinh Trong, 2008a. Some new outcomes of the intermediate term earthquake prediction in Vietnam. Dept. Geology \& Minerals of Vietnam Journal of Geology Series, B(31-32), 231-240. https://www.researchgate.net/publication/335338403 _some_new_outcomes_of_the_intermediate_term_e arthquake_prediction_in_Vie't_nam.

Caprio M., Tarigan B., Worden B., Wiemer S., Wald D.J., 2015. Ground motion to intensity conversion equations (GMICEs): a global relationship and evaluation of regional dependency. Bull. Seis. Soc. Am. 105(3), 1476-1490. https://doi.org/10.1785/0120140286.
Caputo M., Keilis-Borok V., Kronrod T., Molchan G., Panza G.F., Piva A., Podgaetskaja V., Postpischl D., 1973. Models of earthquake occurrence and isoseismals in Italy. Ann. Geofis., 26, 421-444. https://www.annales-geophysicae.net/. https://www.researchgate.net/publication/287114042 _Models_of_earthquake_occurrence_and_isoseismal s_in_Italy.

Caputo M., Keilis-Borok V.I., Kronrod T.I., Molchan G.M., Panza G.F., Piva A., Podgaetskaja V.M., Postpischl D., 1974. The estimation of seismic risk for central Italy. Ann. Geofis., 27(1-2), 349-365. https://doi.org/10.4401/ag-4928.

Caputo M., Keilis-Borok V.I., Kronrod T.L., Molchan G.M., Panza G., Piva A., Podgaezkaya V.M., Postpischl D., 1973. Seismic risk on the territory of Central Italy. In: Keilis-Borok, V.I. (Ed) Computational and Statistical Methods for Interpretation of Seismic Data (Computational Seismology), Nauka, Moscow, 6, 67-106 (in Russian).

Caputo M., Keilis-Borok V., Oficerova E., Ranzman E., Rotwain I. and Solovjeff A., 1980. Pattern recognition of earthquake-prone areas in Italy. Phys. Earth Planet. Int., 21(4), 305-320. https://doi.org/10.1016/0031-9201(80)90135-1.

Cara M., Alasset P.J., Sira C., 2008. Magnitude of Historical Earthquakes, from Macroseismic Data to Seismic Waveform Modelling: Application to the Pyrenees and a 1905 Earthquake in the Alps. In: Fréchet J., Meghraoui M., Stucchi M. (Eds) Historical Seismology. Modern Approaches in Solid Earth Sciences, Springer, Dordrecht, 2, 369-384. ISBNe: 978-1-4020-8222-1. https://doi.org/10.1007/978-1-4020-8222-1_18.

Carlson J.M., 1991. Time intervals between characteristic earthquakes and correlations with smaller events: An analysis based on a mechanical model of a fault. JGR: Solid Earth, 96(B3), 42554267. https://doi.org/10.1029/90JB02474.

Castanos H., Lomnitz C., 2002. "PSHA: is it science?" Engineering Geology, 66(3-4), 315-317. https://doi.org/10.1016/S0013-7952(02)00039-X.

Celebi M., Ghahari S.F., Haddadi H., Taciroglu E., 2020. Response study of the tallest California building inferred from the Mw7.1 Ridgecrest, California earthquake of 5 July 2019 and ambient 
Vietnam Journal of Earth Sciences, 43(2), 111-188

motions, Earthquake Spectra, 36(3), 1096-1118. https://doi.org/10.1177/8755293020906836.

CEN EN-1990, 2002. https://www.phd.eng.br/wpcontent/uploads/2015/12/en.1990.2002.pdf. https://standards.iteh.ai/catalog/standards/cen/be4b0 5f7-4c56-4e2e-a88d-56fce873fcbc/en-1990-2002.

Chakraborty S., 2017. Neo-Deterministic Studies for Scenario Earthquakes in Bangladesh. B.Sc. Engr. Thesis, Department of Civil Engineering, Bangladesh University of Engineering and Technology, Dhaka.

Chen Y., Liu M., Luo G., 2020. Complex Temporal Patterns of Large Earthquakes: Devil's Staircases. Bull. Seismol. Soc. Am. 110(3), 1064-1076. https://doi.org/10.1785/0120190148.

Chiou P., Miao W., 2013. The distribution of annual maximum earthquake magnitude in Southern California. Journal of Probability and Statistical Science, 11(2), 199-210.

https://www.researchgate.net/publication/259970636 _The_Distribution_of_Annual_Maximum_Earthqua ke_Magnitude_in_Southern_California.

Chunga K., Michetti A., Gorshkov A., Panza G.F., Soloviev A., Martillo C., 2010. Identificacion de nudos sismogenicos capaces de generar potenciales terremotos de M>6 y M>6.5 en la Región costera y cadenas montanosas de los Andes Septentrionales del Ecuador. Revista ESPOL-RTE, 23(3), 61-89 (in Spanish).

https://www.researchgate.net/publication/251236551 _Identificacion_de_nudos_sismogenicos_capaces_d e_generar_potenciales_terremotos_de_M6_y_M65_ en_la_Region_costera_y_cadenas_montanosas_de_1 os_Andes_Septentrionales_del_Ecuador.

Cimellaro G.P., Reinhorn A.M., D'Ambrisi A., De Stefano M., 2011. Fragility analysis and seismic record selection. J. Struct. Eng., 137(3), 379-390. https://doi.org/10.1061/(ASCE)ST.1943541X.0000115.

Cimellaro G.P., Tinebra A., Renschler C., Fragiadakis M., 2015. New Resilience Index for Urban Water Distribution Networks. J. Struct. Eng., 142(8), C4015014. https://doi.org/10.1061/(ASCE)ST.1943541X.0001433.

Cilia M., Mooney W., Robinson A., 2017. Earthquake and Tsunami, and a Comparison with Strong-Motion Data. Seis. Res. Lett., 88(5), 1232-1240. https://doi.org/10.1785/0220170030.

Cilia M.G., Baker L.M., 2015, 2018. Abstract: Empirical relationships between instrumental ground motions and observed intensities for two great Chilean subduction zone earthquakes. AGU Fall Meeting, Dec. 14-18, 2018, San Francisco, CA. https://agu.confex.com/agu/fm15/meetingapp.cgi/Pa per/65471.

https://www.seismosoc.org/wpcontent/uploads/2018/06/SSA_2018_Poster_Final.pdf

Cisternas A., Godefroy P., Gvishiani A., Gorshkov A., Kossobokov V., Lambert M., Rantsman E., Sallantin J., Saldano H., Soloviev A., Weber C., 1985. A dual approach to recognition of Earthquake Prone-Areas in the Western Alps. Ann. Geophys, 3(2), 249-270. https://www.researchgate.net/scientificcontributions/Weber-C-2005477307.

Cisternas M., Carvajal M., Wesson R., Ely L.L., Gorigoitia N., 2017. "Exploring the Historical Earthquakes Preceding the Giant 1960 Chile Earthquake in a Time-Dependent Seismogenic Zone.” Bull. Seismol. Soc. Am., 107(6), 2664-2675. https://doi.org/10.1785/0120170103.

Clemente-Chavez A., Zúñiga F.R., Lermo J., FigueroaSoto A., Valdés C., Montiel M., Chavez O., Arroyo M., 2014. On the behavior of site effects in central Mexico (the Mexican volcanic belt - MVB), based on records of shallow earthquakes that occurred in the zone between 1998 and 2011. Nat. Hazards Earth Syst. Sci., 14(6), 1391-1406. https://doi.org/10.5194/nhess-14-1391-2014.

Cornell C.A., 1968. Engineering seismic risk analysis. Bull. Seismol. Soc. Am., 58, 1583-1606. (Received 2 Jan. 1967, Published 1 Oct. 1968) https://pubs.geoscienceworld.org/ssa/bssa/article/58/ 5/1583/116673/engineering-seismic-risk-analysis.

CPTI Working Group, 2004. Parametric Catalog of Italian Earthquakes (CPTI04). National Institute of Geophysics and Volcanology (INGV). https://doi.org/10.6092/INGV.IT-CPTI04. https://emidius.mi.ingv.it/CPTI04/.

CPTI Working Group, 2015. Italian Parametric Earthquake Catalogue (CPTI15) - cited as Rovida A., Locati M., Camassi R., Lolli B., Gasperini P. (eds) (2019) Italian Parametric Earthquake Catalogue (CPTI15), version 2.0. Istituto Nazionale di Geofisica e Vulcanologia (INGV). 
https://doi.org/10.13127/CPTI/CPTI15.2.

Rovida A., et al., 2020. The Italian earthquake catalogue. CPTI15. Bull Earthquake Eng., 18, 2953-2984.

https://doi.org/10.1007/s10518-020-00818-y.

Craig T.J., Calais E., Fleitout L., Bollinger L., Scotti O., 2016. Evidence for the release of long - term tectonic strain stored in continental interiors through intra-plate earthquakes. Geophys. Res. Lett. 43, 6826-6836. https://doi.org/10.1002/2016GL069359. https://agupubs.onlinelibrary.wiley.com/doi/10.1002 /2016GL069359.

Crespi M., Kossobokov V., Panza G.F., Peresan A., 2019. Space-Time Precursory Features within Ground Velocities and Seismicity in North-Central Italy. Pure Appl. Geophys.

https://doi.org/10.1007/s00024-019-02297-y.

D’Amico V., Albarello D., Mantovani E., 1999. A distribution-free analysis of magnitude-intensity relationships: an application to the Mediterranean region. Physics and Chemistry of the Earth, Part A: Solid Earth and Geodesy, 24(6), 517-521. https://doi.org/10.1016/S1464-1895(99)00064-2.

Dal Moro G., Alarif N., Moustafa S.R., 2019. On the efficient acquisition and holistic analysis of Rayleigh waves: Technical aspects and two comparative case studies. Soil Dynamics and Earthquake Engineering, 125, 105742. https://doi.org/10.1016/j.soildyn.2019.105742.

Danciu L., Giardini D., 2015. Global Seismic Hazard Assessment Program - GSHAP legacy. Annals Geophys. 58(1) S0109, pp.9. https://doi.org/10.4401/ag-6734.

Das S., 2019. Earthquake Rupture: The Inverse Problem. In: Gupta H. (Ed) Encyclopedia of Solid Earth Geophysics. Encyclopedia of Earth Sciences Series. Springer, Cham. First online: 23 August 2020. https://doi.org/10.1007/978-3-030-10475-7_142-1.

Decanini L., Gavarini C.E., Mollaioli F., 1995. Proposta di definizione delle relazioni tra intensita' macrosismica e parametri del moto del suolo, Atti 70 Convegno L'ingegnaria sismica in Italia, 1, 63-72.

De Ferrari R., Ferretti G., Barani S., Spallarossa D., 2010. Investigating on the 1920 Garfagnana earthquake $(\mathrm{Mw}=6.5)$ : Evidences of site effects in Villa Collemandina (Tuscany, Italy). Soil Dynamics and Earthquake Engineering, 30(12), 1417-1429. https://doi.org/10.1016/j.soildyn.2010.07.004.

De Natale G., Petrazzuoli S., Romanelli F., Troise C., Vaccari F., Somma R., Peresan A., Panza G.F., 2019. Seismic risk mitigation at Ischia island (Naples, Southern Italy): an innovative approach to prevent catastrophic scenarios. Engineering Geology, 261, 105285. https://doi.org/10.1016/j.enggeo.2019.105285.

Deng Y., Zhang Z., Romanelli F., Ma T., Doglioni C., Wang P., Zhang X., Teng J., Panza G.F., 2014. Transition from continental collision to tectonic escape: a geophysical perspective on lateral expansion of the northern Tibetan Plateau. Earth, Planets and Space, 1-12, ISSN: 1880-5981. https://doi.org/10.1186/1880-5981-66-10.

Ding Z., Chen Y.T., Panza G.F., 2004b. Estimation of Site Effects in Beijing City. Pure Appl. Geophys., 161, 1107-1123. https://doi.org/10.1007/s00024003-2495-9.

Ding Z., Romanelli F., Chen Y.T., Panza G.F., 2004a. Realistic Modeling of Seismic Wave Ground Motion in Beijing City. Pure Appl. Geophys., 161, 10931106. https://doi.org/10.1007/s00024-003-2498-6.

Doglioni C., Carminati E., Petricca, Riguzzi F., 2015. Normal fault earthquakes or graviquakes. Nature: Scientific Reports, 5(12110), 1-12. https://doi.org/10.1038/srep12110.

Douglas J., 2020. Ground motion prediction equations 1964-2020. Dept. Civil Environ. Eng., Univ Strathclyde, Glaskow, UK, pp. 670. http://www.gmpe.org.uk/gmpereport2014.pdf

Dravinski M., Ding G., Wen K.-L., 1996. Analysis of spectral ratios for estimating ground motion in deep basins. Bull. Seism. Soc. Am., 86(3), 646-654. https://pubs.geoscienceworld.org/ssa/bssa/article/86/ 3/646/120084/Analysis-of-spectral-ratios-forestimating-ground.

EC8 (1993, 2008) Eurocode 8: Structures in Seismic Regions - Design - Part 1 General and Building. EC8/EN 1998, Doc. TC250/SC8/N57A. https://eurocodes.jrc.ec.europa.eu/showpage.php?id= 138. https://www.techstreet.com/standards/bs-en1998-1-2004?product_id=1213749\#jumps. https://eurocodes.jrc.ec.europa.eu/doc/EUR23563E N.pdf. 
Egan T., 1989. Building Codes: Designs for Last Quake, Not Next. - Special to The New York Times, Published: October 22, 1989. https://www.nytimes.com/1989/10/22/us/buildingcodes-designs-for-last-quake-not-next.html.

ElGabry M.N., Hassan H.M., 2021. Updated Seismic Input for Next Generation of the Egyptian Building Code. In: Shehata H. and Badr M. (Eds) Sustainable Issues in Infrastructure Engineering. Sustainable Civil Infrastructures SUCI Book Series. SSIGE Official Publications 2020: Part 2. Proc. GeoMEast 2020 International Congress, Cairo, Egypt November 8-12, 2020. Springer, Cham, 55-79. pp.225.

https://www.springerprofessional.de/en/sustainableissues-in-infrastructure-engineering/18654490.

https://www.issmge.org/events/sustainable-civilinfrastructures 1 .

ElGabry M., Hassan H.M., Vaccari F., Magrin A., Romanelli F., Panza G., 2021. Seismic Site Response Characterization for Suez Canal Region, Egypt. In Shehata H. and Badr M. (Eds) Advancements in Geotechnical Engineering. Sustainable Civil Infrastructures SUCI Book Series. SSIGE Official Publications 2020: Part 1. Proc. GeoMEast 2020 International, Congress, Cairo, Egypt November 8-12, 2020. Springer, Cham, 59-78, pp.338. https://doi.org/10.1007/978-3-03062908-3_5.

El-Sayed A., Vaccari F., Panza G.F., 2001. Deterministic seismic hazard in Egypt. Geophys. J. Int., 144(3), 555-567.

https://doi.org/10.1046/j.1365-246x.2001.01372.x.

EMS-98, 1998. European Macroseismic Scale 1998 (EMS-98). Grünthal G. (ed) Cahiers du Centre Européen de Géodynamique et de Séismologie 15, Centre Européen de Géodynamique et de Séismologie, Luxembourg, pp.99. ISBN: 2-87977-008-4.

https://www.gfz-potsdam.de/en/section/seismichazard-and-risk-dynamics/data-productsservices/ems-98-european-macroseismic-scale/.

Fasan M., Magrin A., Amadio C., Romanelli F., Vaccari F., Panza G.F., 2016. A seismological and engineering perspective on the 2016 Central Italy earthquakes. Int. J. Earthquake and Impact
Engineering, 1(4), 395-420. ISSN-online: 23979380. https://doi.org/10.1504/IJEIE.2016.083253.

FEMA P-749, 2010. "Earthquake-Resistant Design Concepts: An Introduction to the [2009 Edition] NEHRP Recommended Seismic Provisions for New Buildings and Other Structures" - A Companion Guide to the 2009 Edition of the NEHRP Recommended Seismic Provisions for New Buildings and Other Structures (FEMA P-750), by Hamburger, R. and Mahoney, M., Prepared for the Federal Emergency Management Agency FEMA of the U. S. Department of Homeland Security by the National Institute of Building Sciences Building Seismic Safety Council BSSC, DC, USA, pp.110. https://www.fema.gov/media-librarydata/20130726-1759-25045-5477/fema_p_749.pdf.

FEMA 65, 2005. Federal Guidelines for Dam Safety: Earthquake Analyses and Design of Dams, May 2005, pp.45, Appendices A-C: pp.26.

https://www.ferc.gov/sites/default/files/202004/fema-65.pdf.

Ferraes S.G., 1967. Test of Poisson process for earthquakes in Mexico City. J. Geophys Res., 72(14), 3741-3742. 06 Dec. 2012 online. https://doi.org/10.1029/JZ072i014p03741.

Field E.H., 1996. Spectral amplification in a sedimentfilled valley exhibiting clear basin-edge-induced waves. Bull. Seism. Soc. Am., 86(4), 991-1005. https://pubs.geoscienceworld.org/ssa/bssa/article/86/ 4/991/120109/Spectral-amplification-in-a-sedimentfilled-Valley.

Field E.H., Jacob K.H., 1995. A comparison and test of various site-response estimation techniques, including three that are not reference-site dependent. Bull. Seism. Soc. Am., 85(4), 1127-1143. https://pubs.geoscienceworld.org/ssa/bssa/article/85/ 4/1127/102625/A-comparison-and-test-of-varioussite-response.

Field E.H. and the SCEC Phase III Working Group, 2000. Accounting for Site Effects in Probabilistic Seismic Hazard Analyses of Southern California: Overview of the SCEC Phase III Report. Bull. Seismol. Soc. Am., 90(6B), S1-S31. https://doi.org/10.1785/0120000512.

Field E.H., Jackson D.D., Dolan J.F., 1999. A mutually consistent seismic-hazard source model for Southern 


\section{J. Bela, G.F. Panza/Vietnam Journal of Earth Sciences 43(2021)}

California. Bulletin of the Seismological Society of America, 89(3), 559-578.

https://www.semanticscholar.org/paper/A-mutuallyconsistent-seismic-hazard-source-model-FieldJackson/42bf39ca891784cc0b92a25a59d3c03306ee $281 b$.

Foulger G.R., Wilson M.P., Gluyas J.G., Julian B.R., Davies R.J., 2018. Global review of human-induced earthquakes. Earth-Science Reviews, 178, 438-514. https://doi.org/10.1016/j.earscirev.2017.07.008.

Fracassi U., Valensise G., 2007. Unveiling the sources of the catastrophic 1456 multiple earthquake: Hints to an unexplored tectonic mechanism in Southern Italy. Bull. Seism. Soc. Am., 97(3), 725-748. https://doi.org/10.1785/0120050250.

Freymueller J.T., 2020. GPS, Tectonic Geodesy. In: Gupta H. (Ed) Encyclopedia of Solid Earth Geophysics. Encyclopedia of Earth Sciences Series. Springer, Cham. First online: 05 December 2019. https://doi.org/10.1007/978-3-030-10475-7_77-1.

Furuya M., 2020. SAR Interferometry. In: Gupta H.K. (Ed) Encyclopedia of Solid Earth Geophysics. Encyclopedia of Earth Sciences Series. Springer, Cham. First online: 08 September 2020. https://doi.org/10.1007/978-3-030-10475-7_97-2.

Gelfand I.M., Guberman S., Keilis-Borok V.I., Knopoff L., Press F., Ranzman E. Ya, Rotwain I.M., Sadovsky A.M., 1976. Pattern recognition applied to earthquake epicenters in California. Phys. Earth Planet. Int., 11(3), 227-283. https://doi.org/10.1016/0031-9201(76)90067-4.

Gelfand I.M., Guberman Sh.I., Izvekova M., KeilisBorok V.I., Rantsman E.Ja., 1972. Criteria of high seismicity determined by pattern recognition. In: A.R. Ritsema (Ed), The Upper Mantle. Developments in Geotectonics, 13(4), 415-422. https://doi.org/10.1016/B978-0-444-41015-3.50028-8.

Gelfand I.M., Guberman Sh.A., Zhidkov M.P., Kaletzkaya M.S., Keilis-Borok V.I., Ranzman E.Ya., Rotwain I.M., 1974a. Recognition of Earthquake-Prone Areas. II. Four regions of Minor Asia and South-Eastern Europe. In: Keilis-Borok V.I. (ed), Computer Analysis of Digital Seismic Data, Computational Seismology, 7, 3-40, Nauka, Moscow (in Russian).

Gelfand I.M., Guberman Sh.A., Zhidkov M.P., KeilisBorok V.I., Ranzman E.Ya., Rotwain I.M., 1974b.
Recognition of Earthquake-Prone Areas. III. Disjunctive nodes with unknown boundaries. In: Keilis-Borok V.I. (ed), Computer Analysis of Digital Seismic Data, Computational Seismology, 7, 41-64, Nauka, Moscow (in Russian).

Geller R.J., Mulargia F., Stark P.B., 2016. "Why we need a new paradigm of earthquake occurrence". In G. Morra, D.A. Yuen, S.D. King, S.-M. Lee and S. Stein (Eds.), Subduction Dynamics: From Mantle Flow to Mega Disasters, Geophysical Monograph, 211, American Geophysical Union, Washington, D.C., USA, 183-191. ISBN: 9781118888858. https://doi.org/10.1002/9781118888865.ch10.

Gerstenberger MC, Marzocchi W, Allen T, Pagani M, Adams J, Danciu L, et al., 2020. Probabilistic seismic hazard analysis at regional and national scales: State of the art and future challenges. Reviews of Geophysics, 58, e2019RG000653, pp 49. https://doi.org/10.1029/2019RG000653

Gholami V., Hamzehloo H., La Mura C., Ghayamghamian M.R., Panza G.F., 2014. Simulation of selected strong motion records of the $2003 \mathrm{Mw}=6.6 \mathrm{Bam}$ earthquake (SE Iran), the modal summation-ray tracing methods in the WKBJ approximation, Geophysical Journal International, 1 Feb. 2014, 196(2), 924-938 (Published 7 Nov. 2013). https://doi.org/10.1093/gji/ggt405.

Gholami V., La Mura C., Hamzehloo H., Panza G.F., 2012. 3- Dimensional Modal Summation simulation of $2003 \mathrm{Mw}=6.6$ Bam Earthquake South Eastern Iran. Proc. 15th World Conference on Earthquake Engineering. Lisbon, Portugal. 24-28 September 2012, pp.10.

https://www.iitk.ac.in/nicee/wcee/article/WCEE201 2_0602.pdf.

Gilbert G.K., 1909. Earthquake Forecasts. Presidential Address to the American Association of Geographers, read at Baltimore, Md., Jan. 1, 1909. Science, 29 (734), 121-136. https://doi.org/10.1126/science.29.734.121.

Godano C., Lippiello E., de Arcangelis L., 2014. Variability of the $b$ value in the Gutenberg-Richter distribution, Geophysical Journal International, 199(3), 1765-1771. https://doi.org/10.1093/gji/ggu359.

Gomez-Capera A.A., D’Amico M., Lanzano G., Locati M., Santulin M., 2020. Relationships between 
Vietnam Journal of Earth Sciences, 43(2), 111-188

ground motion parameters and macroseismic intensity for Italy. Bull Earthquake Eng., 18, 5143-5164.

https://doi.org/10.1007/s10518-020-00905-0.

Gonzalez O., Alvarez J.L., Moreno B., Panza G.F., 2012a. S-Wave Velocities of the LithosphereAsthenosphere System in the Caribbean Region. Pure Appl. Geophys., 169, 101-122. https://doi.org/10.1007/s00024-011-0321-3.

Gonzalez O., Alvarez L., Guidarelli M., Panza G.F., 2007. Crust and Upper Mantle Structure in the Caribbean Region by Group Velocity Tomography and Regionalization. Pure Appl. Geophys., 164(10), 1985-2007. https://doi.org/10.1007/s00024-007-0259-7.

Gonzalez O., Clouard V., Tait S., Panza G.F., 2018. Swave velocities of the lithosphere-asthenosphere system in the Lesser Antilles from the joint inversion of surface wave dispersion and receiver function analysis. Tectonophysics, 734-735, 1-15. https://doi.org/10.1016/j.tecto.2018.03.021.

Gonzalez O., Moreno B., Romanelli F., Panza G.F., 2012b. Lithospheric structure below seismic stations in Cuba from the joint inversion of Rayleigh surface waves dispersion and receiver functions. Geophysical Journal International, 189(2), 1047-1059. https://doi.org/10.1111/j.1365-246X.2012.05410.x.

Gorshkov A.I., Novikova O., 2018. Estimating the validity of the recognition results of EarthquakeProne Areas using the ArcMap. Acta Geophysica, 66, 843-853. ISSN: 1895-7455. https://doi.org/10.1007/s11600-018-0177-3.

Gorshkov A.I., Hassan H.M., Novikova O., 2018. Seismogenic Nodes $(M \geq 5.0)$ in Northeast Egypt and Implications for Seismic Hazard Assessment. Pure Appl. Geophys., 176, 593-610. https://doi.org/10.1007/s00024-018-2012-9.

Gorshkov A.I., Kossobokov V., Soloviev A., 2003. Recognition of Earthquake-Prone Areas. In: KeilisBorok V.I., Soloviev A.A. (Eds), Nonlinear Dynamics of the Lithosphere and Earthquake Prediction Chpt., 6, 239-310, Springer Series in Synergetics. Springer-Verlag, BerlinHeidelberg. ISBN: 978-3-642-07806-4. https://www.springer.com/gp/book/9783540435280 \#. https://doi.org/10.1007/978-3-662-05298-3_6.
Gorshkov A.I., Kossobokov V.G., Rantsman E.Ya, Soloviev A.A., 2005. Recognition of EarthquakeProne Areas: Validity of Results Obtained from 1972 to 2000. In: Chowdhury D.K., Nyland, E., Odom, R., Sen, M., Keilis-Borok, V.I., Levshin, A.L., Molchan, G.M., Naimark, B.M. (Eds), Computational Seismology and Geodynamics, 7, 3744. AGU, Wash. DC, USA. Selected Papers From Volume 32 of Vychislitel'naya Seysmologiya. https://doi.org/10.1029/CS007p0037.

Gorshkov A.I., Kuznetsov I., Panza G.F., Soloviev A., 2000. Identification of future earthquake sources in the Carpatho-Balkan orogenic belt using morphostuctural criteria. Pure Appl. Geophys., 157, 79-95. https://doi.org/10.1007/PL00001101.

Gorshkov A.I., Mokhtari M., Piotrovskaya E., 2010. The Alborz region: identification of seismogenic nodes with morphostructural zoning and pattern recognition. J. Seismol. Earthquake Eng. Spring 2009, 1(1), 1-15

https://www.researchgate.net/publication/234841594_ 110_Gorshkov_A_Mokhtari_M_Piotrovskaya_E_201 0_The_Alborz_region_identification_of_seismogenic _nodes_with_morphostructural_zoning_and_pattern_r ecognition_JSEE_Vol1_No_1_Spring_2009_1-15.

Gorshkov A.I., Panza G.F., Soloviev A.A., Aoudia A., 2002. Morphostructural Zonation and preliminary recognition of seismogenic nodes around the Adria Margin in peninsular Italy and Sicily. J., Seismol. Earthquake Eng., 4(1), 1-24. https://www.sid.ir/en/journal/ViewPaper.aspx ?id=29 380.

Gorshkov A.I., Panza G.F., Soloviev A.A., Aoudia A., 2004. Identification of seismogenic nodes in the Alps and Dinarides. Bollettino della Società Geologica Italiana, 123, 3-18. https://www.researchgate.net/publication/234841610 _90_Gorshkov_AI_Panza_GF_Soloviev_AA_Aoudi a_A_2004_Identification_of_seismogenic_nodes_in _the_Alps_and_Dinarides_Bolletino_della_Societa_ Geologica_Italiana_123_3-18.

Gorshkov A.I., Soloviev A.A., Jiménez M.J., GarcíaFernández M., Panza G.F., 2010. Recognition of earthquake-prone areas $(\mathrm{M} \geq 5.0)$ in the Iberian Peninsula. Rendiconti Lincei - Scienze Fisiche e Naturali, 21, 131-162. https://doi.org/10.1007/s12210-010-0075-3. 
Gorshkov A.I., Zhidkov M., Rantsman E., Tumarkin A., 1991. Morphostructures of the Lesser Caucasus and locations of earthquakes, $M \geq 5.5$. Izvestyia USSR. Request PDF (researchgate.net).

Grünthal G. (ed), 1998. European Macroseismic Scale 1998 (EMS-98). Cahiers du Centre Européen de Géodynamique et de Séismologie 15, Centre Européen de Géodynamique et de Séismologie, Luxembourg. ISBN: 2-87977-008-4.

https://www.gfz-potsdam.de/en/section/seismichazard-and-risk-dynamics/data-productsservices/ems-98-european-macroseismic-scale/.

Grünthal G., 2004. The history of historical earthquake research in Germany. Annals of geophysics = Annali di geofisica, 47(2-3), 631-643. https://doi.org/10.4401/ag-3328.

Grünthal G., Musson R.M.W., 2020. Earthquakes, Intensity. In: Gupta H. (Ed) Encyclopedia of Solid Earth Geophysics. Encyclopedia of Earth Sciences Series. Springer, Cham. First online: 15 February 2020.

https://doi.org/10.1007/978-3-030-10475-7_23-1.

Gumbel E.J., 1958. "Extreme Value Statistics", Columbia Univ. Press, New York - (2004) "Extreme Value Statistics", Dover Publications, Mineola, NY: unabridged re-publication of 1958 edition, pp.400. ISBN: 0-486-43604-7.

https://www.amazon.com/Statistics-ExtremesDover-Books-Mathematics-book/dp/B008TVM18G.

Gupta H., Ed, 2020. Encyclopedia of Solid Earth Geophysics Living Edition. Encyclopedia of Earth Sciences Series (EESS), 2nd Edition. Number of Entries: 255. Springer, Cham. Online, ISBN: 978-3030-10475-7.

https://doi.org/10.1007/978-3-030-10475-7

Gupta I.N., 1980. A note on correlation of Modified Mercalli intensity with peaks of far-field ground motion. Bull Seismol Soc Am., 70(3), 925-932.

https://pubs.geoscienceworld.org/ssa/bssa/articleabstract/70/3/925/102047/A-note-on-correlation-ofModified-Mercalli?redirectedFrom=fulltext

Gutenberg R., C.F. Richter, 1944. Frequency of earthquakes in California, Bull. Seismol. Soc. Am., 34(4), 185-188. ISSN: 0037-1106. https://resolver.caltech.edu/CaltechAUTHORS:2014 0731-150249818. https://pubs.geoscienceworld.org/ssa/bssa/article/34/ 4/185/101140/Frequency-of-earthquakes-in-

California.

Gutenberg B., Richter F., 1949. Seismicity of the Earth and associated phenomena, 273pp., Princeton Univ. Press, Princeton.

https://doi.org/10.1111/j.2153-3490.1950.tb00313.x.

Gutenberg B., Richter C.F., 1956. Magnitude and energy of earthquakes. Annali di Geofisica, 9, 7-12. https://doi.org/10.4401/ag-5590.

https://www.annalsofgeophysics.eu/index.php/annal s/article/view/5590.

Gvishiani A., Gorshkov A., Kossobokov V., Cisternas A., Philip H., Weber C., 1987. Identification of seismically dangerous zones in the Pyrenees. Annales Geophysicae, 5B(6), 681-690.

https://www.researchgate.net/publication/234841582 _29_Gvishiani_A_Gorshkov_A_Kossobokov_V_Ci sternas_A_Philip_H_Weber_C_1987_Identification _of_Seismically_Dangerous_Zones_in_the_Pyrenee s_Annales_Geophysicae_5_B6_pp681-690.

Gvishiani A.D., Soloviev A.A., 1984. Recognition of places on the Pacific coast of the South America where strong earthquakes may occur. Earthquake Predict. Res., 2(4), 237-243.

Gvishiani A.D., Soloviev A.A., Dzeboev B.A., 2020. Problem of Recognition of Strong-Earthquake-Prone Areas: a State-of-the-Art Review. Izvestiya, Physics of the Solid Earth, 56, 1-23. https://doi.org/10.1134/S1069351320010048.

Gvishiani A.D., Gorshkov A.I., Ranzman E.Ya., Cisternas A., Soloviev A.A., 1988. Prediction of Earthquake-Prone Areas in Regions of Moderate Seismicity. Prognozirovanie mest zemletryasenii v regionakh umerennoi seismichnosti. Nauka, Moscow, Russia, pp.187.

https://www.researchgate.net/publication/236160746 _Prediction_of_Earthquake-

Prone_Areas_in_Regions_of_Moderate_Seismicity.

Gvishiani A.D., Zhidkov M.P., Soloviev A.A., 1984. On application of the criteria of high seismicity of Andean mountain belt to Kamchatka. Izv. Akad. Nauk SSSR, Fiz. Zemli, 1, 20-33.

Hamburger R.O., 2016. "Seismic Design Value Maps: Past, Present and Future", STRUCTURE magazine, March 2016, 14-17. 
https://www.structuremag.org/wpcontent/uploads/2016/02/C-CS-HamburgerMar161.pdf.

Hanks T.C., 1997. Imperfect Science, Uncertainty, Diversity, and Experts. Eos, Sept. 2, 1997, 78(35), 369-377.

https://agupubs.onlinelibrary.wiley.com/doi/pdf/10.1 029/97EO00236.

Harbi A., Maouche S., Vaccari F., Aoudia A. Oussadou, Panza G.F., Benouar D., 2007. Seismicity, seismic input and site effects in the Sahel-Algiers region (North Algeria). Soil Dynamics and Earthquake Engineering, 27(5), 427-447. https://doi.org/10.1016/j.soildyn.2006.10.002.

Hasegawa A., 2020. Seismicity, Subduction Zone. In: Gupta H.K. (Ed) Encyclopedia of Solid Earth Geophysics. Encyclopedia of Earth Sciences Series. Springer, Dordrecht. First online: 17 March 2020. https://doi.org/10.1007/978-3-030-10475-7_14-1.

Hassan H.M., Fasan M., Sayed M.A., Romanelli F., ElGabry M.N., Vaccari F., Hamed A., 2020. Sitespecific ground motion modeling for a historical Cairo site as a step towards computation of seismic input at cultural heritage sites. Engineering Geology $268,105524$.

https://doi.org/10.1016/j.enggeo.2020.105524.

Hassan H.M., Romanelli F., Panza G.F., ElGabry M.N., Magrin A., 2017. Update and sensitivity analysis of the neo-deterministic seismic hazard assessment for Egypt. Engineering Geology, 218, 77-89. https://doi.org/10.1016/j.enggeo.2017.01.006.

Hays W.W., 1980. Procedures for estimating Earthquake Ground Motions, U.S. Geol. Surv., Prof. Paper 1114, pp.77. https://pubs.usgs.gov/pp/1114/report.pdf.

Heaton T., 2007. "Will performance-based earthquake engineering break the power law?" Seismol. Res. Lett., 78(2), 183-185. http://dx.doi.org/10.1785/gssrl.78.2.183. https://resolver.caltech.edu/CaltechAUTHORS:2012 1121-131441532.

Hough S.E., Page M., 2016. Potentially Induced Earthquakes during the Early Twentieth Century in the Los Angeles Basin. Bull. Seismol. Soc. Am., 106(6), 2419-2435. T. Page https://doi.org/10.1785/0120160157.
Housner G.W., Jennings P.C., 1977. Earthquake design criteria for structures, Calif. Inst. of Tech. Caltech EERL 77-06, Pasadena, CA, Nov., pp.52. https://core.ac.uk/download/pdf/4891324.pdf777.

Housner G.W., Jennings P.C., 1982. Earthquake design criteria, Earthquake Engineering Research Institute EERI, Oakland, CA USA, pp.140, ISBN: 1593701578.

https://www.eeri.org/productspage/monographs/earthquake-design-criteria-3/.

Howath H., 2015. Human exposure to wind-induced motion in tall buildings: and assessment of guidance in ISO 6897 and ISO 10137. Conf. Paper - 50th United Kingdom Conference on Human Responses to Vibration, held at ISVR, University of Southampton, Southampton, England, 9-10 September 2015, pp.11.

https://www.researchgate.net/publication/299450220 _Human_exposure_to_wind-

induced_motion_in_tall_buildings_and_assessment_ of_guidance_in_ISO_6897_and_ISO_10137.

Irwandi I., 2017. Advantages of Realistic Model Based on computational method: NDSHA versus Standard PSHA. IOP Conf. Ser.: Earth and Environ. Sci. 56. 10th Aceh International Workshop and Expo on Sustainable Tsunami Disaster Recovery (AIWESTDR2016) 22-24 Nov. 2016, Banda Aceh, Indonesia, $10 \mathrm{pp}$. https://doi.org/10.1088/1755-1315/56/1/012007.

Irwandi I., Umar M., Khaizal J., Asrurifak M., Usama F., Ridwan M., 2020. The Neo-Deterministic Seismic Hazard map (NDSHA) of Sumatra compared with official 2010 and 2017 derived from PSHA method. IOP Conf. Ser.: Mater. Sci. Eng. 712, 012017, 3rd National Conference on Wind \& Earthquake Engineering and International Seminar On Sustainable Construction Engineering 12-13 July 2019, Kuala Lumpur, Malaysia, 8pp. https://doi.org/10.1088/1757-899X/712/1/012017.

Ismail-Zadeh A., Kossobokov V., 2020. Earthquake Prediction, M8 Algorithm. In: Gupta H. (Ed) Encyclopedia of Solid Earth Geophysics. Encyclopedia of Earth Sciences Series, 2nd Edition. Springer, Cham. First Online: 30 May 2020. https://doi.org/10.1007/978-3-030-10475-7_157-1.

ISO 10137, 2007. International Organization for Standardization. Bases for design of structures- 
J. Bela, G.F. Panza/Vietnam Journal of Earth Sciences 43(2021)

serviceability of buildings and walkways against vibration. Standard ISO 10137:2007, Geneva, International Organization for Standardization. https://www.iso.org/standard/37070.html.

Iturrarán-Viveros U., Sánchez-Sesma F.J., 2020. Seismic Wave Propagation in Real Media: Numerical Modeling Approaches. In: Gupta H. (Ed) Encyclopedia of Solid Earth Geophysics. Encyclopedia of Earth Sciences Series. Springer, Cham. First online: 29 March 2020. https://doi.org/10.1007/978-3-030-10475-7_6-1.

Jackson D.D., Kagan Y.Y., 2020. Characteristic Earthquakes and Seismic Gaps. In: Gupta H. (Ed) Encyclopedia of Solid Earth Geophysics. Encyclopedia of Earth Sciences Series. Springer, Cham. First Online 28 December 2019. https://doi.org/10.1007/978-3-030-10475-7_181-1.

Jamtveit B., Ben-Zion Y., Renard F., Austrheim H., 2018. Earthquake-induced transformation of the lower crust. Nature, 556, 487-491. https://doi.org/10.1038/s41586-018-0045-y.

Junbo J., 2017. Modern Earthquake Engineering: Offshore and Land-based Structures. SpringerVerlag GmbH Germany, pp.848. ISBN: 978-3-64231853-5. ISBN: 978-3-642-31854-2 (eBook). https://doi.org/10.1007/978-3-642-31854-2.

Kagan Y.Y., Jackson D.D., Geller R.J., 2012. Characteristic earthquake model, 1884-2011, R.I.P. Editorial Nov. 1, 2012, Seismol. Res. Lett., 83(6), 951-953. https://doi.org/10.1785/0220120107.

Kahneman D., 2011. Thinking, Fast and Slow. Farrar, Straus and Giroux, New York, pp.512. ISBN: 9780374275631 (see also Obrien, 2012; Sunstein and Thaler, 2016). https://www.amazon.com/ThinkingFast-Slow-Daniel-Kahneman/dp/0374533555.

Kanamori H., 1981. "The Nature of Seismicity Patterns Before Large Earthquakes”, In: Simpson, D.W. and Richards, PG. (eds.) Earthquake Prediction: An International Review, Maurice Ewing Series, American Geophysical Union Washington, D. C., 4, 1-19. ISBN: 9780875904030. https://doi.org/10.1029/ME004p0001. http://resolver.caltech.edu/CaltechAUTHORS:20141 111-150708151.

Kanamori H., 2004. The diversity of the physics of earthquakes. Proceedings of the Japan Academy, Series B, 80(7), 297-316. https://doi.org/10.2183/pjab.80.297. https://physicstoday.scitation.org/doi/10.1063/1.138 7590.

Kárník V., Algermissen S.T., 1978. Seismic zoning. In: The assessment and mitigation of earthquake risk, 11-47. United Nations Educational, Scientific and Cultural Organization UNESCO 1, 75700 Paris, Printed by NICI, Ghent. ISBN: 92-3-101451X French edition: 92-3-201451-3. https://www.abebooks.it/products/isbn/97892310145 12?cm_sp=bdp-_-ISBN10-_-PLP.

Kato T., 2020. Slow Earthquake. In: Gupta H. (Ed) Encyclopedia of Solid Earth Geophysics. Encyclopedia of Earth Sciences Series. Springer, Cham. First online: 29 December 2019. https://doi.org/10.1007/978-3-030-10475-7_20-1.

Keilis-Borok V.I., 2018. Prediction of Extreme events in Nature and Society. A.A. Soloviev (Ed.), Ori Books, pp.520. ISBN: 1940076447. https://doi.org/10.28935/9781940076447. https://www.amazon.com/Prediction-ExtremeEvents-Nature-Society/dp/1940076447.

Keilis-Borok V.I., Soloviev A.A. (Eds), 2003. Nonlinear dynamics of the lithosphere and earthquake prediction. Springer, Heidelberg, Germany, pp.337. ISBNe: 978-3-662-05298-3. https://www.springer.com/us/book/9783540435280.

Kijko A., 2004. Estimation of the Maximum Earthquake Magnitude, mmax. Pure Applied Geophys., 161, 1655-1681. https://doi.org/10.1007/s00024-004-2531-4.

Kijko A., 2020. Seismic Hazard. In: Gupta H. (Ed) Encyclopedia of Solid Earth Geophysics. Encyclopedia of Earth Sciences Series. Springer, Cham. First online: 15 December 2019. https://doi.org/10.1007/978-3-030-10475-7_10-1.

Klügel J.-U., Mualchin L., Panza G.F., 2006. A scenario-based procedure for seismic risk analysis. Engineering Geology, 88(1-2), 1-22. https://doi.org/10.1016/j.enggeo.2006.07.006.

Kim Y., Hwang W., 2019. High-Cycle, Low-Cycle, Extremely Low-Cycle Fatigue and Monotonic Fracture Behaviors of Low-Carbon Steel and Its Welded Joints. Materials, 12(24), 4111, pp.23. https://doi.org/10.3390/ma12244111. 
Klügel J-U., 2015. Lessons not yet learned from the Fukushima disaster. Acta Geod Geophys, 50, 5-19. https://doi.org/10.1007/s40328-014-0084-2.

Klügel J.-U., 2008. Seismic Hazard Analysis - Quo Vadis? Earth-Science Reviews, 88(1-2), 1-32. https://doi.org/10.1016/j.earscirev.2008.01.003.

Konno K., Ohmachi T., 1998. Ground-motion characteristics estimated from spectral ratio between horizontal and vertical components of microtremor, Bull. Seism. Soc. Am., 88(1), 228-241.

https://pubs.geoscienceworld.org/ssa/bssa/article/88/ 1/228/102764/Ground-motion-characteristicsestimated-from.

Korzybski A., 1931. "The Map is not the Territory." In 1931 Alfred Korzybski gave a presentation at a meeting of the American Association for the Advancement of Science in New Orleans where he used the phrase "the map is not the territory." Korzybski used this phrase to mean that people in general do not have access to absolute knowledge of reality, but merely possess a subset of that knowledge that is then tinted through the lenses of their own experience. He further added that it is important for people to know that their understanding of things, "the map", is not a true representation of reality itself or everything represented by reality, or "the territory." https://www.solutionsiq.com/resource/blogpost/map-territory-agile-teams-know-difference/.

Korzybski A., 1931. A non-aristotelian system and its necessity for rigour in mathematics and physics, Paper presented before the American Mathematical Society at the New Orléans, Louisiana Meeting of the American Association for the Advancement of Science A.A.A.S., Dec. 28, 1931. Reprinted in Science and Sanity: An Introduction to NonAristotelian Systems and General Semantics, International Non-Aristotelian Library Publishing Company, 1933, 747-761.

Kossobokov V.G., 2003. The Physics of Earthquakes, Seismic Occurrence and its Prediction. In: A.M. Correig (Ed). Terratrèmols i Temporals de Llevant: Dos Exemples de Sistemes Complexos: Jornades Científiques de l'Institut d'Estudis Catalans, Secció de Ciències i Tecnologia (Sèrie Jornades Científiques: 15). Institut d'Estudis Catalans (IEC), Barcelona, 71-90.
https://www.google.com/books/edition/Terratr\%C3 \%A8mols_i_temporals_de_llevant/TUSyma50ViM $\mathrm{C} ? \mathrm{hl}=\mathrm{en} \& \mathrm{gbpv}=1$

Kossobokov V.G., 2004. Earthquake prediction: Basics, achievements, perspectives. Acta Geodaetica et Geophysica Hungarica, 39(2-3), 205-221. https://doi.org/10.1556/ageod.39.2004.2-3.6.

Kossobokov V.G., 2017. Seismic Roulette: Earthquake Prediction Problem in a Big Data World. http://school2017.gcras.ru/doc/KossobokovV_1.pdf.

Kossobokov V.G., Shebalin P., 2003. 4. Earthquake Prediction. In: Keilis-Borok, V.I., A.A. Soloviev (Eds). Nonlinear Dynamics of the Lithosphere and Earthquake Prediction, 141-207. Springer Series in Synergetics. Springer, Berlin, Heidelberg. ISBN 978-3-642-07806-4. https://doi.org/10.1007/978-3662-05298-3_4.

https://www.springer.com/us/book/9783540435280.

Kossobokov V.G., Mazhkenov S.A., 1994. On similarity in the spatial distribution of seismicity, In: Chowdhury, D.K. et al. (Eds). Computational Seismology and Geodynamics. AGU, The Union, Washington DC, 1, 6-15. First Publ. 1992. https://doi.org/10.1029/CS001p0006.

Krinitzsky E.L., 1993a. Earthquake probability in engineering - Part 1: The use and misuse of expert opinion. The Third Richard H. Jahns Distinguished Lecture in Engineering Geology. Engineering Geology, 33(4), 257-288. https://doi.org/10.1016/0013-7952(93)90030-G.

Krinitzsky E.L., 1993b. Earthquake probability in engineering - Part 2: Earthquake recurrence and the limitations of Gutenberg-Richter b-values for the engineering of critical structures. The Third Richard H. Jahns Distinguished Lecture in Engineering Geology. Engineering Geology, 36(1-2), 1-52. https://doi.org/10.1016/0013-7952(93)90017-7.

Krinitzsky E.L., 1993c. The Hazard of Using Probabilistic Seismic Hazard Analysis. Civil Engineering, New York. November 1993, 63(11), 152. https://trid.trb.org/view/383477.

Krinitzsky E., 1998. The Hazard in Using Probabilistic Seismic Hazard Analysis for Engineering. Environmental and Engineering Geoscience, IV(4), 425-443.

https://doi.org/10.2113/gseegeosci.IV.4.425. 


\section{J. Bela, G.F. Panza/Vietnam Journal of Earth Sciences 43(2021)}

Krinitzsky E.L., 1995. Problems with logic trees in earthquake hazard evaluation. Engineering Geology, 39, 1-3. https://doi.org/10.1016/00137952(94)00060-F.

Krinitzsky E.L., 2003. How to combine deterministic and probabilistic methods for assessing earthquake hazards, Engineering Geology, 70(1-2), 157-163. https://doi.org/10.1016/S0013-7952(02)00269-7.

Kulhanek O., Persson L., 2020. Seismogram Interpretation. In: Gupta H. (Ed) Encyclopedia of Solid Earth Geophysics. Encyclopedia of Earth Sciences Series. Springer, Cham. First online: 09 December 2019. https://doi.org/10.1007/978-3-030-10475-7_219-1.

La Mura C., Yanovskaya T.B., Romanelli F., Panza G.F., 2011. Three-Dimensional Seismic Wave Propagation by Modal Summation: Method and Validation. Pure Appl. Geophys., 168, 201-216. First Online: 22 May 2010. https://doi.org/10.1007/s00024-010-0165-2.

Lachet C., Bard P.-Y., 1994. Numerical and theoretical investigations on the possibilities and limitations of Nakamura's technique. J. Phys. Earth, 42(5), $377-$ 397. https://doi.org/10.4294/jpe1952.42.377.

Lee W.H.K., 2020. Seismology, Rotational. In: Gupta H. (Ed) Encyclopedia of Solid Earth Geophysics. Encyclopedia of Earth Sciences Series. Springer, Cham. First online: 28 December 2019. https://doi.org/10.1007/978-3-030-10475-7_17-1.

Li S., Chen Y., Yu T., 2020. Comparison of macroseismic-intensity scales by considering empirical observations of structural seismic damage. Earthquake Spectra, 10(2), 357-379. https://doi.org/10.1177/8755293020944174.

Lliboutry L., 2000. Quantitative geophysics and geology, Springer-Verlag, London, UK, pp.XV, 480. ISBN: 978-1-85233-115-3. https://www.springer.com/gp/book/9781852331153.

Lucia Luzi, Francesca Pacor, Rodolfo Puglia, Giovanni Lanzano, Chiara Felicetta, Maria D'Amico, Alberto Michelini, Licia Faenza, Valentino Lauciani, Iunio Iervolino, George Baltzopoulos, Eugenio Chioccarelli, 2017. The Central Italy Seismic Sequence between August and December 2016: Analysis of Strong-Motion Observations. Seismological Research Letters, 88(5), 1219-1231. https://doi.org/10.1785/0220170037.
Madariaga R., 2020. Earthquake Source Theory. In: Gupta H. (d) Encyclopedia of Solid Earth Geophysics. Encyclopedia of Earth Sciences Series. Springer, Cham. First online: 19 February 2020. https://doi.org/10.1007/978-3-030-10475-7_62-1.

Magrin A., Gusev A.A., Romanelli F., Vaccari, F., Panza G.F., 2016. Broadband NDSHA computations and earthquake ground motion observations for the Italian territory. Int. J. Earthquake and Impact Engineering IJEIE, 1(1/2), 131-158. ISSN online: 2397-9380.

https://doi.org/10.1504/IJEIE.2016.10000979.

https://www.inderscience.com/info/inarticletoc.php? jcode $=$ ijeie $\&$ year $=2016 \&$ vol $=1 \&$ issue $=1 / 2$. http://dx.doi.org/10.1504/IJEIE.2016.080038.

Magrin A., Peresan A., Kronrod T., Vaccari F., Panza G.F., 2017. Neo-deterministic seismic hazard assessment and earthquake occurrence rate. Engineering Geolology, 229, 95-109. https://doi.org/10.1016/j.enggeo.2017.09.004.

Malhotra P.K., 2015. Normalized Response Spectrum of Ground Motion, The Bridge and Structural Engineer, 45(1), 1-11.

https://www.researchgate.net/publication/281212369 _Normalized_Response_Spectrum_of_Ground_Moti on.

Marku S., Panza G., Ormeni R., 2014. The necessity of an anti-seismic law in Albania based on NDSHA method of risk calculation. Bul. Shk. Gjeol. 1/2014 Special Issue. Proceedings of XX CBGA Congress, Tirana, Albania, 24-26 September 2014, 462-465. https://www.academia.edu/43151518/Beqiraj_A_Ion escu_C_Christofides_G_Uta_A_Beqiraj_Goga_E_a nd_Marku_S_Proceedings_XX_Congress_of_the_C arpathian_Balkan_Geological_Association_Septemb er_24_26_2014_Tirana_Albania_Special_Issue_Vol _1_2014_Special_Sessions.The full volume with abstracts may be downloaded from: www.fgjm.edu.al/cbga.

Martelli A., Clemente P., De Stefano A., Forni M., Salvatori A., 2014. Recent Development and Application of Seismic Isolation and Energy Dissipation and Conditions for Their Correct Use. In: Ansal, A. (Ed) Perspectives on European Earthquake Engineering and Seismology. Geotechnical, Geological and Earthquake Engineering, Springer, Cham, 34, 449-488. 
https://doi.org/10.1007/978-3-319-07118-3_14.

Martin S.S., Szeliga W., 2010. A catalog of felt intensity data for 570 earthquakes in India from 1636 to 2009. Bull. Seismol. Soc. Am., 100(2), 562-569. https://doi.org/10.1785/0120080328.

McCaffrey R., 2020. Earthquakes and Crustal Deformation. In: Gupta H. (Ed) Encyclopedia of Solid Earth Geophysics. Encyclopedia of Earth Sciences Series. Springer, Cham. First online: 28 December 2019.

https://doi.org/10.1007/978-3-030-10475-7_2-1.

McCann M.W., Sauter F., Shah H.C. Shah, 1980. A technical note on PGA-intensity relations with applications to damage estimation. Bull. Seismol. Soc. Am., 70(2), 631-637. A technical note on PGAintensity relations with applications to damage estimation Bulletin of the Seismological Society of America.

McGuire R.K., 1976. "Fortran computer program for seismic risk analysis", U.S. Geological Survey Open-file Rpt. 76-67.

https://doi.org/10.3133/ofr7667.

McGuire R.K., 1992. Perceptions of earthquake risk. Bull. Seismol. Soc. Am., 82, 1977-1992. https://pubs.geoscienceworld.org/ssa/bssa/article/82/ 4/1977/119698/perceptions-of-earthquake-risk.

McGuire R.K., 1995. "Probabilistic seismic hazard analysis and design earthquakes: Closing the loop", Bull. Seismol. Soc. Am., 85(5), 1275-1284. https://pubs.geoscienceworld.org/ssa/bssa/articlestandard/85/5/1275/119907/probabilistic-seismichazardanalysis-and-design.

McGuire R., 2001. Deterministic vs Probabilistic Earthquake Hazards and Risks, Soil Dynamics and Earthquake Engineering, 21(5), 377-384. https://doi.org/10.1016/S0267-7261(01)00019-7.

McGuire R.K., 2004. Seismic Hazard and Risk Analysis. Earthquake Engineering Research Institute EERI Monograph. Oakland, CA., pp. 221. https://www.eeri.org/productspage/monographs/seismic-hazard-and-risk-analysis-3/

Meletti C., Patacca E., Scandone P., 2000. Construction of a seismotectonic model: the case of Italy. In: G.F. Panza, M. Radulian and C. Trifu (Eds) Seismic Hazard of the Circum-Pannonian Region. Pure Appl. Geophys. - Topical Volume, 157, 11-35. Birkhäuser, Basel. https://doi.org/10.1007/978-3-0348-8415-0_2.
McGuire R.K., 2008. "Probabilistic seismic hazard analysis: Early history”, Earthquake Engng. Struct. Dyn. 37, 329-338. Published online 19 October 2007 in Wiley InterScience (www.interscience.wiley.com). https://onlinelibrary.wiley.com/doi/pdf/10.1002/eqe. 765.

Milkova K., Dumova-Jovanoska E., Drogreshka K., Chernih, 2018. Region specific application of Neodeterministic analysis for reliable seismic hazard assessment. Proc. 16th European Conference on Earthquake Engineering - 16ecee 18-21 June 2018, Thessaloniki, Greece. ID: 11201.

http://papers.16ecee.org/files/16ecee2018\%20NeoD eterministicAnalysis.pdf.

https://www.researchgate.net/publication/345777511 _region_specific_application_of_neo-

deterministic_analysis_for_reliable_seismic_hazard _assessment.

Miranda E., 1996. Strength Reduction Factors in Performance-Based Design. EERC-CUREe Symposium in Honor of Vitelmo V. Bertero, January 31 - February 1, 1997, Berkeley, California. https://tarjomefa.com/wpcontent/uploads/2015/11/3241-English.pdf.

Miranda E., Bertero V.V., 1994. Evaluation of Strength Reduction Factors for Earthquake-Resistant Design. Earthquake Spectra, 10(2), 357-379. https://doi.org/10.1193/1.1585778.

Mohanty W.K., Verma A.K., Vaccari F., Panza G.F., 2013. Influence of epicentral distance on local seismic response in Kolkata City, India. J Earth Syst Sci., 122, 321-338. https://doi.org/10.1007/s12040-013-0275-1.

Molchan G., Kronrod T., Panza G.F., 2011. Hot/Cold Spots in Italian Macroseismic Data. Pure Appl. Geophys, 168(3-4), 739-752. https://doi.org/10.1007/s00024-010-0111-3.

Molchan G., Kronrod T., Panza G.F., 1997. Multi-scale seismicity model for seismic risk. Bull. Seismol. Soc. Am., 87(5), 1220-1229. https://pubs.geoscienceworld.org/ssa/bssa/article/87/ 5/1220/120232/Multi-scale-seismicity-model-forseismic-risk.

Molin D., Stucchi M., Valensise G., 1996. Maximum macroeconomic intensities observed in Italian municipalities/Massime intensità macrosismiche 


\section{J. Bela, G.F. Panza/Vietnam Journal of Earth Sciences 43(2021)}

osservate nei comuni italiani. Evaluated from the GNDT macroseismic database and data from the ING/SGA Catalogue of Strong Earthquakes in Italy. Developed for the Department of Civil Protection. Massime intensità macrosismiche osservate nei cmuni italiani (ingv.it).

Moratto L., Suhadolc P., G. Costa G., 2011. ShakeMaps for three relevant earthquakes in the Southeastern Alps: Comparison between instrumental and observed intensities, Tectonophysics, 509(1-2), 93106. https://doi.org/10.1016/j.tecto.2011.06.004.

Morfe J., Schmitz M., Alvarado L., Álvarez L., Zapata J., y Rendón H., 2015. Simulation of seismic wave propagation, and amplitude and period characteristics for the seismic microzoning of Guarenas and Guatire cities. Boletín de Geología, 37(1), 27-43.

http://www.scielo.org.co/scielo.php?script=sci_artte xt\&pid=S0120-02832015000100003 - Boletín de Geología - Home Page (scielo.org.co)

https://www.researchgate.net/publication/282823246 _Simulation_of_seismic_wave_propagation_and_a mplitude_and_period_characteristics_for_the_seismi c_microzoning_of_guarenas_and_guatire_cities.

Mostafa S.I., Abdelhafiez H.E., Abdel Aziz K., Abdel Aal A., 2019. Deterministic scenarios for seismic hazard assessment in Egypt. Journal of African Earth Sciences, 160, 103655. https://doi.org/10.1016/j.jafrearsci.2019.103655.

Motaghi K., Tatar M., Priestley K., Romanelli R., Doglioni C., Panza G.F., 2015. The deep structure of the Iranian Plateau. Gondwana Research, 28(1), $407-$ 418. https://doi.org/10.1016/j.gr.2014.04.009.

Moustafa et al., 2020. Review of Site Effects Methodologies: with full references. https://assets.researchsquare.com/files/rs44214/v1/af14e0d3-6b45-48a2-949e9f0aa028bf68.pdf.

Mridula, Sinhval A., Wason H.R., 2013. A review on pattern recognition techniques for seismic hazard analysis. Proc. International Conference on Emerging Trends in Engineering and Technology, 854-858. 4th International Conference on Emerging Trends in Engineering and Technology (IETET 2013) Advances in Engineering and Technology Volume 3, Haryana, India 25-27 October 2013. ISBN: 978-1-63439-120-7
https://www.semanticscholar.org/paper/A-Reviewon-Pattern-Recognition-Techniques-for-MridulaSinhval/7ab92279e9d5a8afecf06c041073aea47f9b9 1eb. DOI: 03.AETS.2013.3.4_1 C) Association of Computer https://doi.org/03.AETS/3.4_1.

Mualchin L., 2011. History of Modern Earthquake Hazard Mapping and Assessment in California Using a Deterministic or Scenario Approach, Pure and Applied Geophys. 168, 383-407. https://doi.org/10.1007/s00024-010-0121-1.

Muço B., 2013. Probabilistic seismic hazard assessment in Albania, Ital. J. Geosci., 132 (f,2), 194-202. https://doi.org/10.3301/IJG.2012.33.

Muço B., Vaccari F., Panza G.F., 2001 Seismic zonation of Albania using a deterministic approach. The Albanian Journal of Natural \& Technical Sciences, 10, 5-19.

Muço B., Vaccari F., Panza G.F., Kuka N., 2002. Seismic zonation in Albania using a deterministic approach. Tectonophysics, 344(3), 277-288. https://doi.org/10.1016/S0040-1951(01)00279-7.

Mulargia F., Stark P., Geller R., 2017. Why is Probabilistic Seismic Hazard Analysis (PSHA) still used? Phys. Earth Planet. Int., 264, 63-75. https://doi.org/10.1016/j.pepi.2016.12.002.

Musson R.M.W., 2019. Great Earthquakes. In: Gupta H. (Ed) Encyclopedia of Solid Earth Geophysics. Encyclopedia of Earth Sciences Series. Springer, Cham. First online: 04 December 2019. https://doi.org/10.1007/978-3-030-10475-7_7-1.

Nagao T., Kamogawa M., Uyeda S., 2020. Earthquake Precursors and Prediction. In: Gupta H. (Ed) Encyclopedia of Solid Earth Geophysics. Encyclopedia of Earth Sciences Series. Springer, Cham. First Online 30 October 2019. https://doi.org/10.1007/978-3-030-10475-7_4-1.

Nakamura Y., 1989. A method for dynamic characteristics estimation of subsurface using microtremor on the ground surface. Quart. Rept. Railway Tech. Res. Inst. RTRI, 30(1), 25-33. https://trid.trb.org/view/294184.

Nakamura Y., 2008. On the H/V Spectrum. The 14th World Conference on Earthquake Engineering Oct. 12-17, 2008, Beijing, China, pp.10. https://www.iitk.ac.in/nicee/wcee/article/14_070033.PDF. 
Vietnam Journal of Earth Sciences, 43(2), 111-188

Nakamura Y., Gurler D.E., 2001. Estimation of dynamic characteristics of ground and structures with microtremor measurements- A supportive tool for strong ground motion instrumentation. In: Erdik M., Celebi M., Mihailov V., Apaydin N. (Eds) Strong Motion Instrumentation for Civil Engineering Structures. NATO Science Series (Series E: Applied Sciences), 373, 303-311. Springer, Dordrecht. https://doi.org/10.1007/978-94-010-0696-5_21.

Negro C., Vitaliani R., Saetta A., Berto L., Panza G., Vaccari F., Martelli A., Indirli M., 2013. Comparison of seismic hazard assessment procedures and equilibrium limit state analysis for the Prigioni statues of Michelangelo. SE-50EEE, International Conference on Earthquake Engineering, 50 Years Skopje Earthquake, 19632013, May 2013, Skopje, Former Republic of Macedonia, Conf. Paper, pp. 9.

https://www.researchgate.net/publication/259849473 _Comparison_of_seismic_hazard_assessment_proce dures_and_equilibrium_limit_state_analysis_for_the _Prigioni_statues_of_Michelangelo.

Nekrasova A.K., Kossobokov V.G., 2006. General law of similarity for earthquakes: Evidence from the Baikal region. Dokl. Earth Sc., 407, 484-485. https://doi.org/10.1134/S1028334X06030305.

Nekrasova A.K., Kossobokov V.G., Peresan A., Magrin A., 2014. The comparison of the NDSHA, PSHA seismic hazard maps and real seismicity for the Italian territory. Nat, Hazards (2013), 70, 629-641. https://doi.org/10.1007/s11069-013-0832-6.

Novikova O., Gorshkov A., 2013. Recognition of earthquake prone areas $(M \geq 6.0)$ in the Kopet Dagh region using the GIS technology. J. Seismol. Earthquake Eng., 15(2), 101-109.

https://www.sid.ir/en/Journal/ViewPaper.aspx?ID=4 89634.

NTC, 2008. Norme tecniche per le costruzioni, D.M. 14 Gennaio 2008, Rome, Italy. http://www.ingegneriasoft.com/NTC2008_Norme_t ecniche_per_le_costruzioni.htm.

NTC, 2018. Aggiornamento delle "Norme tecniche per le costruzioni”, D.M. 17 Gennaio 2018, Rome, Italy. https://www.ediltecnico.it/nuove-norme-tecnicheper-costruzioni-ntc/.

http://www.gazzettaufficiale.it/atto/serie_generale/ca ricaDettaglioAtto/originario?atto.dataPubblicazione
Gazzetta $=2018-02$ -

20\&atto.codiceRedazionale $=18$ A00716\&elenco30gi orni=true

https://www.gazzettaufficiale.it/atto/serie_generale/c aricaDettaglioAtto/originario?atto.dataPubblicazione Gazzetta=2018-02-

20\&atto.codiceRedazionale $=18 \mathrm{~A} 00716 \& 77$

http://www.gazzettaufficiale.it/eli/gu/2018/02/20/42/ so/8/sg/pdf

Nunziata C., Costanzo M.R., 2020. Ground Shaking Scenario at the Historical Center of Napoli (Southern Italy) for the 1456 and 1688 Earthquakes. Pure Appl. Geophys., 177, 3175-3190. https://doi.org/10.1007/s00024-020-02426-y.

Okal E., 2019. Energy and Magnitude: A Historical Perspective. Pure Appl. Geophys., 176, 3815-3849. https://doi.org/10.1007/s00024-018-1994-7.

Okal E.A., 2020. Earthquake, Focal Mechanism. In: Gupta H. Ed) Encyclopedia of Solid Earth Geophysics. Encyclopedia of Earth Sciences Series. Springer, Cham. First online: 10 march 2020. https://doi.org/10.1007/978-3-030-10475-7_158-1.

Olsen K.B., 2000. Site Amplification in the Los Angeles Basin from Three-Dimensional Modeling of Ground Motion. Bull. Seismol. Soc. Am., 90(6B), S77-S94. https://doi.org/10.1785/0120000506.

PAGEOPH Topical Volume 168, 2011. Advanced Seismic Hazard Assessment, Vol. 1 and Vol. 2, G.F. Panza, K. Irikura, M. Kouteva-Guentcheva, A. Peresan, Z. Wang and R. Saragoni R. (Eds) Pure Appl. Geophys., Birkhäuser, Basel, Switzerland, Vol. 1, ISBN: 978-3-0348-0039-6, Vol. 2, ISBN: 978-3-0348-0091-4. http://www.springer.com/it/book/9783034800396. http://www.springer.com/it/book/9783034800914.

Panda D., Kundu B., Gahalaut V.K., 2020. Earthquakes in the Himalaya. In: Gupta H. (Ed) Encyclopedia of Solid Earth Geophysics. Encyclopedia of Earth Sciences Series. Springer, Cham. First online: 20 August 2020. https://doi.org/10.1007/978-3-030-10475-7_263-1.

Panza G.F., 2017. NDSHA: Robust and Reliable Seismic Hazard Assessment. Proceedings, International Conference on Disaster Risk Mitigation, Dhaka, Bangladesh, September 23-24, pp.10. 
https://arxiv.org/ftp/arxiv/papers/1709/1709.02945.p df.

Panza G.F., 2019. NDSHA: Reliable Paradigm for Seismic Hazard Assessment. Keynote in: F. Dobran (Ed) Resilience and Sustainability of Cities in Hazardous Environments, 52-56, pp.510. GVES, Napoli-New York. ISBN: 978-88-903183-1-3. International Conference on Resilience and Sustainability of Cities in Hazardous Environments 26-30 Nov. 2018, Naples, Italy.

http://congress.gvess.org/downloads/Resilience_and _Sustainability_of_Cities_in_Hazardous_Environme nts.pdf.

Panza G.F., 2020. Paolo Scandone la rivoluzione nelle Geoscienze e nuovi paradigmi: NDSHA e Polarized Plate Tectonics. Atti Convegni Lincei: L'eredità scientifica di Paolo Scandone, geologo, in press.

Panza G.F., Bela J., 2019. NDSHA: a new paradigm for reliable seismic hazard assessment. Engineering Geology Vol. 275 SI, 20 September 2020, Article 105403 , pp.14.

https://doi.org/10.1016/j.enggeo.2019.105403.

Supplementary

Material: BIBLIOGRAPHICJOURNEY to NEW PARADIGM! pp 103.

https://www.academia.edu/43513046/Supplementar y_material_for_NDSHA_A_new_paradigm_for_reli able_seismic_hazard_assessment_

Panza G.F., Romanelli F., 2001. Beno Gutenberg contribution to seismic hazard assessment and recent progress in the European-Mediterranean region. Earth-Science Reviews 55 (1-2), 165-180. https://doi.org/10.1016/S0012-8252(01)00051-4.

Panza G.F., Pontevivo A., 2004. The Calabrian Arc: a detailed structural model of the lithosphereasthenosphere system. Rendiconti, Accademia Nazionale delle Scienze detta dei XL, Memorie di Scienze Fisiche e Naturali, 122(28), 51-88. https://media.accademiaxl.it/memorie/S5-VXXVIIIP2-2004/Panza-Pontevivo51-88.pdf.

Panza G.F., Alvarez L., Aoudia A., Ayadi A., Benhallou H., Benouar D., Bus Z., Chen Y., Cioflan C., Ding Z., El-Sayed A., Garcia J., Garofalo B., Gorshkov A., Gribovszki K., Harbi A., Hatzidimitriou P., Herak M., Kouteva M., Kuznetzov I., Lokmer I., Maouche S., Marmureanu G., Matova M., Natale M., Nunziata C., Parvez I.A., Paskaleva I., Pico R.,
Radulian M., Romanelli F., Soloviev A., Suhadolc P., Szeidovitz G., Triantafyllidis P., Vaccari F., 2002. Realistic modeling of seismic input for megacities and large urban areas (the UNESCO/IUGS/IGCP project 414). Episodes 25 (3), 160-184.

https://doi.org/10.18814/epiiugs/2002/v25i3/002. https://www.osti.gov/etdeweb/servlets/purl/20305549.

Panza G.F., Cazzaro R., Vaccari F., 1997. Correlation between macroseismic intensities and seismic ground motion parameters. Annals Geophys., 40(5), 1371-1382. https://doi.org/10.4401/ag-3872.

Panza G.F., Kossobokov V., Peresan A., Nekrasova A., 2014. Why are the Standard Probabilistic Methods of Estimating Seismic Hazard and Risks Too Often Wrong. In: Wyss, M. (Ed) Earthquake Hazard, Risk, and Disasters, Elsevier, London, UK, 309-357. ISBN: 978-0-12-394848-9.

https://doi.org/10.1016/B978-0-12-394848-9.00012-2.

Panza G.F., La Mura C., Romanelli F., Vaccari F., 2020. Earthquakes, Strong-Ground Motion. In: Gupta H. (Ed) Encyclopedia of Solid Earth Geophysics. Encyclopedia of Earth Sciences Series. Springer, Cham. First online: 28 December 2019. https://doi.org/10.1007/978-3-030-10475-7_141-1.

Panza G.F., La Mura C., Peresan A., Romanelli F., Vaccari F., 2012. Seismic Hazard Scenarios as Preventive Tools for a Disaster Resilient Society. Advances in Geophysics, 53, 93-165. https://doi.org/10.1016/B978-0-12-380938-4.00003-3. Panza G.F., Peresan A., 2016. Difendersi dal terremoto si può - L'approccio neo-deterministico. EPC Editore, Roma, pp. 180. ISBN: 978-88-6310-738-8 https://www.epc.it/Prodotto/Editoria/Libri/Difenders i-dal-terremoto-si-puo\%27/3342.

Panza G.F., Peresan A., Margin A., 2014. Neodeterministic scenarios of seismic hazard for Friuli Venezia Giulia and the surrounding areas. Servizio Geologico D'Italia. Memorie descrittive della Carta Geologica D'Italia Descriptive memories of the geological map of Italy 94, 1-103. ISPRA Serv. ISBN: 8893110040.

Memorie descrittive della carta geologica d'Italia vol.94 - Panza G. F., Peresan A., ISPRA Serv. Geologico d'Italia, Trama libro, 9788893110044. Libreria Universitaria. 
https://www.isprambiente.gov.it/it/pubblicazioni/per iodici-tecnici/memorie-descrittive-della-cartageologica-ditalia/scenari-neo-deterministici-dipericolosita-sismica-per-il-friuli-venezia-giulia-e-learee-circostanti.

Panza G.F., Peresan A., La Mura C., 2013. Seismic hazard and strong motion: an operational neodeterministic approach from national to local scale. In UNESCO-EOLSS Joint Committee Eds, Geophysics and Geochemistry, Encyclopedia of Life Support Systems (EOLSS), Developed under the Auspices of the UNESCO, Eolss Publishers, Oxford, UK, pp.48. http://www.eolss.net

https://www.researchgate.net/publication/288033593

_Seismic_hazard_and_strong_ground_motion_an_op erational_neo-

deterministic_approach_from_national_to_local_scale

Panza G.F., Peresan A., Margin A., 2014. Neodeterministic scenarios of seismic hazard for Friuli Venezia Giulia and the surrounding areas. Servizio Geologico D'Italia. Memorie descrittive della Carta Geologica D'Italia, 94, 1-103. ISPRA.

https://www.isprambiente.gov.it/it/pubblicazioni/per iodici-tecnici/memorie-descrittive-della-cartageologica-ditalia/scenari-neo-deterministici-dipericolosita-sismica-per-il-friuli-venezia-giulia-e-learee-circostanti.

Panza G.F., Peresan A., Sansò F., Crespi, M., Mazzoni A., Nascetti A., 2018. How geodesy can contribute to the understanding and prediction of earthquakes. Rendiconti Lincei. Scienze Fisiche e Naturali, 29(Suppl 1), 81-93. https://doi.org/10.1007/s12210017-0626-y.

Panza G.F., Romanelli F., Vaccari F., 2001. Seismic wave propagation in laterally heterogeneous anelastic media: Theory and applications to seismic zonation. Advances in Geophysics, 43, 1-95. Published: 2 Oct. 2000, ISBN: 9780120188437. https://doi.org/10.1016/S0065-2687(01)80002-9.

Panza G.F., Peresan A., Vaccari F., Romashkova L., Kossobokov V., Gorshkov A., Kuznetsov I., 2003. Earthquake preparedness: the contribution of earthquake prediction and deterministic hazard research. In: A.M. Correig (Ed) Terratrèmols i Temporals de Llevant: Dos Exemples de Sistemes Complexos: Jornades Científiques de l'Institut d'Estudis Catalans, Secció de Ciències i Tecnologia
(Sèrie Jornades Científiques: 15), Institut d'Estudis Catalans (IEC), Barcelona, 91-116, 2003.

ISBN: 84-7283-679-7

https://www.google.com/books/edition/Terratr\%C3

$\%$ A8mols_i_temporals_de_llevant/TUSyma50ViM $\mathrm{C}$ ?hl=en\&gbpv $=1$.

Panza G.F., Romanelli F., Vaccari F., Decanini L., Mollaioli F., 2004. Seismic ground motion modelling and damage earthquake scenarios: A possible bridge between seismologists and seismic engineers. In: Chen, Y.T., Panza, G.F. and Wu, Z.L. (Eds) Earthquake: Hazard, Risk, and Strong Ground Motion, 323-349, Seismological Press, Beijing, China.

https://inis.iaea.org/collection/NCLCollectionStore/_ Public/34/014/34014796.pdf?r=1\&r=1.

Panza G.F., Romanelli F., Vaccari F., Decanini L., Mollaioli F., 2003. Seismic ground motion modelling and damage earthquake scenarios, a bridge between seismologists and seismic engineers. In: Proceedings of the OECD/NEA Workshop on the Relations between Seismological DATA and Seismic Engineering, 484 pages. Istanbul, 16-18 October 2002, NEA/CSNI/R, 18, 241-266. https://www.osti.gov/etdeweb/biblio/21080989.

Panza G.F., Schwab F.A., Knopoff L., 1972. Channel and crustal Rayleigh waves. Geophys. J.R. Astr. Soc., 30, 273-280.

https://www.academia.edu/28781261/Channel_and_ Crustal_Rayleigh_Waves.

Panza G.F., Vaccari F., Costa G., Suhadolc P., Faeh D., 1996. Seismic input modeling for Zoning and Microzoning. Earthquake Spectra, 12(3), 529-566. https://doi.org/10.1193/1.1585896.

Panzera F., D'Amico S., Burjanek J., Pischiutta M., 2017. Advance in seismic site response: Usual practices and innovative methods, 1-2. In: Panzera, F., D'Amico, S., Burjanek, J., Pischiutta, M. (Eds.) Advance in seismic site response: usual practices and innovative methods. SI Seismic site response. Physics and Chemistry of the Earth Parts A/B/C 98, pp.172. https://doi.org/10.1016/j.pce.2017.04.005 https://www.sciencedirect.com/journal/physics-andchemistry-of-the-earth-parts-a-b-c/vol/98/suppl/C

Parkfield EQ Prediction, 1985. "The Parkfield, California, earthquake prediction experiment", by 
Bakun W.H., Lindh A.G., Science, 229(4714), 619624. https://doi.org/10.1126/science.229.4714.619.

Perron V., Gélis C., Froment B., Hollender F., Bard P.Y., Cultrera G., Cushing E.M., 2018. Can broadband earthquake site responses be predicted by the ambient noise spectral ratio? Insight from observations at two sedimentary basins. Geophys. J. Int., 215(2), 1442-1454. https://doi.org/10.1093/gji/ggy355.

Parvez I.A., Vaccari F., Panza G.F., 2003. A deterministic seismic hazard map of India and adjacent areas. Geophys. J. Int., 155(2), 489-508. https://doi.org/10.1046/j.1365-246X.2003.02052.x.

Parvez I.A., Magrin A., Vaccari F., Ashish Mir R.R., Peresan A., Panza G.F., 2017. Neo-deterministic seismic hazard scenarios for India - a preventive tool for disaster mitigation. J. Seismol., 21, 1559-1575. https://doi.org/10.1007/s10950-017-9682-0.

Parvez I.A., Romanelli F., Panza G.F., 2011. Long period ground motion at bedrock level in Delhi city from Himalayan earthquake scenarios. Pure Appl. Geophys, 168, 409-477. https://doi.org/10.1007/s00024-010-0162-5.

Parvez I.A., Vaccari F., Panza G.F., 2003. A deterministic seismic hazard map of India and adjacent areas. Geophys. J. Int., 155(2), 489-508. https://doi.org/10.1046/j.1365-246X.2003.02052.x.

Paulatto M., Pinat T., Romanelli F., 2007. Tsunami hazard scenarios in the Adriatic Sea domain, Nat. Hazards Earth Syst. Sci., 7(2), 309-325. https://doi.org/10.5194/nhess-7-309-2007.

Peng Y., Wang Z., Woolery E.W., Lyu Y., Carpenter N.S., Fang Y., Huang S., 2020. Ground-motion site effect in the Beijing metropolitan area. Engineering Geology 266, 105395-105427. https://doi.org/10.1016/j.enggeo.2019.105395.

Peresan A., Gorshkov A., Soloviev A., Panza G.F., 2015. The contribution of pattern recognition of seismic and morphostructural data to seismic hazard assessment. Bollettino di Geofisica Teorica ed Applicata, 56(2), 295-328.

https://doi.org/10.4430/bgta0141.

http://www3.ogs.trieste.it/bgta/pdf/bgta0141_PERE SAN.pdf.

Peresan A., Panza G.F., 2012. Improving Earthquake Hazard Assessments in Italy: An Alternative to
Texas Sharpshooting. Eos, 18 December 2012, 93(51), 538-539.

https://doi.org/10.1029/2012EO510009.

Peresan A., Kossobokov V., Romashkova L., Panza G.F., 2005. Intermediate-term middle-range earthquake predictions in Italy: a review. EarthScience Reviews, 69(1-2), 97-132. https://doi.org/10.1016/j.earscirev.2004.07.005.

Peresan A., Kossobokov V., Romashkova L., Magrin A., Soloviev A., Panza G.F., 2016. Time-dependent neo-deterministic seismic hazard scenarios: Preliminary report on the M6.2 Central Italy earthquake, 24th August 2016. New Concepts in Global Tectonics Journal, 4(3), 487-493.

https://www.ae-

info.org/attach/Acad_Main/Sections/Earth_cosmic_s ciences/Activities/Personal_Reports/Panza_Guiliano _AmatriceNCGT.pdf.

Peresan A., Magrin A., Nekrasova A., Kossobokov V.G., Panza G.F., 2013. Earthquake recurrence and seismic hazard assessment: a comparative analysis over the Italian territory. Proceedings of the ERES 2013 Conference, WIT Transactions on The Built Environment, 132, 23-34. ISSN: 1743-3509. https://doi.org/10.2495/ERES130031.

Peterson D.W., 1988. "Volcanic hazards and public response." Journal of Geophysical Research, 93, 4161-4170. https://doi.org/10.1029/JB093iB05p04161.

Poggi V., Burjanek J., Michel C., Fäh D., 2017. Seismic site-response characterization of high-velocity sites using advanced geophysical techniques: application to the NAGRA-Net. Geophys. J. Int., 210, 645-659. https://doi.org/10.1093/gji/ggx192.

Pokharel T., Goldsworthy H.M., 2015. Lessons Learned from the Nepal Earthquake 2015. Proceedings of the Tenth Pacific Conference on Earthquake Engineering - Building an Earthquake-Resilient Pacific, 6-8, November 2015, Sydney, Australia. https://doi.org/10.13140/RG.2.1.1657.3528.

Pontevivo A., Panza G.F., 2006. The LithosphereAsthenosphere System in the Calabrian Arc and Surrounding Seas-Southern Italy. Pure Appl. Geophys., 163, 1617-1659. https://doi.org/10.1007/s00024-006-0093-3. 
Rastgoo M., Rahimi H., Romanelli F., Vaccari F., Panza G.F., 2018. Neo-deterministic seismic hazard assessment for Alborz Region, Iran. Engineering Geology, 242, 70-80. https://doi.org/10.1016/j.enggeo.2018.05.025.

Reid H.F., 1910. The Mechanics of the Earthquake. In: The California Earthquake of April 18, 1906. Report of the State Investigation Commission, Carnegie Institution of Washington, Washington, D.C., 2, 16-28.

Reid H.F., 1911. The elastic-rebound theory of earthquakes. University of California Publications, Bulletin of the Department of Geological Sciences, 6, 413-444.

https://earthquake.usgs.gov/earthquakes/events/1906 calif/18april/reid.php.

Rhoades D.A., Christophersen A., Hainzl S., 2020. Statistical Seismology. In: Gupta H. (Ed) Encyclopedia of Solid Earth Geophysics. Encyclopedia of Earth Sciences Series. Springer, Cham. First online: 10 October 2019. https://doi.org/10.1007/978-3-030-10475-7_208-1.

Richter F., 1935. An instrumental earthquake magnitude scale. Bull. Seism. Soc. Am., 25(1), 1-32. ISSN 0037-1106

https://pubs.geoscienceworld.org/bssa/issue/25/1. https://resolver.caltech.edu/CaltechAUTHORS:2014 0804-143558638.

Romanelli F., Vaccari F., 1999. Site response estimation and ground motion spectrum scenario in the Catania area. Journal of Seismology, 3(3), 311-326. https://doi.org/10.1023/A:1009847213825.

Romanelli F., Cao D. Trieu, Dinh V.T., Thai A.T., Panza G.F., 2013. Multi-scenario based assessment of seismic hazard: a must for the effective definition of the seismic input. In: Proceedings of the International conference on Sustainable Built Environment for Now and the Future, March 26-27, Hanoi, Vietnam, 613-620.

https://www.researchgate.net/publication/342380810_R omanelli_F_Cao_DTrieu_Dinh_VT_Thai_AT_and_ Panza_GF_2013_Multi-

scenario_based_assessment_of_seismic_hazard_a_ must_for_the_effective_definition_of_the_seismic_i nput_Proc_The_international_conference_on.

Romanelli F., Peresan A., Vaccari F., Panza G.F., 2012. Multi Scenario based Seismic Hazard assessment.
In: Proceedings of the International scientific conference, Geophysics - cooperation and sustainable development, 180-189, Hanoi \& Sapa Nov. 14-17.

Romanowicz B., 2020. Surface Waves. In: Gupta H. (Ed) Encyclopedia of Solid Earth Geophysics. Encyclopedia of Earth Sciences Series. Springer, Cham. First online: 11 August 2020. https://doi.org/10.1007/978-3-030-10475-7_143-1.

Rosling H., 2018. Factfulness: Ten Reasons We're Wrong About the World--and Why Things Are Better Than You Think. Flatiron Books, New York, pp. 341 .

https://www.amazon.com/Factfulness-Reasons-

World-Things-

Better/dp/1250107814/ref=asc_df_1250107814/?tag =hyprod-

20\&linkCode $=$ df0\&hvadid $=265989256760 \&$ hvpos $=$ \&hvnetw $=$ g\&hvrand $=13136547458901574740 \&$ hvp one $=\&$ hvptwo $=\&$ hvqmt $=\&$ hvdev $=\mathrm{c} \& \mathrm{hvdv} \mathrm{cmdl}=\& \mathrm{~h}$ vlocint $=\&$ hvlocphy $=9031458 \&$ hvtargid $=$ pla 432996236769\&psc $=1$

Rugarli P., 2014. Validazione Strutturale. Diagonali, EPC editore, Roma, pp.653.

https://www.epc.it/Prodotto/Editoria/Libri/Validazio ne-strutturale/2120.

Rugarli P., 2016. The Role of the Standards in the Invention of the Truth. Atti dei Convegni Lincei, 306, 59-76, Bardi Editore, Roma.

https://www.lincei.it/it/pubblicazioni.

https://www.castaliaweb.com/ita/pubblicazioni/The_ Role_Of_The_Standards_In_The_Invention_Of_Th e_truth.pdf.

Rugarli P., 2018. Norme tecniche per le Costruzioni 2018, EPC Editore, Roma. ISBN: 978-88-6310-846-0. https://www.epc.it/Prodotto/Editoria/Libri/Normetecniche-per-le-Costruzioni-2018/885.

Rugarli P., Amadio C., Peresan A., Fasan M., Vaccari F., Magrin A., Romanelli F., Panza G.F., 2019a. Neo-Deterministic Scenario-Earthquake Accelerograms and Spectra: a NDSHA approach to seismic analysis. Chpt. 6. In: J. Jia and J.K. Paik (Eds) Engineering Dynamics and Vibrations: Recent Developments, 187-241, pp.400. CRC Press Boca Raton, Florida, USA. ISBN 978-1-4987-1926-1. https://doi.org/10.1201/9781315119908-6. https://doi.org/10.1201/9781315119908. 


\section{J. Bela, G.F. Panza/Vietnam Journal of Earth Sciences 43(2021)}

Rugarli P., Vaccari F., Panza G.F., 2019b. Seismogenic nodes as a viable alternative to seismogenic zones and observed seismicity for the definition of seismic hazard at regional scale. Vietnam Journal of Earth Sciences, 41(4), 289-304.

http://dx.doi.org/10.15625/0866-7187/41/4/14233.

Rundle J., Turcotte D.L., Klein W., 2000. Geocomplexity and the Physics of Earthquakes. American Geophysical Union, Geophys. Mon. Series, 120, 284pp. https://doi.org/10.1029/GM120 https://agupubs.onlinelibrary.wiley.com/doi/book/10 $.1029 / \mathrm{GM} 120$.

Sandron D., Suhadolc P., Costa G., 2008. Source complexity effects on ground shaking scenarios. Bollettino di Geofisica Teorica ed Applicata, 49(2), 227-237.

https://www.researchgate.net/publication/299052161 _Source_complexity_effects_on_ground_shaking_sc enarios.

Sarwar F., Iqbal S., Vaccari F., Magrin A., Rukh L., 2018. Preliminary Neo-Deterministic Seismic Hazard Assessment in Pakistan and Adjoining Regions. Indian Journal of Natural Sciences, 9(51), 15787-15800.

https://arts.units.it/retrieve/handle/11368/2948808/2 81756/Farhana_18_IJONS.pdf https://www.researchgate.net/publication/329718137 _Preliminary_Neo-

Deterministic_Seismic_Hazard_Assessment_in_Pak istan_and_Adjoining_Regions.

Saxe J.S., 1873. "The Blind Men and the Elephant", a re-telling of an Indian parable that deals with perception and the subjective nature of truth: featuring six blind men who wish to observe an elephant. https://www.commonlit.org/en/texts/theblind-men-and-the-elephant?search_id=3423435.

Scalera G., Boschi E., Favali P., Frugoni F., Smriglio G., 1995. Map of Maximum Felt Intensity in Italy/Mappa della Massima Intensità Macrosismica Risentita in Italia. https://doi.org/10.13140/2.1.4826.4003.

SCEC Phase III Report, 2000. Accounting for Site Effects in Probabilistic Seismic Hazard Analyses of Southern California: Overview of the SCEC Phase III Report. Edward H. Field; the SCEC Phase III Working Group. Bull. Seimsol. Soc. Am., 90(6B), S1-S31. https://doi.org/10.1785/0120000512.
Schneider J.F., Oro J., Smolka A., Suhadolc P., Wu Z., 2020. Seismology, Global Earthquake Model. In: Gupta H. (Ed) Encyclopedia of Solid Earth Geophysics. Encyclopedia of Earth Sciences Series. Springer, Cham. First online: 10 July 2020. https://doi.org/10.1007/978-3-030-10475-7_164-1.

Schwartz D.P., Coppersmith K.J., 1984. Fault behavior and characteristic earthquakes: Examples from the Wasatch and San Andreas fault zones. J. Geophys. Res. JGR Solid Earth 89(B7) 5681-5698. https://doi.org/10.1029/JB089iB07p05681.

Schwartz D.P., Coppersmith K.J., 1984. Introduction to the Special Section on Fault Behavior and the Earthquake Generation Process. JGR Solid Earth, 89(B7), 5669-6354. AGU Chapman Conference on Fault Behavior and the Earthquake Generation Process October 11-15, 1982 Snowbird, Utah. American Geophysical Union, Wash. D.C., pp.258. Online 20 Sept. 2012 ISSN: 0148-0227. https://doi.org/10.1029/JB089iB07p05669.

Siegel E., 2016. Science Is Not A Democracy And Can Never Be One. Science Is Not A Democracy, And Can Never Be One (forbes.com) https://www.forbes.com/sites/startswithabang/2016/ 05/06/science-is-not-a-democracy-and-can-neverbe-one/?sh=26a00669798b.

Š́lený J., Panza G.F., 1991. Inversion of seismograms to determine simultaneously the moment tensor components and source time function for a point source buried in a horizontally layered medium. Studia Geophysica et Geodaetica 35, 166-183. https://link.springer.com/article/10.1007/BF01614064

Š́lený J., Panza G.F., Campus P., 1992. Waveform inversion for point source moment tensor retrieval with variable hypocentral depth and structural model. Geophys. J. Int., 109(2), 259-274. https://doi.org/10.1111/j.1365-46X.1992.tb00097.x.

Soloviev A.A., Novikova O.V., Gorshkov A.I., Piotrovskaya E.P., 2013. Recognition of potential sources of strong earthquakes in the Caucasus Regionusing GIS technologies. Doklady Earth Sci., 450, 658-660. https://doi.org/10.1134/S1028334X13060159.

Soloviev A.A., Gvishiani A.D., Gorshkov A.I., Dobrovolsky M.N., Novikova O.V., 2014. Recognition of Earthquake-Prone Areas: 
Methodology and Analysis of the Results. Izvestiya, Physics of the Solid Earth, 50, 151-168.

https://doi.org/10.1134/S1069351314020116.

Soloviev A.A. Ed, 2018. Prediction of extreme events in nature and society - Keilis-borok, Author. Oris Books-Dragonwell Publishing, pp.503. ISBN: 9781-940076-44-7

http://publishing.dragonwell.org/

https://www.springer.com/us/book/9783540435280.

Somerville P., 2000. Seismic Hazard Evaluation. in Proc. 12th World Conference on Earthquake Engineering, WCEE2000, Jan. 30-Feb. 4, 2000, Auckland, NewZealand Zealand; Paper 2833, pp.8. http://www.iitk.ac.in/nicee/wcee/article/2833.pdf.

Srivastava R.P., Vedanti N., Dimri V.P., 2020. Fractals and Chaos. In: Gupta H.K. (Ed) Encyclopedia of Solid Earth Geophysics. Encyclopedia of Earth Sciences Series. Springer, Cham. First online: 09 September 2020. https://doi.org/10.1007/978-3-03010475-7_34-1.

Stark P.B., 2017. "Pay No Attention to the Model Behind the Curtain", To Appear in Significant Digits: Responsible use of quantitative Information, Saltelli A., and Guimarães Pereira, Â. (Eds), Version 13, Dec. 2017, Megaloceros Press, University of Bergen, Bergen, Germany (in press), pp. 21.

https://www.stat.berkeley.edu/ stark/Preprints/eucC urtain15.pdf

Stark P.B., Freedman D.A., 2001, rev. 2016. What is the chance of an earthquake, UC Berkeley Dept. Statistics Tech Rpt., 611, pp.13.

https://www.stat.berkeley.edu/ stark/Preprints/611.p df.

Steckler M.S., Mondal D.R., Akhter S.H., Seeber L., Feng L., Gale J., Hill E.M., Howe M., 2016. Locked and loading megathrust linked to active subduction beneath the Indo-Burman Ranges, Nature Geoscience, 9, 615-618. https://doi.org/10.1038/ngeo2760.

Stein R.S., Sevilgen V., 2019. Albania earthquake strikes highest-hazard zone in the Balkans, devastating nearby towns, Temblor. 26 Nov. 2019. http://doi.org/10.32858/temblor.057.

Sun R., Vaccari F., Marrara F., Panza G.F., 1998. The main features of the local geological conditions can explain the macroseismic intensity caused in Xiji-
Langfu (Beijing) by the Ms=7.7 Tangshan 1976 earthquake. Pure Appl. Geophys. 152, 507-521. https://doi.org/10.1007/s000240050164.

Taleb N.N., 2007. The Black Swan: The Impact of the Highly Improbable. Random House Publishing Group, Inc., pp.400. ISBN: 0812979184 9781400063512: The Black Swan: The Impact of the Highly Improbable (Incerto) - AbeBooks Taleb, Nassim Nicholas: 1400063515.

Tall D., Vinner S., 1981. "Concept Image and Concept Definition in Mathematics with particular reference to Limits and Continuity", Educational Studies in Mathematics, 12(2), 151-169.

https://link.springer.com/article/10.1007/BF00305619

Thenhaus P.C., Campbell K.W., 2003. Seismic hazard analysis. In: Chen, W.F. and Scawthorn, C. (eds.) Earthquake Engineering Handbook. Boca Raton: CRC Press, Chpt. 8, pp.50.

https://www.taylorfrancis.com/books/978042911501 1/chapters/10.1201\%2F9781420042443-12.

Thurber C.H., 2020. Earthquakes, Location Techniques. In: Gupta H.K. (Ed) Encyclopedia of Solid Earth Geophysics. Encyclopedia of Earth Sciences Series. Springer, Cham. First online: 08 September 2020. https://doi.org/10.1007/978-3-030-10475-7_25-2.

Tiberti M.M., Lorito S., Basili R., Kastelic V., Piatanesi A., Valensise G., 2009. Scenarios of EarthquakeGenerated Tsunamis for the Italian Coast of the Adriatic Sea. Pure Appl. Geophys., 165, 2117-2142. https://doi.org/10.1007/s00024-008-0417-6.

Toda S., 2020. Paleoseismology. In: Gupta H. (Ed) Encyclopedia of Solid Earth Geophysics. Encyclopedia of Earth Sciences Series. Springer, Cham. First online: 29 December 2019. https://doi.org/10.1007/978-3-030-10475-7_9-1.

Tramelli A., Convertito V., Pino N.A., Piochi M., Troise C., De Natale G., 2014. The 2012 Emilia, Italy, Quasi-Consecutive Triggered Mainshocks: Implications for Seismic Hazard. Seismol. Res. Lett., 85(5), 970-976. https://doi.org/10.1785/0220140022.

Tuyen N.H., Gorshkov A.I., Thi Lu Ngo, 2012. Recognition of Earthquake-Prone Areas $(M \geq 5.0)$ applied for North Vietnam and adjacency. J. Sci. Earth, 34(3), 251-265. https://www.researchgate.net/publication/236025216 _Recognition_of_earthquake- 
prone_areas_M_50_applied_for_North_Vietnam_an d_adjacency.

Tuyen N.H., Phach Ph.V., Shakirov R.B., Trong C.D., Hung Ph.N., Anh L.D., 2018. Geoblocks Recognition and Delineation of the Earthquake Prone Areas in the Tuan Giao Area (Northwest Vietnam). Geotectonics, 52, 359-381. https://doi.org/10.1134/S001685211803007X.

Tversky A., Kahneman D., 1974. Judgement under uncertainty: heuristics and biases, Science, 185(4157), 1124-1131.

https://doi.org/10.1126/science.185.4157.1124.

USBR, 2019. Seismic Hazard Analysis. Chpt. B-2 in U.S. Bureau of Reclamation, Risk Management: Best Practices and Risk Methodology: Best Practices in Dam and Levee Safety Risk Analysis Training Course, pp.36. Re: Maximum Credible Earthquake MCE.

https://www.usbr.gov/ssle/damsafety/risk/BestPracti ces/Chapters/B2-SeismicHazardAnalysis.pdf https://www.usbr.gov/ssle/damsafety/risk/methodolo gy.html.

USGS PSHA - Project 17, 2015a. Project 17 Developing Next-Generation Seismic Design Value Maps: A Preliminary Planning Report. Prepared for the Federal Emergency Management Agency and U.S. Geological Survey by the Project 17 Planning Committee and R.O. Hamburger, of National Institute Building Sciences Building Seismic Safety Council BSSC, Sept. 28, 2015, pp.131.

https://www.nehrp.gov/pdf/Project17PlanningReport .pdf

USGS PSHA, 2015b. Special Issue on the 2014 USGS National Seismic Hazard Maps. Spectra SI (2015), Earthquake Spectra, 31(S1), 271. https://journals.sagepub.com/toc/eqsa/31/1_suppl

USGS PSHA - UCERF3, 2015a. "UCERF3: A New Earthquake Forecast for California's Complex Fault System". USGS Fact Sheet 2015-3009, March 2015, pp.6. https://pubs.usgs.gov/fs/2015/3009/pdf/fs20153009.pdf. http://dx.doi.org/10.3133/fs20153009.

USGS PSHA - UCERF3, 2015b. "Long-Term TimeDependent Probabilities for the Third Uniform California Earthquake Rupture Forecast (UCERF3)”. Bulletin of the Seismological Society of America, March 10, 2015, 105(2A), 511-543. - by Working Group on California Earthquake
Probabilities: Field E.H., Biasi G.P., Bird P., Dawson T.E., Felzer K.R. Jackson D.D., Johnson K.M., Jordan T.H., Madden C., Michael A.J., Milner K.R., Page M.T., Parsons T., Powers P.M., Shaw B.E., Thatcher W.R., Weldon R.J. II, Zeng Y. https://doi.org/10.1785/0120140093.

http://www.wgcep.org/

https://pubs.geoscienceworld.org/ssa/bssa/articleabstract/105/2A/511/331850/long-term-timedependent-probabilities-forthe?redirectedFrom=fulltext.

Vademecum Sveb, 2015. Vademecum for the seismic verification of existing buildings. Panza G., Romanelli F., Vaccari F., Giorgio Altin G. (Eds), Provincia di Trieste, pp.15. http://www.xeris.it/resources/Vademecum/Provincia TS_Vademecum_verifica_sismica_luglio2015_ENG .pdf

Vittori E., Deiana G., Esposito E., Ferreli L., Marchegiani L., Mastrolorenzo G., Michetti A.M., Porfido S., Serva L., Simonelli A.L., Tondi E., 2000. Ground effects and surface faulting in the September-October 1997 Umbria-Marche (Central Italy) seismic sequence. Journal of Geodynamics, 29(3-5), 535-564. ISSN: 0264-3707. https://doi.org/10.1016/S0264-3707(99)00056-3.

Wald D.J., Quitoriano V., Heaton T., Kanamori H., 1999a. Relationships between Peak Ground Acceleration, Peak Ground Velocity and Modified Mercalli Intensity in California. Earthquake Spectra, 15(3), 557-564.

https://journals.sagepub.com/doi/pdf/10.1193/1.1586 058.

Wald D.J., Quitoriano V., Heaton T., Kanamori H., Scrivner C.W., Worden C.B., 1999b. TriNet 'ShakeMaps': Rapid Generation of Instrumental Ground Motion and Intensity Maps for Earthquakes in Southern California. Earthquake Spectra, 15(3), 537-556.

https://journals.sagepub.com/doi/pdf/10.1193/1.1586 057.

Wald D.J., Worden C.B., Thompson E.M., Hearne M., 2019. Earthquakes, ShakeMap. In: Gupta H. (Ed) Encyclopedia of Solid Earth Geophysics. Encyclopedia of Earth Sciences Series. Springer, Cham. First online: 12 December 2019. https://doi.org/10.1007/978-3-030-10475-7_182-1. 
Wang Z., 2012. "Comment on 'PSHA Validated by Quasi Observational Means' by R.M.W. Musson”. Seismol. Res. Lett., 83(4), 714-716. https://doi.org/10.1785/0220120016.

Wang Z., 2015. Predicting or Forecasting Earthquakes and the Resulting Ground-Motion Hazards: A Dilemma for Earth Scientists. Seismol. Res. Lett., 86(1), 1-5. https://doi.org/10.1785/0220140211.

Wang Z., Cobb J.C., 2013. A critique of probabilistic versus deterministic seismic hazard analysis with special reference to the New Madrid seismic zone, In: R.T. Cox, M.P. Tuttle, O.S. Boyd and J. Locat, J. (Eds). Geol. Soc. Amer. GSA Special Paper 493: Recent Advances in North American Paleoseismology and Neotectonics East of the Rockies, 259-275. https://doi.org/10.1130/2012.2493(13).

Wang Z., Ormsbee L., 2005. Comparison between probabilistic seismic hazard analysis and flood frequencyanalysis. Eos, Transactions American Geophysical Union, 86(5), 45, 51-52. https://doi.org/10.1029/2005EO050001.

Wang K., Rogers G., 2014. Earthquake Preparedness Should Not Fluctuate on a Daily or Weekly Basis, EDITORIAL | May 01, 2014. Seismol. Res. Lett., 85(3), 569-571. https://doi.org/10.1785/0220130195.

Wang G., Shi J., 2010. Earthquake Spatial Coherence Analysis from Simulated Accelerograms. In: G. Song and R.B. Malla (Eds) Earth and Space 2010: Engineering, Science, and Construction in Challenging Environments, Proc. 12th Biennial Internat. Conf. on Engineering, Construction, and Operations in Challenging Environments, Honolulu, Hawaii, March 14-17, 2010. (C2010 ASCE, 27362745. https://doi.org/10.1061/41096(366)258.

Wang G., Liang S., Panza G.F., 2010. Earthquake Inputs for Structural Aseismic Design in Cities. In: G. Song and R.B. Malla (Eds) Earth and Space 2010: Engineering, Science, and Construction in Challenging Environments, Proc. 12th Biennial Internat. Conf. on Engineering, Construction, and Operations in Challenging Environments, Honolulu, Hawaii, March 14-17, 2727-2735. https://doi.org/10.1061/41096(366)257.

Ward S.N., 2020. Tsunami. In: Gupta H. (Ed) Encyclopedia of Solid Earth Geophysics.
Encyclopedia of Earth Sciences Series. Springer, Cham. First online: 15 February 2020. https://doi.org/10.1007/978-3-030-10475-7_22-1.

Wells D.L., Coppersmith K.J., 1994. New empirical relationships among magnitude, rupture length, rupture width, rupture area, and surface displacement. Bull. Seismol. Soc. Am., 84(4), 9741002.

https://pubs.geoscienceworld.org/ssa/bssa/article/84/ 4/974/119792/New-empirical-relationships-amongmagnitude.

Wesnousky S.G., 1994. The Gutenberg-Richter or characteristic earthquake distribution, which is it? Bull. Seismol. Soc. Am., 84(6), 1940-1959. https://pubs.geoscienceworld.org/ssa/bssa/articleabstract/84/6/1940/119861/The-Gutenberg-Richteror-characteristic-earthquake.

Wood H.O, Neumann F., 1931. Modified Mercalli intensity scale of 1931, Bull. Seismol. Soc. Am., 21(4), 277-283.

https://pubs.geoscienceworld.org/ssa/bssa/article/21/ 4/277/115039/Modified-Mercalli-intensity-scale-of1931.

Wyss M., 2015. Testing the Basic Assumption for Probabilistic Seismic-Hazard Assessment: 11 Failures. Seismol. Res. Lett., 86(5), 1405-1411. https://doi.org/10.1785/0220150014.

Wyss M., Nekrasova A., Kossobokov V., 2012. Errors in expected human losses due to incorrect seismic hazard estimates. Natural Hazards, 62, 927-935. https://doi.org/10.1007/s11069-012-0125-5.

Yamazaki F., Maruyama Y., 2020. Seismic Microzonation. In: Gupta H. (Ed) Encyclopedia of Solid Earth Geophysics. Encyclopedia of Earth Sciences Series. Springer, Cham. First online: 19 February 2020. https://doi.org/10.1007/978-3-030-10475-7_187-1.

Zhang X., Teng J., Sun R., Romanelli F., Zhang Z., Panza G.F., 2014b. Structural model of the lithosphere-asthenosphere system beneath the Qinghai-Tibet Plateau and its adjacent areas. Tectonophysics, 634, 208-226. https://doi.org/10.1016/j.tecto.2014.08.017.

Zhang Z., Deng Y., Chen L., Wu J., Teng J. and Panza G., 2013a. Seismic structure and rheology of the crust under mainland China. Gondwana Research, 23(4), 1455-1483. 
J. Bela, G.F. Panza/Vietnam Journal of Earth Sciences 43(2021)

https://doi.org/10.1016/j.gr.2012.07.010.

Zhang Z., Teng J., Romanelli F., Braitenberg C., Ding Z., Zhang X., Fang L., Zhang S., Wu J., Deng Y., Ma T., Sun R., Panza G.F., 2014a. Geophysical constraints on the link between cratonization and orogeny: Evidence from the Tibetan Plateau and the North China Craton. Earth-Science Reviews, 130, 1 48. https://doi.org/10.1016/j.earscirev.2013.12.005.

Zhang Z., Wang Y., Deng Y., Chen L., Wu J., Teng J., Chen Y., Fan W. and Panza G.F., 2013b. Geophysical constraints on mesozoic disruption of North China Craton by underplating-triggered lower-crust flow of the Archaean lithosphere. Terra Nova, 25(3), 245-251. https://doi.org/10.1111/ter.12032.

https://www.researchgate.net/publication/259575555 _Geophysical_constraints_on_mesozoic_disruption_ of_North_China_Craton_by_underplatingtriggered_lowercrust_flow_of_the_Archaean_lithosphere.

Zhang Z., Wu J., Deng Y., Teng J., Zhang X., Chen Y., Panza G.F., 2012. Lateral variation of the strength of lithosphere across the eastern North China Craton: New constraints on lithospheric disruption. Gondwana Research, 22(3-4), 1047-1059. https://doi.org/10.1016/j.gr.2012.03.006.

Zhang H., Shi Z., Wang G., Sun X., Yan R., Liu C., 2019. Large Earthquake Reshapes the Groundwater Flow System: Insight From the Water-Level Response to Earth Tides and Atmospheric Pressure in a Deep Well. Water Resources Research, 55(5), 4207-4219. https://doi.org/10.1029/2018WR024608.

Zhang L., Carpenter N.S, Wang Z., Lyu Y., Li S., 2018. Scenario based seismic hazard analysis for the Xianshuihe fault zone, Southwest China. Pure Appl. Geophys., 175, 707-720. https://doi.org/10.1007/s00024-017-1686-8.

Yamazaki F., Maruyama Y., 2020. Seismic Microzonation. In: Gupta H. (Ed) Encyclopedia of Solid Earth Geophysics. Encyclopedia of Earth Sciences Series. Springer, Cham. First online: 19 February 2020. https://doi.org/10.1007/978-3-03010475-7_187-1.

Yu Y., Gao M., Xu G., 2020. Seismic Zonation. In: Gupta H. (Ed) Encyclopedia of Solid Earth Geophysics. Encyclopedia of Earth Sciences Series. Springer, Cham. First online: 01 January 2020. https://doi.org/10.1007/978-3-030-10475-7_184-1. 